Anja Schmidt-Kleinert

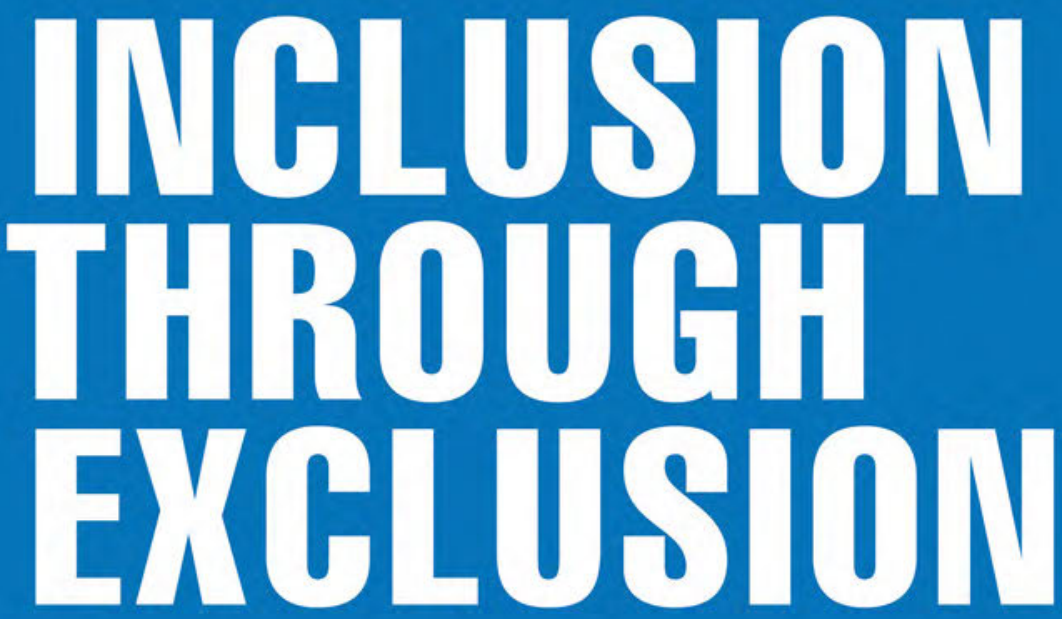

How Young Immigrant Israelis in the Nationalist Yisra'el Beitenu Party Read Israeli Citizenship

[transcript] Political Science 
Anja Schmidt-Kleinert

Inclusion through Exclusion

Political Science | Volume 67 
Anja Schmidt-Kleinert (Ph.D.) is a research associate at the Department of Political Science at the Philipps University of Marburg, Germany. She received her doctorate degree from Bielefeld University, Germany, and specialises in the political extreme right, citizenship studies, and discourse studies. 
Anja Schmidt-Kleinert

\section{Inclusion through Exclusion}

How Young Immigrant Israelis

in the Nationalist Yisra'el Beitenu Party Read Israeli Citizenship 
Dissertation, Faculty of Education, Bielefeld University

Bibliographic information published by the Deutsche Nationalbibliothek

The Deutsche Nationalbibliothek lists this publication in the Deutsche Nationalbibliografie; detailed bibliographic data are available in the Internet at http://dnb.d-nb.de

\section{(c) (1) $\Theta \Theta$}

This work is licensed under the Creative Commons Attribution-NonCommercialNoDerivatives 4.0 (BY-NC-ND) which means that the text may be used for non-commercial purposes, provided credit is given to the author. For details go to http://creativecommons.org/licenses/by-nc-nd/4.o/

To create an adaptation, translation, or derivative of the original work and for commercial use, further permission is required and can be obtained by contacting rights@ transcript-verlag.de

Creative Commons license terms for re-use do not apply to any content (such as graphs, figures, photos, excerpts, etc.) not original to the Open Access publication and further permission may be required from the rights holder. The obligation to research and clear permission lies solely with the party re-using the material.

\section{(C) 2018 transcript Verlag, Bielefeld}

Cover layout: Maria Arndt, Bielefeld

Printed by Majuskel Medienproduktion GmbH, Wetzlar

Print-ISBN 978-3-8376-4559-0

PDF-ISBN 978-3-8394-4559-4

https://doi.org/10.14361/9783839445594 


\section{Acknowledgement}

I would like to thank the interviewees, who agreed to talk to me, and all the people I met during my field work-without their trust this book would not have been possible.

I would like to thank Tamar Rapoport for her professional support, and personal friendship.

I would like to thank my former colleagues at the DGS Graduate School "Group-Focused Enmity" (Bielefeld University and Philipps-University at Marburg, Germany). In particular I would like to thank Petra Feldmann, Manuela Freiheit, Olga Michel, and Kristina Seidelsohn for thrilling thematic and methodological discussions, critical-constructive questions, their general openness to discuss vague ideas, and their social support.

I would like to thank the reviewers of my dissertation, Wilhelm Heitmeyer and Mathias Bös.

I would like to thank Olaf Glöckner for his friendship.

I would like to thank Herrn K., Liori, and Numi for their love, and support, for giving me space to work, and for reminding me that life is not work alone. 



\section{Contents}

Acknowledgement |5

List of Figures | 11

1 Introduction | 13

\section{THEORETICAL-METHODOLOGICAL APPROACH}

2 The Grounded Theory Methodology | 23

2.1 The Grounded Theory Methodology as an Alternative Approach | 23

2.2 Major Rifts and Developments $\mid 25$

2.3 The Tool Kit $\mid 28$

3 Theoretical Sensitivity I: Pre-Concepts and Pre-Knowledge | 31

3.1 A Typology of Civic Engagement $\mid 33$

3.2 Motivation and Moral Values | 35

3.3 Resources for Civic Engagement | 37

3.4 Immigrants and Civic Engagement $\mid 39$

4 The Data Material | 41

4.1 Theoretical Sampling of the Data $\mid 42$

4.2 Descriptive Analysis of the Interviewees | 46

4.3 Codes and Categories | 49

5 A Coding Paradigm of Belonging | 53

5.1 Bourdieu's Cultural Theory of Action | 53

5.2 The Integrated Framework | 63

6 Theoretical Sensitivity II: Framing the Study | 73

6.1 Features of Israeli Society $\mid 73$

6.2 The Yisra'el Beitenu Party | 91 


\section{A MATERIAL THEORY OF BELONGING}

7 The Interviewees' Objective Position in Israeli Society: Jews, Russians, Israelis? | 103

7.1 The Objective Position of FSU Immigrants: Majority or Minority? | 104

7.2 Analysis of Power Resources I: "Move Uphill" | 105

7.3 Analysis of Discursive Practice I: "Sabras" vs. "Russian Whores" | 112

8 Talking about Civic Engagement: “The Dirty Game of Politics" | 117

8.1 Analysis of Power Resources II: Role Models | 118

8.2 Analysis of Discursive Practice II: "It [...] Come[s] Naturally" | 121

9 Serving the Country: "The State of Israel Demands" | 127

9.1 Analysis of Habitual Dispositions I: "You Get [What] You Give" | 128

9.2 Analysis of Habitual Dispositions II: "I Went Through Some Kind of Brainwash" | 130

9.3 Analysis of Discursive Practice III: A Matter of Solidarity | 134

10 Loyalty to the Jewish State:

"We are [...] a [...] Pitskalle" | 139

10.1 Analysis of Discursive Practice IV: "Every Israeli..." | 140

10.2 Analysis of Discursive Practice V: "It Hurts" | 142

11 Palestinians as Quasi Non-Citizens: "They Will Stab Me in the Back" | 149

11.1 Analysis of Discursive Practice VI:

"People from the Village" | 149 
11.2 Analysis of Discursive Practice VII:

"Palestinians = Hamas" | 153

11.3 Analysis of Discursive Practice VIII:

Two Sides of the Same Coin | 159

12 The Claim of Citizen's Rights:

"I Came Here to Live among Jews" | 161

12.1 Analysis of Discursive Practice IX: "Zionist Values" | 161

12.2 Analysis of Power Resources III: An Ideological Match | 163

12.3 Analysis of Discursive Practice X: Catchy Slogans | 170

12.4 Analysis of Discursive Practice XI: "Papa Lieberman" | 173

12.5 Analysis of Discursive Practice XII: "It Was Chemistry" | 175

12.6 Analysis of Discursive Practice XIII:

"Second-Class Citizens" | 176

13 A Grounded Theory of Belonging:

“All [Jewish] Israelis, Unite!” | 179

13.1 Citizenship | 181

13.2 Serving the Country | 182

13.3 Loyalty to the Jewish State $\mid 183$

13.4 Palestinian Citizens and Non-Citizens as a

Perceived Threat $\mid 184$

13.5 Citizen's Rights $\mid 185$

13.6 Engagement with the Yisra'el Beitenu Party | 186

13.7 Citizenship as a Discursive Strategy:

The Interviewees' Sense of Belonging | 187

Bibliography | 195 



\section{List of Figures}

Figure 1 Previous Empirical Research on

Civic Engagement, Author's Own Presentation | 35

Figure 2 The Sample, Author's Own Presentation | 43

Figure 3 Category: Identification,

Author's Own Presentation | 50

Figure 4 A Suggested "Structure-Disposition-Practice" Framework of Civic Engagement, Author's Own Presentation | 71 



\section{Introduction}

Unlike in most other destination countries of Jewish emigration from the former Soviet Union (FSU), Israelis with an FSU family background have founded several political parties on the national level. One of the still existing ones is the Yisra'el Beitenu party (Hebr., Our House Israel, hereinafter also IB).

Avigdor Lieberman, who had immigrated to Israel from Moldova in 1978, back then a Soviet Republic, founded the Yisra'el Beitenu party in 1999. Lieberman became a member of the Likud party, served as the "former director-general of the prime minister's office [Netanyahu]" and was a "long-term associate of Benjamin Netanyahu" (Khanin 2010: 106). According to Khanin, Lieberman left the Likud party because of a "major conflict with the traditional Likud establishment" (ibid.). The Yisra'el Beitenu party was founded as a "Russian right-wing political movement" (ibid.); the party's founding members comprised basically of four different groups: "former Likud members, previous members of the Yisra'el baAliyah party [another sectoral party representing the interests of Israelis with an FSU background], municipal activists of Ashdod Beitenu, and former Soviet Zionist activists" (ibid.). In 2006, Lieberman's party first entered the governing coalition of the former Israeli Prime Minister, Ehud Olmert; the party's political leader, Avigdor Lieberman, was appointed to the new post of Minister for Dealing with Strategic Threats. In the 2009 general elections for the $18^{\text {th }}$ Knesset, the Israeli parliament, the Yisra'el Beitenu party won 11.7 per cent of the total votes, i.e. 15 seats; among its voters were Russianspeaking immigrants as well as Israeli-born voters. The party became the third largest parliamentary group in the Knesset, and Lieberman was appointed Minister of Foreign Affairs in the government of Benjamin 
Netanyahu. Within ten years of its existence, Lieberman's party had succeeded in expelling the Labour party, one of the two oldest and biggest Israeli political parties, from the first ranks.

Yet, ever since Lieberman's appearance in the front lines of Israeli politics, several voices in Israeli and international media as well as the public have discussed whether this would provoke a trend in Israeli politics toward a more ultra-nationalist and extreme right policy. In this context, Lieberman and his political party have been characterised as "right-wing extremist", "nationalist" or "racist"; and Israeli media have shown concern especially about Lieberman's verbal attacks against Palestinian citizens and concrete political actions, particularly law initiatives introduced by party representatives in the Knesset. ${ }^{1}$

Previous research papers that deal with the Yisra'el Beitenu party have adopted some of the attributes ascribed to the party or its leader in the media discourse, e.g. by referring to the party as an "extreme right-wing party headed by a West Bank settler, Avigdor Lieberman" (Peled 2011: 278), or a "Russian party" (Meller 2010: 1). Against the background of the emergence of the Yisra'el Beitenu party, in particular the degree of political adaptation of Israelis with an FSU family background to the patterns of the Israeli majority has been questioned. Newspaper articles, but also scientific research, have taken for granted a certain inclination or predisposition of those immigrants (not only in Israel) for "conservative" or even extreme right political attitudes. Quantitative studies on political attitudes of $\left(1^{\text {st }}\right.$ generation) Russian-speaking Israelis suggest a certain stable set of those attitudes described as more right-wing and conservative than those of other Jewish segments in Israeli society (e.g. Philippov/ Knafelman 2011; Philippov/ Bystrov 2011; Arian et al. 2010). The authors imply that as a group they carry a particular "collective habitus", namely that of a "Soviet man" (Horowitz 1989), which is distinct from that of native-born Israelis and which can be explained by their socialisation in the former Soviet Union, or by post-Soviet realities. Those empirical studies struggle with the seemingly contradictory findings that those Israelis on the one hand claim an increasing

1 However, interestingly, as I am writing up the analysis of my material the Yisra'el Beitenu party is no longer considered the most dangerous party of Netanyahu's government, but Naftali Bennett's HaBait haYehudi (Hebr.: The Jewish Home) is - though Lieberman's approaches have not changed. 
sense of belonging (Arian et al. 2010: 81-3), yet, on the other hand, display political attitudes, which are interpreted as hints to the maintenance of a "Soviet legacy" (Khanin 2011: 56). However, there are few voices, who acknowledge that the electoral success at the national level also shows the party's ability to take on sentiments of (the Jewish) Israeli society and gain political use of it. Against the background of the party's electoral success, it is no longer true that its constituents are recruited mainly among Israelis with a Russian-speaking family background.

On the contrary, the party has become a mainstream phenomenon-and problem. Thus, the idea for the present study stems from the observation that despite several consecutive electoral successes of Yisra'el Beitenu in Israel since 2006, the media discourse about the party is rather negative. The point of departure was the question of how young Israelis with an FSU family background (the so-called " $1.5^{\text {th" }}$ and second generations), who engage in the framework of IB, speak about their civic engagement in a broader sense and about their political engagement with IB in particular. In this context, I argue that previous research has asked the wrong questions about the phenomenon of the emergence of the Yisra'el Beitenu party, but also the party's passive and active supporters. I argue that questions like the following two examples from previous studies-whether the Yisra'el Beitenu party is a "Russian party", or whether IB voters support strong leadership because of their "Soviet legacy", do not help to understand the phenomenon. This is true for the younger generation of Israelis with an FSU family background who have lived in Israel for most of their lives, as much as for Israeli-born supporters of the party. Instead, an approach which delves into the underlying reasonings of the IB constituents' political choice is needed.

In addition, looking for possible explanations in adjacent areas of research does not offer much in understanding the phenomenon at hand. Most empirical studies on civic engagement either concentrate on an individual's current psychological state of mind or belief system, or on the process of socialisation, in which the individual belief system that motivates engagement develops; yet, they rarely combine both aspects. Besides, previous studies - to my best knowledge - hardly answer the question of how people rationalise their civic engagement. ${ }^{2}$

2 One of the few exceptions is Helen Haste's lay theory approach. 
Rather, previous empirical studies usually look at civic engagement from an entirely positive angle. Ever since Almond and Verba's classical study on civic engagement, citizens, who are actively engaged, are considered as representing a civic ideal and to show particular features like political interest or democratic values. Studies on civic engagement agree that the active involvement of citizens in public matters is essential for the establishment and maintenance of stable democracies. In the normative eyes of society as well as of the researchers, active engagement is presented as "a civic virtue" (Almond/ Verba 2016). Engagement with a political party that by considerable portions of society is considered to not represent those democratic values, is not addressed in those studies.

Yet, this is just the case with the interviewees taking part in the present study. Immigrant (political) adaptation, again, is usually looked at from the angle of structural adaptation to the host society, or single aspects or resources but not with a holistic approach combining the macro and micro levels. Moreover, it is rather an exception that immigrants are considered architects of their own fortune.

Departing from the current state of research just described, I suggest a different approach to understand the (political) adaptation of immigrants in the present study. Taking Israelis with an FSU family background, who engage with the Yisra'el Beitenu party, as a case study, I suggest taking their perspective, and, above all, regarding them as active in their process of adaptation. The initial research interest of the present study was to understand how the participants had become engaged with the Yisra'el Beitenu party. I organized the research by applying a grounded theory approach, which has two advantages: a) it enables the researcher to take a micro-sociological perspective or the perspective of the individual as a social actor, and b) it equips the researcher with a flexible methodological framework, which is open to developing new theoretical insight. In-depth interviews about the individual paths of the participants toward civic engagement with IB served as the main data material; I conducted these interviews in 2009 and 2010. I applied a snowball system-approach and targeted young Israelis who, at the time the interviews were conducted, were active in various forms in the framework of the party. I interviewed party activists as well as those engaged in community activities and programmes, which co-operated in one way or another with a local branch of the party. In order to outreach to potential interviewees, I initially approached party 
officials at different levels: national (i.e. members of the Knesset) as well as local representatives. In addition, I contacted student cells of the party within the students' councils at the Universities of Haifa and Tel Aviv. Yet, the most successful way to find interviewees was through a personal network of colleagues in Israel or German colleagues with contacts in Israel. When I approached the potential interviewees, I explained I would be interested in their story about how they had become engaged. I did not explicitly say, however, that I approached them because of their connection to the Yisra'el Beitenu party but instead only made the engagement with IB as well as the public discourse about the party and its political leader, Lieberman, a topic in the interview itself.

I conducted interviews with young Israelis (aged 18-29) with an FSU family background. Most of them had immigrated as children (the then oldest interviewee immigrated to Israel at the age of 11) from the former Soviet Union. The interviews were conducted in two field phases: in 2009-by chance not too long after the IDF (Israeli Defence Forces) operation Cast Lead in the Gaza strip - I approached young activists who acted clearly in the framework of the party (members of the Knesset, parliamentary assistants, local spokesmen as indicated on the website of the party etc.). The participants I had interviewed in 2009 lived all over the country: in Bat Yam near Tel Aviv, in Ashdod (in the south, close to the Gaza Strip), Haifa, Jerusalem and in Ari'el in the Occupied Territories. In 2010, coinciding with the Gaza flotilla raid, I concentrated on Haifa and Natserat Illit (a neighbouring Jewish town of the Christian Nazareth).

In the course of the analysis of the interview material it became obvious that the interviewees first made their presentation of Israeli citizenship a central point of reference in their narratives, and second and used the notion of citizenship they presented as a discursive strategy to construct a sense of belonging to Israeli society. In particular, I have examined how the interviewees put their engagement in the context of their view of Israeli citizenship and the role they play as citizens, and they do so in two ways: on the one hand, they do it indirectly through narratives referring to personal experiences and/ or collective knowledge such as the public discourse about the political party they are engaged with. On the other hand, the interviewees do so directly by way of lining up their arguments, for example by reproducing or modifying the public discourse. Thus, in the further process I developed more detailed questions, in particular about how the 
interviewees frame their engagement a) indirectly, through the reference to personal experiences and collective "reservoirs of knowledge" (Keller 2011a: 78), e.g. the public discourse about the political party they are engaged with, and b) directly, through argumentative strategies, such as the reproduction or modification of that public discourse, with their interpretation of Israeli citizenship and the role citizens have, and which are the goals they pursue by doing so. In a further analytical step, Pierre Bourdieu's concepts of social space, field, habitus, capital, and social practice serve as a theoretical-methodological framework, or, as introduced by Strauss (1987), a coding paradigm. In order to answer questions about immigrant's political incorporation, I argue that the various levels can be integrated into what Edgerton and Roberts called a "structure-dispositionpractice' explanatory framework" (Edgerton/ Roberts 2014). Their aim is to open up Bourdieu's key concepts of social space, capital, habitus, field, and practice for quantifiable research.

However, I suggest integrating Bourdieu's concepts into qualitative research on the political adaptation of immigrants - or rather one particular way of incorporation - in order to get a more comprehensive picture of how immigrant adaptation can work. Thus, in order to make Bourdieu's concepts applicable, I combine them with different approaches of discourse analysis. A sociology of knowledge-based approach to discourse analysis (SKAD), as suggested by Keller (e.g. 2011a), shall help to grasp objective structures because with the help of this method it is in particular possible to analyse collectively shared amounts of social knowledge, e.g. for instance in the form of patterns of interpretation. I understand social practice here as discursive, as Helen Haste (1992) in particular emphasises the impact of the situative context on an individual's line of argument.

In the present study, I can show how the interviewees actively construct a sense of belonging to Israeli society based on a particular reading of Israeli citizenship: perceived citizen's duties of contribution and loyalty condition the allocation of citizen's rights. The interviewees present Israeli citizenship as a conditional relationship between citizen's duties and rights. They identify several segments, Jewish and non-Jewish in Israeli society, whichin their eyes - do not fulfil one (Jewish ultra-orthodox, "draft dodgers") or any (Palestinian citizens) of their duties as citizens. In contrast to those other segments, the interviewees claim to have fulfilled their citizen's duties and hence to be good citizens. Alongside with the adaptation of migrated and 
Israeli anti-Muslim racism as rooted in the society's ethno-nationalist discourse, the interviewees feel legitimized to decide who belongs to the collective and who are the ultimate (national) others. Based on their individual strategies of coping with personal experiences, their perception of Israeli society and the Israeli ethno-nationalist discourse as well as their engagement with the Yisra'el Beitenu party, the interviewees construct three arguments:

- that the ultimate (national) others-non-Jewish, in particular the Palestinian, minorities - should be deprived of their basic citizen's rights and, consequently, their Israeli citizenship,

- that Palestinian citizens and non-citizens are an ultimate threat to Israel's security, and

- that Israel's security situation is directly linked to broader processes of what the interviewees present as an "Islamisation of the Western world".

The book is structured as follows: in the theoretical-methodological part (chapters 2, 3, 4, and 5) I will first outline the grounded theory methodology as developed by Glaser and Strauss in 1967, which serves as the methodological basis for the present study (chapter 2). In chapter 4, I will describe the process of data collection and analysis and describe the data material. Finally, I will explain the necessity to adapt the approach, in particular the coding paradigm, to the needs of the present study and offer an extension to it based on Bourdieu's work and different approaches to discourse analysis in chapter 5. In order to frame the empirical findings, chapters 3 and 6 review the state of research on three aspects I regard as important to contextualise the present empirical study: previous research on civic engagement, features of the Israeli society, the Yisra'el Beitenu party.

Part II outlines a material theory of belonging, as developed from the systematic analysis of the empirical material. In chapters 7 and 8 , I will provide a descriptive analysis of the interviewees' objective position in social space as well as their sense of place, and their narratives of personal civic engagement, i.e. their motivation, sources, and (lack of) resources for becoming engaged. In chapters 9 and 10, I will show how the interviewees frame their narratives of civic engagement with a particular interpretation of Israeli citizenship and Israeli society. They present a conditional reading of citizenship, consisting of two dimensions of a citizen's duties-contribution 
and loyalty to the Jewish state-, allocating citizen's rights. I will discuss these dimensions in detail. In chapters 11 and 12, I will show a) that and how the interviewees construct their belonging to the Israeli society on the basis of being good citizens and against the constructed notion of Palestinians as the other, and b) how the interviewees consider the Yisra'el Beitenu party as the rightful political representative of those good citizens. In the final chapter (chapter 13), I will summarise the main empirical findings and critically discuss those findings against the background of the study's theoretical considerations. 
I Theoretical-Methodological Approach 



\section{The Grounded Theory Methodology}

As outlined in the introduction, some confusion arose from the previous research, usually with respect to the role of the individual. In order to deal with this confusion and the related open questions it was necessary to use a research approach that is open to the categories, which would emerge from the field rather than testing the hypotheses of existing theories. Thus, in order to pursue one of the goals of the present study, namely to take the perspective of the individual, a flexible and open approach was required, that enables the researcher to enter the field with a vaguely formulated research interest and develop more precise research questions and categories of analysis, or revise them in the course of the research process rather than imposing stiff constraints on the project. In this context, the present study is a suitable example of the basic claim of GTM: the necessity of discovering new (middle-range) social theories because the existing ones cannot explain every social phenomenon (Glaser/ Strauss 1968: 20).

In the present chapter, I will redraw the basic implications of a Grounded Theory methodology (GTM) for qualitative research.

\subsection{THE GROUNDED THEORY METHODOLOGY AS AN ALTERNATIVE APPROACH}

The Grounded Theory methodology, originally developed by Anselm Strauss and Barney Glaser in 1967 (Glaser/ Strauss 1968), for research design, data collection and data analysis, and presentation of empirical 
results meets these needs. ${ }^{1}$ The approach is an explorative way of doing research, and it is a style rather than a method (Mey/ Mruck 2011a: 22). It allows the "controlled and verifiable discovery of theory grounded in the data, governed by rules" (Mey/ Mruck 2011a: 11).

The emphasis on the grounding, or the discovery of theory in empirical data demands a particular approach to data collection and analysis. Glaser and Strauss emphasise several main elements of a methodology in their original book The Discovery of Grounded Theory (1967) that would ensure that this goal was reached, and the quality of research maintained at the same time:

- data collection, data analysis and the development of a grounded theory happen in a cyclical process and in relation to each other,

- the analysis transcends empirical description through abstraction or conceptual thinking; the methods applied here are specific modes of coding and constant comparison,

- "the theory should fit the data" (Glaser/ Strauss 1968: 261); this is ensured through the process of relating the emerging theory back to the empirical data by modes of theoretical sensitivity, theoretical sampling, and the constant writing of memos.

Based on their general critique of established empirical research before GTM, Glaser and Strauss suggest an alternative approach: in contrast to a deductive way of testing hypotheses, of "adapt[ing] some ideas, derived from a somewhat established formal theory, to the area under study" (Glaser/ Strauss 2010: 51), the researcher should "[enter] the field and investigate[...] the area under study by taking a particular sociological perspective, a focus, by having a general question or problem in mind" (ibid.). Thus, in the very beginning it is not necessary, but rather helpful not to have an elaborate theoretical concept, but to enter the field with an "open-mind" instead (Breuer 2010: 144). In this context, the discoverers state that the "generation of theory [...] [is] a process" (Glaser/ Strauss 2010: 49), in the course of

1 I can neither go into detail about the epistemological origins of the grounded theory approach, nor about the further developments of GT-methodologies here. The reader may find a broad and detailed introduction for example in Breuer 2018; Strübing 2014; Mey/ Mruck, 2011b; Clarke 2011; Bryant/ Charmaz 2008. 
which the researcher goes back and forth between data collection, data analysis, and conceptual thinking by way of constant comparison.

The authors implicitly describe a hermeneutic circle, or, as Breuer put it, a "hermeneutic spiral" (Breuer 2010: 55), at the end of which (i.e. at the time of going public with the empirical results) stands an integrated theory. The idea that the "generation of theory [...] [is] a process" (Glaser/ Strauss 2010: 49) is also true for the emerging theory itself: it can only be of temporary validity and is rather an "ongoing theoretical discussion" (ibid.).

There are two forms of theory, which can be generated by way of the grounded theory methodology: material theory is bound to a particular subject studied. Formal theory, in turn, goes beyond a particular subject, and rather deals with "formal or conceptual areas of the social sciences" (Glaser/ Strauss 2010: 50). Glaser and Strauss insist that it is important to decide for one or the other because that decision has major implications for the theoretical sampling, i.e. the cases which should be compared (cf. ibid.).

\subsection{MAJOR RIFTS AND DEVELOPMENTS}

Since Barney Glaser and Anselm Strauss published their original book The Discovery of Grounded Theory, the approach has undergone major changes, both due to the need for its specification or applicability to the research reality, but also due to major rifts about central questions among its discoverers. As a consequence of these rifts, the critique of the original book, and the work the two discoverers continued individually or in other teams to date, it would be more precise to speak of several "grounded theory methodologies" (Mey/ Mruck 2011a: 12; cf. also Clarke/ Keller 2014: para. 49).

In the present study, I refer to the work(s) of the original authors, but I have also added my own considerations, in particular concerning the idea of a coding paradigm. Steinhardt identified two major differences between Glaser and Strauss of how to deal with issues inherent in the original version. One of them concerns the issue of theoretical sensitivity, the other one, connected to this, is that of the question of how to verify the theory in the data (Steinhardt 2015: 32).

A major point of criticism of the approach suggested by Glaser and Strauss was that of an "inductivist self-misunderstanding" (Kelle 2005: para. 
24; e.g. also Kelle/ Kluge 2010: 18-21), inherent in the concept. This critique was at least partly possible because the Discovery was rather a "Kampfansage" (Mey/ Mruck 2011a: 13) than an elaborate and fully applicable methodological concept. With regard to that critique, several authors state that Glaser and Strauss were "aware of the [methodological] limits of a strictly inductive approach" (Mey/ Mruck 2011a,: 31). Glaser and Strauss state: "of course, the researcher does not approach reality as a tabula rasa, he must have a perspective that will help him see relevant data and abstract significant categories from his scrutiny of the data" (Glaser/ Strauss 1968: 3).

In the Discovery book, the authors demonstrate the concept of theoretical sensitivity as follows: "[...] the sociologist should be sufficiently theoretically sensitive [emphasis in the original], so that he is able to conceptualise and formulate a theory, which is emerging from the data. [...] But the theoretical sensitivity of a sociologist is defined by two further factors: first, his personal interests and his character come into play, second it demands him to theoretically penetrate the field he studies and to systematise his insights" (Glaser/ Strauss 2010: 62). As a consequence, “[being] 'highly sensitive' and a 'systematic approach' can be translated in the way that the researcher has ideas, from which he [...] can fetch the most by means of systematic comparative analysis" (Glaser/ Strauss 2010: 263).

Thus, the concept can be understood in two complementary ways. On the one hand, it can mean "the availability of useful heuristic concepts that make possible the identification of theoretically relevant phenomena in the data material" (Kelle 1996: 32). On the other hand, Glaser (2011) adds more precisely: "[first, the researcher's] personal and temperamental bent to maintain analytical distance, tolerate confusion and regression, while remaining open, trusting to preconscious processing and to conceptual emergence [...] [and second, his or her] ability to develop theoretical insight into the area of research combined with the ability to make something of these insights" (Glaser 2011, p. 147-8; c.f. also Mey/ Mruck 2011a: 31).

Glaser (1978) was the first to react to the inductivist critique and made a suggestion of how to apply the idea of theoretical sensitivity. As an attempt to make the GTM-approach more applicable, Glaser (1978) developed his concept-indicator-model, which is based on the epistemological assumption that empirical phenomena that we can observe are carriers of social meaning - a meaning that we can understand through our interpretation of 
them a) as social beings on the basis of our everyday knowledge as members of a certain Lebenswelt (Schuetz 1974), and b) as researchers through an interpretation based on our professional sociological knowledge, which is laid out on a more abstract level.

In order to grasp the complexity of the potential directions, Glaser (1978) developed theoretical codes, which shall guide the researcher's attention in the course of dealing with the data. Interestingly, this is what Strübing rather ascribes to Strauss's further work on the methodology and labels with the term "abductive thinking" (Strübing 2008: 52-4). Strauss (1987) adapted Glaser's underlying concept-indicator-model, which the latter had developed ten years earlier (cf. Mey/ Mruck 2011a: 24). However, in contrast, Strauss's coding paradigm, giving clear heuristic instructions about what to pay attention to, has been received as a solution to original ambiguity and vagueness in the German tradition of GTM-reception. It would allow the researcher to approach his or her data material with the necessary openness, yet take (sociological) pre-knowledge into account (Steinhardt 2015: 32).

This reflects the basic controversy between Glaser and Strauss in the course rather well and also the different perception and reception of the continuous work of both authors, which has been much about the role of previous knowledge in present research. Glaser's position that a grounded theory must emerge from the empirical data (Glaser 1978) has been rejected as an "empiricist idea" (Kelle 2005: para. 48), at least in the Germanspeaking reception of Glaser's individual work after the Discovery. In my view, the controversy between Glaser and Strauss is not so much about whether to incorporate pre-knowledge into the analysis or not, but rather about when to do so. Whereas Glaser accepts this adaptationonly at a later stage of the analysis in order to give a grounded theory space to emerge, Strauss incorporates pre-knowledge as a heuristic concept in the form of his suggested coding paradigm from the very beginning of data analysis. Accordingly, Kelle identifies the concept of emergence of theory from the data as "rather problematic" (Kelle 2005: para. 48) as well; and also Kelle and Kluge state that "Glaser appears to hold to the inductivist rhetoric" (Kelle/ Kluge 2010: p. 21; emphasis added). However, in addition to this, Kelle hints to the alternative laid out already in the original book: the concept of theoretical sensitivity. As a consequence, Kelle suggests to handle the issue with regard to the need of the researcher: Glaser's approach of the "emergence" of grounded theory from the empirical data through theoretical 
coding opens the analysis to an experienced researcher's "broad knowledge of social theory [...] [and] his combination of theoretical concepts from different schools of thought" (Kelle 2005: para. 51). On the other hand, Strauss's coding paradigm provides inexperienced researchers with a clear guideline of what to pay attention to in the coding process, but at the same time may limit his or her attention to the individual, the micro-level of sociological analysis (Kelle 2005: para. 50).

\subsection{THE TOOL KIT}

In order to systematically analyse the collected data, Glaser and Strauss suggest a method of constant comparison, the first step of which is coding (Glaser/ Strauss 2010: 119-120). In this context, Glaser and Strauss criticise other qualitative methods but remain very vague about their own way of coding. In order to bridge this gap, after their split-up Strauss (1987) developed a coding paradigm based on Glaser's (1978) concept-indicatormodel. Against his own background as a pupil of the Chicago School (cf. Breuer 2010: 75), Strauss suggested a paradigm, which consisted of theoretical categories focussing on the individual and its actions, the conditions, strategies of action and the outcome of these actions. Strauss (1987) further suggested organising the analysis in several steps, namely open, axial and selective coding. The analysis is laid out as an iterative process, but the individual analytical steps of coding build on each other and the step to begin with is called open coding.

In the GTM literature, open coding is often described as "to pry open the data" (Mey/ Mruck 2011a: 25), usually with the help of W-questions (who, what, where, when, etc.) as well as the application of codes (in the form of either sociological terms or in-vivo) as a means to get a feeling for the structure of the material. Axial coding, in contrast, takes place on a more abstract level and shall help to create an order between the codes or to find a relationship between them that can be integrated into analytical categories. The development of categories is already in the centre of the methodological approach in the Discovery book: categories are abstract concepts which derive from the analysis through the researcher's ability of abstract thinking and they have features which fill the categories with empirical content (Glaser/ Strauss 2010: 54). In order to guide the analytical process, the 
researcher should develop working hypotheses and more detailed questions about the field of study; these hypotheses are necessarily derived from the data. Working hypotheses are to make assumptions about the "relationship between categories" (Glaser/ Strauss 2010: 49). Constant comparison on different levels of thinking - the comparison between data ("incidents"; Glaser/ Strauss 1968) and codes, between codes, between codes and categories, between categories - shall help the researcher to find similarities and differences and to integrate the findings into an explanatory theoretical concept, (a) key category(ies). The final step of the coding process is selective coding, in which the researcher looks for further empirical evidence or features to describe those key category(ies).

According to Glaser and Strauss, the emergence of an integrated theory from the empirical data shall be ensured through several criteria of quality. The writing of memos ("stop coding and write a memo about your ideas" (Glaser/ Strauss 1968: 113) shall help to gather flashes of inspiration immediately and in relation to the data they have emerged from, to reflect on these ideas, and to organise and reduce confusion, frustration, or other emotions related to the research process (Glaser/ Strauss 2010: 121). A second criterion is the concept of theoretical sampling, which describes the process of data collection and shall help control which further data is needed; the emerging theory here serves as a guideline (Glaser/ Strauss 2010: 53). The sampling, or the choice of "groups of comparison" (Glaser/ Strauss 2010: 56), is organised by creating minimal and maximal contrast groups on the basis of a previous analysis of the data material, which is aimed at finding as many empirical features for categories as possible (Glaser/ Strauss 2010: 56-60). 



\section{Theoretical Sensitivity I: Pre-Concepts and Pre-Knowledge}

Breuer suggests that researchers reflect on their position toward the study throughout the process in order to be aware of any pre-concepts of knowledge, personal experiences, or feelings that may influence their way of thinking (cf. Breuer 2010: 131). I agree with him, and thus I am going to describe here how I have come to study the issue at hand. In the present chapter, I will reflect on those pre-concepts of knowledge, personal experiences, or feelings that may influence my way of thinking, as Breuer suggests. Besides, I will outline major directions of previous research on civic engagement. With regard to the issue of theoretical sensitivity, I have assumed the position suggested by Kelle (2005), and applied Strauss' coding paradigm. However, in parallel to entering the field, I used "broad reading" (cf. Breuer 2010: 135) of previous research to get an idea of how to start data collection and organise the theoretical sampling (cf. Steinhardt 2015: 37). ${ }^{1}$

The present study has come a long way. My first personal encounter with how immigrants see their place in a new cultural environment was when I conducted biographic interviews with non-Jewish immigrant women in

1 In their latest, revised edition, Breuer, Muckel and Dieris (2018) suggest a twostep procedure for the review of literature relevant to the present research. At the very beginning of the process, one should get a broad and general overview, while later on - as part of the verification of grounding the present theory in the empirical data - the researcher should get a deeper knowledge of relevant previous concepts on the issue at hand (Breuer 2018: 145). 
Israel, $\left(1^{\text {st }}\right.$ generation $)$ immigrants from the former Soviet Union ${ }^{2}$ for my master thesis (Schmidt, 2006). Before these encounters, migration had been something very abstract for me: I grew up in a small town in the former GDR and remember just two single "Ausländer [foreigners]" because they were black. After school I studied close to home, and the picture I had of my social environment stayed very much the same. Occasionally, I heard a mixture of German and a foreign language, suggesting that the speaker had immigrated, but my network of personal acquaintances and friends was exclusively German. Thus, I was astonished and fascinated at the same time to hear personal stories of migration, the difficulties, those women had encountered in the process of leaving and adapting, particularly those in maintaining a consistent and stable identity and the individual strategies these women had developed to cope with them.

Yet at the same time I was shocked, for instance, by the - in my eyesextreme right opinions those women uttered with respect to the peace process between Israelis and Palestinians, or the cultural superiority they displayed towards Palestinian-Israeli citizens. Continuing to study migration, or rather immigrant adaptation, against this background, I became interested in the political dimension of this process as well as in the $2^{\text {nd }}$ generation, i.e. those who have already grown up in their parents' country of destination.

However, when I wanted to return to the immigrant group I had already encountered, I was told there was no need to study their political attitudes and blame them for being right-wing extremists as they had enough problems "here in Israel". However, I did not agree; on the contrary, I do think there is a need to study the political adaptation of immigrants; and, again, Israelis with an FSU family background can serve as a case study. Hence, my initial interest was to understand who engages with the Yisra'el Beitenu party. Based on what I knew from previous research about the adaptation of FSU immigrants, I decided at the very beginning that I wanted to know more about the children of those immigrants, who very often immigrated with their adult parents but were usually not the focus of previous research. Thus, I decided to focus on how young Israelis with an FSU immigrant background become engaged with the Yisra'el Beitenu party. I started to collect data at a very early stage of the research process.

2 A short introduction to that immigrant group is Gitelman 2004; in more detail cf. Glöckner 2011. 
At that point, I had only a general knowledge of Israeli society in general and FSU immigration to Israel in particular. This context knowledge came from two sources: from my previous research on non-Jewish Russian spouses who had immigrated with their Jewish husbands (Schmidt 2006) on the one hand, and from overview reading about research on civic engagement in order to identify research gaps for the preparation of a Ph.D. proposal.

Since I was interested in the individual's perspective on civic engagement and thought of it as rooted in the individuals' biographies, indepth interviews with politically engaged people about their civic engagement were my first choice. Such kind of data would allow the interviewees to set their own focus and at the same time I would be able to work with a framework of open questions concerning civic engagement based on assumptions retrieved from the literature on civic engagement.

\subsection{A TYPOLOGY OF CIVIC ENGAGEMENT}

One can identify three main dimensions of research investigating civic engagement: publications in the first research dimension deal with theoretical and conceptual questions of a typology of civic engagement. Researchers of the second dimension are more concerned with aspects of citizenship education; in this context, they particularly study the motivation of engaged individuals to participate in democratic activities. A third line of research concentrates on the empirical variety of political participation focussing on different aspects (e.g. resources for civic engagement, or civic engagement of immigrants). Figure 1 shows the approaches of previous empirical studies on civic engagement.

Recent empirical studies appeal for a conceptual turn when looking at civic engagement, especially with regard to the younger generations. In this context, these studies affirm that those voices in the discussion are wrong who warn that participation is declining. On the contrary, the argument goes that the variety of activities has grown and especially young people (in the U.S.) today are not less active, but active in different ways than the generations before them. Dalton (2008) shows in his study that it is not so much engagement in general that is declining; instead, he can show a change in citizenship norms. He identifies two dimensions of citizenship, namely citizen's duties and citizen's rights (Dalton 2008: 80-1), and with the shift in 
emphasis from the former towards the latter over the last two decades or so, informal forms of political participation have become more relevant (Dalton 2008: 83); social research has only started to take these phenomena into consideration. though. ${ }^{3}$ As a first step, recent studies have tended to expand their concept of civic engagement. In this respect, various authors call for a broader definition of participation, i.e. to not solely understand it in strictly political terms (such as voting or formal membership in a political party) but to include also a whole (new) range of informal or extra-parliamentary political activities.

Several authors (e.g. Marsh et al. 2007; Miller 1992) demand a turn in the approach to civic engagement, which would take into account that nowadays especially young people become engaged in informal contexts of politics rather than joining for instance a political party. Haste and Hogan (2006) argue in a similar way based on empirical findings showing that lay

3 Research in this area builds on the empirical finding that the concept of citizenship has been contested (e.g. Haste/ Hogan 2006) and shows that notions of who a "good citizen" is have changed. Nowadays, young people still consider obeying the law the most important civic duty, but at the same time seem to rate e.g. community engagement as equally important as voting and even more important than partisanship (e.g. Haste/ Hogan 2006; Lister et al. 2003; TorneyPurta et al. 2001). The underlying conclusion of this contested concept is that what citizenship stands for should be left to the citizen under examination (Haste/ Hogan 2006). In this context, Torney- Purta and Klandl Richardson explored anticipated future civic engagement. They looked at how adolescents' conceptualisations of a "good citizen" can be predicted by various contextual factors of political socialisation; those predictor variables include school-related (political information, political efficacy), family-related (political discussions with parents (and peers), trust in the government), and organisation-related (preadult activities) (Torney-Purta/ Klandl Richardson 2004: 51). The authors can show that depending on different strengths of these factors a different outcome in anticipated civic engagement can be predicted: they find that informed voting is highly influenced by school-related factors as well as political discussions at home, whereas a high interest in current politics predicts future partisanship, volunteering in the local community is highly influenced by everyday experiences and a high level of perceived efficacy, and protesting is highly encouraged by political discussions with parents. 
people do not follow the strict distinction between the political and moral or social spheres that is common in the political sciences. Ekman and Amnå (2009) developed or revised a typology in order to "map [...] the totality of different types [emphasis in the original] of political and civic participation" (Ekman/ Amnå 2009: 15). Furthermore, the authors introduced the distinction between non-participation and participation, distinguishing within the latter between pre-political and manifest forms of action, and added the category of attention as a necessary pre-condition for action.

Figure 1.: Previous Empirical Studies on Civic Engagement

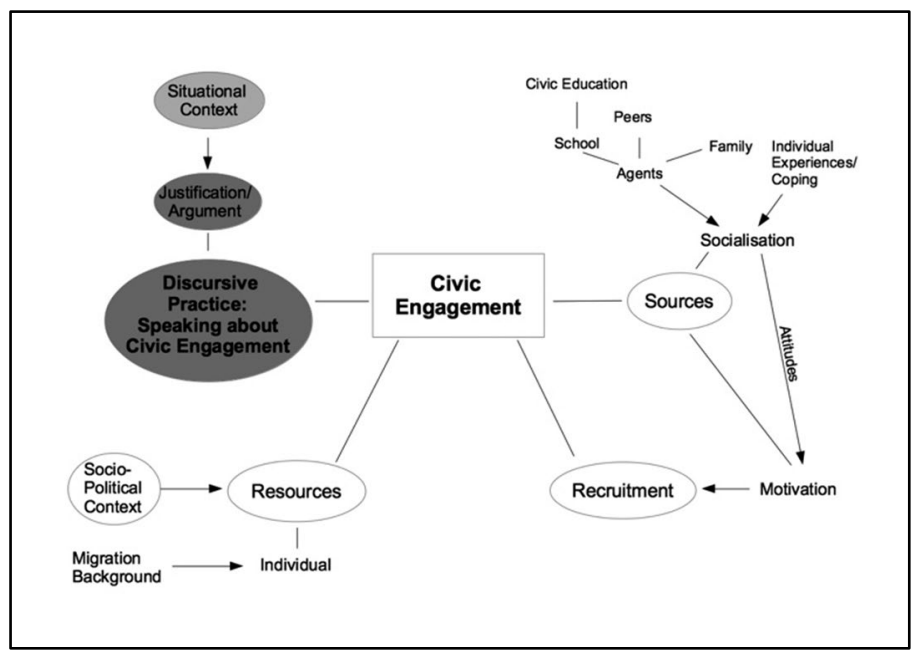

Source: Author's Own Presentation

\subsection{MOTIVATION AND MORAL VALUES}

Although the typology presented above suggests something different, empirical studies on civic engagement tend to answer the question why young people do not engage rather than the question why they become engaged. Motivation research has identified three areas of political participation: some are more value-orientated (ideology: "conventional (political)", i.e. voting behaviour, partisanship, political discussions etc.), some are more action-orientated (issue/ concern: "civic", i.e. helping the 
community, engagement in a social movement ${ }^{4}$ etc. or "make one's voice heard", i.e. protest etc.) (Haste/ Hogan 2006: 480).

Berger suggests an alternative approach and conceptualizes motivation in the context of individual moral development. In his theoretical paper he maintains that research must consider the motivation for engagement and argues in favour of submerging "civic engagement" into political, social or moral forms of engagement; he calls the very merging of social and moral engagement into social-moral engagement "civil" (Berger 2009). This is to elaborate a clear distinction between the various forms in which individuals can become engaged in, with or by something (Berger 2009: 340). Yet, as Bruter and Harrison empirical study ${ }^{5}$ (2009) shows, it is not so easy to link the different theoretical concepts of motivation with a particular form of civic engagement. Motivation for civic engagement affects an individual's belief system as well as the particular situation in which the activity takes place. Berger, however, does not give hints on how to determine these aspects. Yet research on motivation based on survey data cannot answer the question whether political interest, "civic awareness" (Haste/ Hogan 2006) or "sensitivity" (Ekman/ Amnå 2009) lead to civic action or vice versa or, in other words, "[whether] sensitisation [is] a consequence of pre-existing socio-political or moral values and action patterns, or sensitisation [does] arise from some personal experience that engages the individual and then extends the domain of concerns" (Haste/ Hogan 2006: 490). The major critique of Berger's approach is that he left the relationship of the latter (political participation) with the two former (non-participation and civil participation) dimensions unclear (Ekman/ Amnå 2009: 18).

And I would like to add a further point of criticism here: Berger mentions that some people might act according to "indefensible [for democratic citizens] moral codes [e.g. extremist of all kinds]" (Berger 2009: 343). He only implicitly claims that moral values, as he understands them, are not universal, but distinctively democratic, "relating to moral principles such as toleration, reciprocity and law-abidingness" (ibid.). What does this mean for

4 "Engagement in a social movement" is considered as informal political activity elsewhere (Ekman/ Amnå 2009).

5 In their empirical study on party activists they identified three different types of activists: moral-, social-, and professional-minded. 
empirical research on engagement in a non-democratic context, as the present study is going to do ${ }^{6}$

\subsection{RESOURCES FOR CIVIC ENGAGEMENT}

A third line of research is concerned with the concrete resources an individual has at his or her disposal. But why are those so important to investigate? The empirical answer those studies give is that not only do different kinds of participation put different demands on the participant but, as Verba et al. (1995) pointed out, this will lead to different people engaging in different kinds of acts, and, according to Klandermans, with different "motivational dynamics" (Klandermans 2004: 361). Within this line of research, researchers put emphasis on the relationship between civic engagement and different variables, mainly previous engagement and social capital:

Previous engagement Quintelier explored the relationship between previous memberships in various voluntary associations-cultural, deliberate, help organisations vs. expressive, religious-ethic or youth organisations,particular skills acquired in such associations and different forms of political participation (Quintelier 2008: 362). Summarising, Quintelier defined civic engagement as the "socialisation of attitudes [i.e. decision-making, political efficacy, social trust] and skills [deliberation, compromise, cooperation]" (Quintelier 2008: 356-7). She distinguished between "traditional" and "civic" forms of engagement as well as "political consumerism" (Quintelier 2008: 359). ${ }^{7}$ Either way, Quintelier found that the type of organisation in which one participates matters as much as the number of the individual's

6 Möller (2016) suggested-similar to the present study-to change to perspective and to ask about how the social actors make sense of their engagement.

7 Yet the distinction (if there is one) between those forms seems arbitrary here; according to the typology developed by Ekman/ Amnå, all three forms suggested by Quintelier contain activities of manifest (formal and informal) political participation. Besides, it is important to note that the direction of relationship is unclear, i.e. whether membership in a voluntary association facilitates political participation or vice versa. 
actual memberships in organisations as well as the skills that members are able to develop during their activities; all of these factors influence the various forms of political participation.

Social capital Putnam's influential study (2000) about social capital and political participation, his conclusions about declining social capital in the U.S. and the ensuing discussion about democracy at stake, introduced a new concept under an old name. In contrast to Bourdieu's concept (e.g. Bourdieu 1986), Putnam's social capital consists of three main components: the moral obligation to participate, social trust as an underlying condition that, again, is provided by individuals' social networks as more or less institutionalised opportunity structures. However, Putnam's work and particularly his concept of social capital, or rather its theoretical shortcomings, have provoked highly controversial critique; among the most severely criticised points was Putnam's conception of social capital as producing an entirely positive outcome (Braun 2001). Thus, a research line concentrating on the relationship between political participation (in its manifest and latent dimensions) and social capital (e.g. Teney and Hanquinet 2012; Berger 2009; Braun 2001) rather applies Bourdieu's concept. ${ }^{8}$

Bjørnskov (2006) proposed that different forms of social capital should lead to different forms of political participation, mediated by factors like socio-economic status (SES). Building on this, Teney and Hanquinet (2012) identified six types of social capital, which they connected to very different types of political participation. As expected, those with various social contacts also highly participated in all kinds of activities of manifest as well as latent forms (Teney and Hanquinet 2012: 9). However, the result that astonished the authors most was that another group with mainly onedimensional contacts, above all within a religious community, also showed

8 Interestingly, in contrast to empirical studies on civic engagement of "citizens", research on the engagement of immigrants rather employs a social capital approach based on Putnam's work about the "civic community" (e.g. Putnam 2000; Putnam et al., 1994). Many empirical studies on the subject build on the work of Fennema/ Tillie (e.g. Fennema/ Tillie, 1999; 2001; Tillie 2004) about immigrant political participation in Amsterdam and test the "amount of 'ethnic' social capital (participation in ethnic associational life)" (Jacobs/ Tillie, 2004: 419) of a certain ethnic minority. 
high numbers in political participation, yet again mainly within a religious community (Teney/ Hanquinet 2012: 10). Besides, the latter showed little hints to activities of latent forms of participation (ibid.). La Due Lake and Huckfeldt also started from a critique of Putnam's "excessive focus on organisational involvement and its consequences for the production of social capital" (La Due Lake and Huckfeldt 1998: 582). They concluded that "social capital [is] a by-product of social interactions [with other people who are similarly engaged] that enhances individual civic capacity and political expertise, thereby allowing individuals to become more fully engaged in politics" (La Due Lake and Huckfeldt 1998: 581-2). Besides they find that these interactions produce certain types of "politically relevant" social capital "because of the expertise of discussants, the frequency of political discussion, and network size" (La Due Lake and Huckfeldt 1998: 583).

\subsection{IMMIGRANTS AND CIVIC ENGAGEMENT}

As shown in the previous sections, certain predispositions (i.e. motivation) and resources are considered major conditions for becoming engaged. Verba et al. (1995) employ a third necessary condition: the moment of recruitment. With regard to the political participation of immigrants, de Rooij added the dimension of "integration" and immigration-specific features, in particular patterns of mobilisation and time of residence (de Rooij 2012: 455). Accordingly, she stated that immigrants become engaged in conventional rather than unconventional and low rather than high-cost activities (de Rooij 2012: 457).

Structural factors But with regard to immigrants, one must consider not only individual but also structural factors, the most important one being citizenship. Bäck and Soininen (1998) considered an individual's citizenship status as the main reason for "significant exclusion" of immigrants from political participation (e.g. also Schönwälder et al. 2011). With regard to conventional political engagement, i.e. party activism, one approach is what Bird (2003) coined "descriptive representation" and refers to the role of political parties in selecting immigrant candidates. She studied ethnic minorities on the macro- + micro-levels as well as additional factors and found that a candidate's selection depends on several factors: supply-side + 
demand-side + ethnic voting behaviour + the individual level of integration + practices of consociational accommodation + the electoral system. Sobolewska (2013) added that legal structure, ideological climate and intraparty organisation or party strategies also have to be considered.

Resources or capital? Verba et al. (1995) referred to (social) capital as a resource for civic engagement. ${ }^{9}$ Empirical studies on civic and political engagement employ not only social, but also other forms of capital as distinguished by Bourdieu (e.g. 1983). On the basis of a former study, which showed that "that Irish political parties made minimal efforts to attract the support of immigrant voters and did little or nothing to encourage these to become party members" (Fanning/ O'Boyle 2010: 417), in a follow-up study Fanning/ O'Boyle explored “individual motivations for political participation, status factors (i.e. residency/ citizenship) and finally, how social capital interacts and combines with other forms of capital (human and cultural capital) in affecting the political agency of immigrants" (Fanning/ O'Boyle 2010: 418). They employed the term "socio-political capital" (ibid.), based on Bourdieu's concept of capital, in order to "reflect the interrelationship of these various forms of capital" (ibid.). ${ }^{10}$ Besides the influence of political socialisation on the development of a "distinct political habitus" of the immigrant candidate interviewees, the authors found that a candidate's social relationships, especially “outside the community of origin, would foster political participation" (Fanning/ O’Boyle 2010: 433; cf. also Softic 2016).

9 Anthias (2007) argues in favour of using the term "capital" over the term "resource" with regard to the "mobilisability" of the former across borders and contexts.

10 As examined here, it includes the educational qualifications of respondents and their socio-economic status; prior political socialisation; membership of immigrant and Irish organisations; and religiosity (Fanning/ O'Boyle 2010: 419). 


\section{The Data Material}

In the present chapter I will describe the process of data collection and data analysis in the present study.

When I approached the potential interviewees, I explained to them that I would be interested in their story about how they had become engaged. I did not explicitly say, however, that I approached them because of their connection to the Yisra'el Beitenu party; but made the engagement with IB as well as public discourse about the party and its political leader, Lieberman, an issue in the interview itself. In the interviews, I used this framework as guiding questions or rather topics that I would adjust to the course of the interview and in the process of data collection, if necessary. However, I asked every interviewee an opening question (cf. Schuetze 1983): "Please tell me how you have become engaged [further, depending on the current engagement of the participant] in your community, with the students' council, with IB, etc.”.

The empirical data is mainly based on in-depth interviews about civic engagement in general, and engagement with the Yisra'el Beitenu party in particular. ${ }^{1}$ Besides, I collected context data that I also have included into the analysis: material from the Yisra'el Beitenu party's 2009 electoral campaign, material from the party's official website in English, Russian and Hebrew (newsfeed, the party programme, screenshots of their website), newspaper articles on FSU immigrants and on the Yisra'el Beitenu party, information obtained from informal interviews and talks, fragments of discussions in

1 All the names in this work were made anonymous, unless marked otherwise. However, I tried to keep the original "sound" and chose names accordingly. 
social media on the Yisra'el Beitenu party and Israeli politics, workshop and conference proceedings on the Israeli society.

\subsection{THEORETICAL SAMPLING OF THE DATA}

Before I started the actual fieldwork in June 2009, I had made contacts with two young political activists in Israel through a colleague who herself had immigrated to Germany from the former Soviet Union as a child. One of these activists referred me directly to a member of the IB Knesset faction (Max), the other contact referred me to a former activist of the party who had been engaged on the local level (Nitsan). After initial contact with potential interviewees, I proceeded via the snowball system-approach and asked the interviewees whether they could forward me to further people affiliated with the party. Through Max I reached out to Katya, Ilan and Ljuba, who were all parliamentary assistants to Knesset members of the IB faction.

Furthermore, I directly contacted party representatives on different levels: national (member(s) and the party's secretary general) ${ }^{2}$ as well as local representatives. ${ }^{3}$ Figure 2 shows the sample of interviewees.

When I contacted people in the party's local or central administration over the phone, I asked them to connect me to young Russian-speaking Israelis who are actively involved in political or civic activities in the framework of the party. In most cases, I was rejected; in other cases, people agreed to meet me in person or referred me to potential interviewees. In Haifa, the local representative declined my request because she could not think of anyone who would meet the profile. Yet the most successful way to find interviewees was through mutual friends or acquaintances. I obtained the contacts through a personal network of colleagues in Israel or such colleagues with contacts in Israel.

2 Members of the Knesset were listed according to their party affiliation on the parliamentary website.

3 For this purpose, I used the section "Our people in the city" on the official IB party website (Partija "Yisra'el Beitenu" ("Our House Israel") 2013); besides, I contacted student cells of the party within the students' councils at the Universities of Haifa and Tel Aviv. 
Figure 2: The Sample

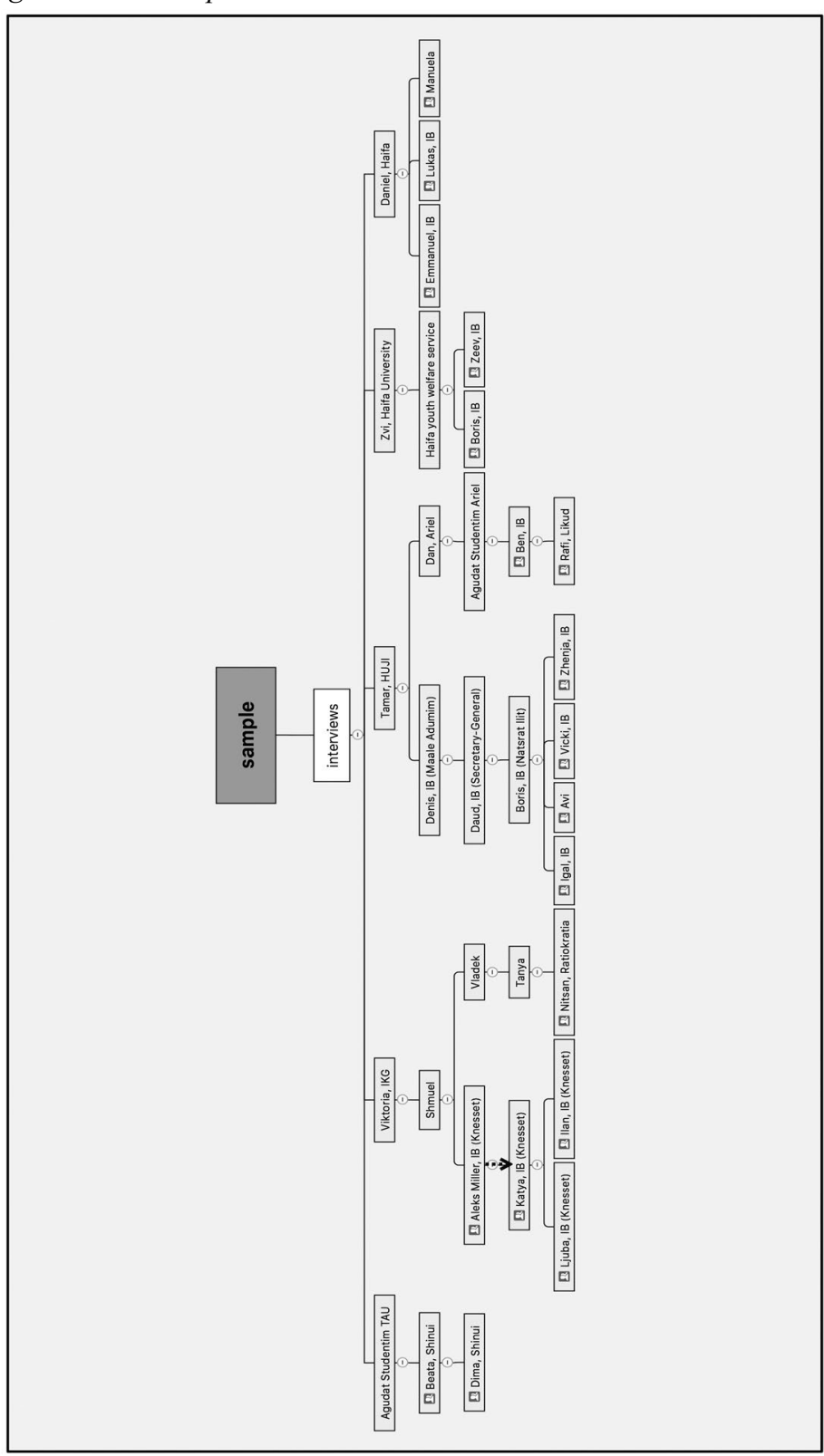

Source: Author's Own Presentation 
This went surprisingly very well. However, after giving it some thought, I reached two conclusions. On the one hand, I am certain that being referred to a friend was a sign of trust toward me that is not to be underestimated. This also explains, at least partly, why my request was more commonly rejected on the phone. On the other hand, I realised that the party officials had become increasingly confident about their political position after the 2009 electoral success of the party and its inclusion in Netanyahu's governing coalition.

Micha, a local IB representative from Ma'ale Adumim-one of the largest Jewish settle-ments in the West Bank, near Jerusalem-, for instance, agreed to meet me after I had contacted him through a local police officer, the husband of an acquainted Ph.D. student at the Hebrew University. At short notice, Micha set up a meeting with the secretary general of the party in Jerusalem. That meeting in particular opened many, many doors since the secretary general functioned as one of the gate-keepers in the present study; among other things, it paved the way to the local party branches in Natserat Illit and Ari'el (another large settlement in the northern part of the West Bank).

The participants I had interviewed in 2009 lived all across the country: in Bat Yam near Tel Aviv (Katya, parliamentary assistant), in Ashdod, i.e. in the south, close to the Gaza Strip (Ilan, parliamentary assistant), in Haifa (Nitsan, who founded his own political party after leaving IB), in Jerusalem (Ljuba, parliamentary assistant) and in Ari'el (Max, member of the Knesset, Ben, member of the student's council at Ari'el University). Additionally, I had the chance to interview Viktoria, Dima, and Rafi - three party activists who were not engaged with IB but with the Shinui party (Viktoria, whom I had "found" through the student's council of Tel Aviv University), or the Likud (Dima, a friend of Viktoria's, and Rafi, Ben's roommate at Ari'el college).

In 2010, I concentrated on Haifa, where I spoke with young people who would regularly visit a youth club in the Hadar neighbourhood of Haifa. I got in touch with these young people through local colleagues during my time as a visiting scholar at Haifa University (e.g. Boris and Emmanuel, IB voters, and Zeev, a local activist). The Natserat Illit contacts were established thanks to the help of Denis (e.g. Avi, Vicky, Igal, Zhenja—local activists).

In particular during my second field trip, data collection and analysis were geared to the principles of theoretical sampling and of minimal and 
maximal contrasting (e.g. Glaser/ Strauss 2010; Kelle 2005), which Glaser and Strauss suggest for data organisation. When I had entered the field, I had just a vague research interest in 2009 and started to analyse the first interviews with open coding. Moreover, I began to read about previous research on civic engagement. The focus of my analysis was still on the individual stories about ways into civic engagement, which differed depending on the proximity of the interviewees to the organisational centre of the party: based on the first circle of coding I assumed that those closer to the centre had come from previous political engagement, while those further away from the centre had been more concerned with community or social issues. Thus, when I returned to the field about ten months later, I conducted interviews according to the following criteria of minimal and maximal contrasting with regard to the interviewees' engagement with the Yisra'el Beitenu party:

- active v. passive political engagement,

- formal v. informal political engagement,

- party work on national v. local level,

- party office-holder vs. voluntary engagement,

- engaged with IB v. other political party.

However, I was not able to satisfy the theoretical sampling completely; and the reasons for this are twofold. For one thing, it was due to difficulties in respect of limited time and money for the data collection, especially in view of the geographical distance, secondly, there was the problem of the availability of potential interviewees during field phases. As mentioned above, in some areas or cities there were just not (enough) young people engaged within the framework of the party. Aleks, a local IB office holder in Natserat Illit, was the only (young) person I was able to establish contact with on the regional level, and he did not agree to an interview. As a result, I was not able to fill the matrix with interviewees who hold a party office on a local level. 


\subsection{DESCRIPTIVE ANALYSIS OF THE INTERVIEWEES}

I conducted 29 interviews with young Israelis (aged 18-29) with an FSU family background. Most of them had immigrated as children (the then oldest interviewee immigrated to Israel at the age of 11) from the former Soviet Union. Igal's parents - he was one of the two interviewees who were born in the country to immigrants from FSU countries - had come to Israel as early as in the 1980s, thus in a previous immigration wave from the Soviet Union. ${ }^{4}$ The interviewees form two groups: one, which is actively involved in party work and one, which in its mainly local engagement is only loosely connected to an IB representative.

Previous civic engagement Civic engagement often serves as the starting point for engagement in general and political engagement in particular. In accordance with previous empirical studies, engagement with the Yisra'el Beitenu party is rarely the starting point for active engagement. Only a small minority among the participants had not been actively engaged prior to their IB engagement. If the interviewees were engaged before, it was in one of the following scenarios:

1. formal engagement

- ideological membership: Zionist institutions or youth movements (Vicky),

- students' council (Max),

2. informal engagement

- community work (Ilan, Katya).

Recruitment Various empirical studies (e.g. de Rooij 2012; Verba et al. 1995) have pointed to the fact that most engaged people have become recruited at a certain point. This is also true for the interviewees in the present study. Based on the analysis of the interview material, I interpret this moment of recruitment a little broader and included not only those interviewees who were approached by a particular person, but also those cases of rather indirect

4 For more details on this wave, see e.g. Beizer 2005 
ways of recruitment, e.g. a job offer in the course of which the interviewees actively entered the IB framework.

Generally, the interviewees described two main ways of becoming engaged with the party. Either they had been active before in one way or another and had been recruited by an IB representative on the basis of these activities. On the local level, those who recruited them were people already active in the party, very close to the interviewees in their everyday lives-e.g. friends (Nitsan) or kin (Igal, Lukas, Vicky, Igal, Avi)-, and had asked for help with a certain issue. This kind of recruitment is of very informal character, it is often not ideological but rather a gesture of friendship and mutual support.

In contrast, on the national party level it was rather a Yisra'el Beitenu party official who could win the individual over. The usual pattern of recruitment here is to get to know to an IB representative through working on a specific project (Ilan, Max, Katya). Recruitment on the national level occurred in a much more formal way. While the first contact with a party official might have happened on the interviewee's initiative, it served the interests of the party at the same time, namely their readiness to actively look for new members. Bagno ${ }^{5}$ pointed out that the party was actively looking for young activists in various societal fields and on various societal levels in order to recruit them as members and by these means used the trust these activists gained in their communities for its own political purposes.

\section{Operation Cast Lead (2009) and the Gaza flotilla raid (2010) My}

field trips took place shortly after or coincided with these events, so, occasionally the interviewees referred to them in their line of argument; and they were also widely discussed in (the) (social) media. That is why I shortly outline them here. The military operation Cast Lead against Hamas in Gaza started at the end of December 2008 and ended in January 2009, only three weeks before the general elections for the $18^{\text {th }}$ Knesset. Its declared goal was to stop rockets being fired from the Gaza strip to the south of Israel. In the aftermath of these events, the United Nations launched the Goldstone report, which in Israel was regarded as one-sided because it accused the country of disproportionately condoning civil casualties.

5 Olena Bagno. Informal Meeting at City University New York City (CUNY), New York City. (December 30, 2011), author's own notes 
The Gaza flotilla was a political campaign which started from Turkey: Six ships were heading for the Gaza strip in May 2010. While the participants claimed to be taking relief supplies to the civilians in Gaza, Israel suspected them of delivering weapons for Hamas. When they entered Israeli territorial waters, the ships were demanded to leave by Israeli military. When they did not, IDF entered the ships: on one of them at least four people were killed through gunshot. The incident caused a long-term deterioration of TurkishIsraeli diplomatic relations (cf. Schiftan 2010; Pedatzur 2010).

Narrative style As mentioned above, the interviews are conceptualised as discursive practice. Against this background, I will be able to show how the interviewees use their narratives to turn to an invisible audience. This means, at times, not the interviewer is the partner in the current communication, but an imagined, absent partner is addressed. This must be understood as an argumentative strategy and thus serves a purpose.

At the same time, I had to consider that for the interviewees it would not be the first time that they told their life stories or parts of them. Thus, talking about one's life in a particular way, emphasising parts and leaving out others, has to be regarded as actively taking part in the reproduction or modification of discourse (Schäfer/ Völter 2005).

Cross-cultural communication and power relations Last but not least, I would like to reflect on power relations in the context of the interviews (e.g. Ebert/ Okamoto 2015; Lomsky-Feder/ Rapoport 2003). I approached the interviewees in Hebrew, but left it open to switch to Russian if requested. Occasionally, I felt that this caused irritation due to the foreign accent I had, and I was urged quite often to tell my personal story of interest in the issue in order to win the (potential) interviewee's trust. I do not think, however, that the fact that I was a foreigner was the reason for some of them to decline to tell their story. On the contrary, it may have particularly invoked their interest. During the interviews themselves, I often had the impression that the interviewees felt urged to explain something they had said in more detail to me, assuming I would not know - and often I really did not. The form of explanation they delivered ranged from adding details in a neutral way, so I would understand the matter, through flirting with me, through considering me as a collaborator, i.e. using my European or German descent 
as a strategy to make an argument, to patronising me about how things work in Israeli society.

Language often did help; however, it did not always do so (e.g. Kruse et al. 2012). On the one hand, both the interviewees and I had various languages at our disposal to choose from if something was incomprehensible or if a term was missing. The interviewees made massive use of it, especially when speaking about everyday life: though they usually had a very high level of Hebrew, they referred to very familiar things, things of daily routine, in Russian. Yet sometimes, the interviewees felt the need to explain things in English instead, perhaps because they had not an adequate, more understandable way to describe these things.

\subsection{CODES AND CATEGORIES}

As suggested, I started the analysis as soon as I had collected the first data and developed more detailed questions based on open coding in order to apply and adjust them in the process. As a very first step, I organised the material according to topics that either the interviewees would bring up or that I had brought up by asking about an issue. I used those topics as in vivo codes. The interviewees spoke about their personal experiences, growing up in families with an immigrant background, individual and collectively shared difficulties in the process and their individual ways of coping with those difficulties and about their military service as a central experience. In the process of open coding, I had developed first hypotheses about how young people become involved.

Yet I also found that the interviewees did not speak as much about their engagement as about their views on Israeli society and their own place in it - in other words, that they constantly referred to the macro-level, e.g. to cultural codes and to public discourse. Besides, I needed to extend the paradigm in such a way that it would be possible to include the role of discourse.

A second step in the process of coding was to approach the material with axial coding, as a way to organise the codes into categories and to fill those categories with empirical content by ascribing features to them, which in turn are based on the data or the codes. Axial coding is rather abstract thinking, aiming at systematisation of the preliminary findings and putting them into 
Figure 3.: Category: Identification

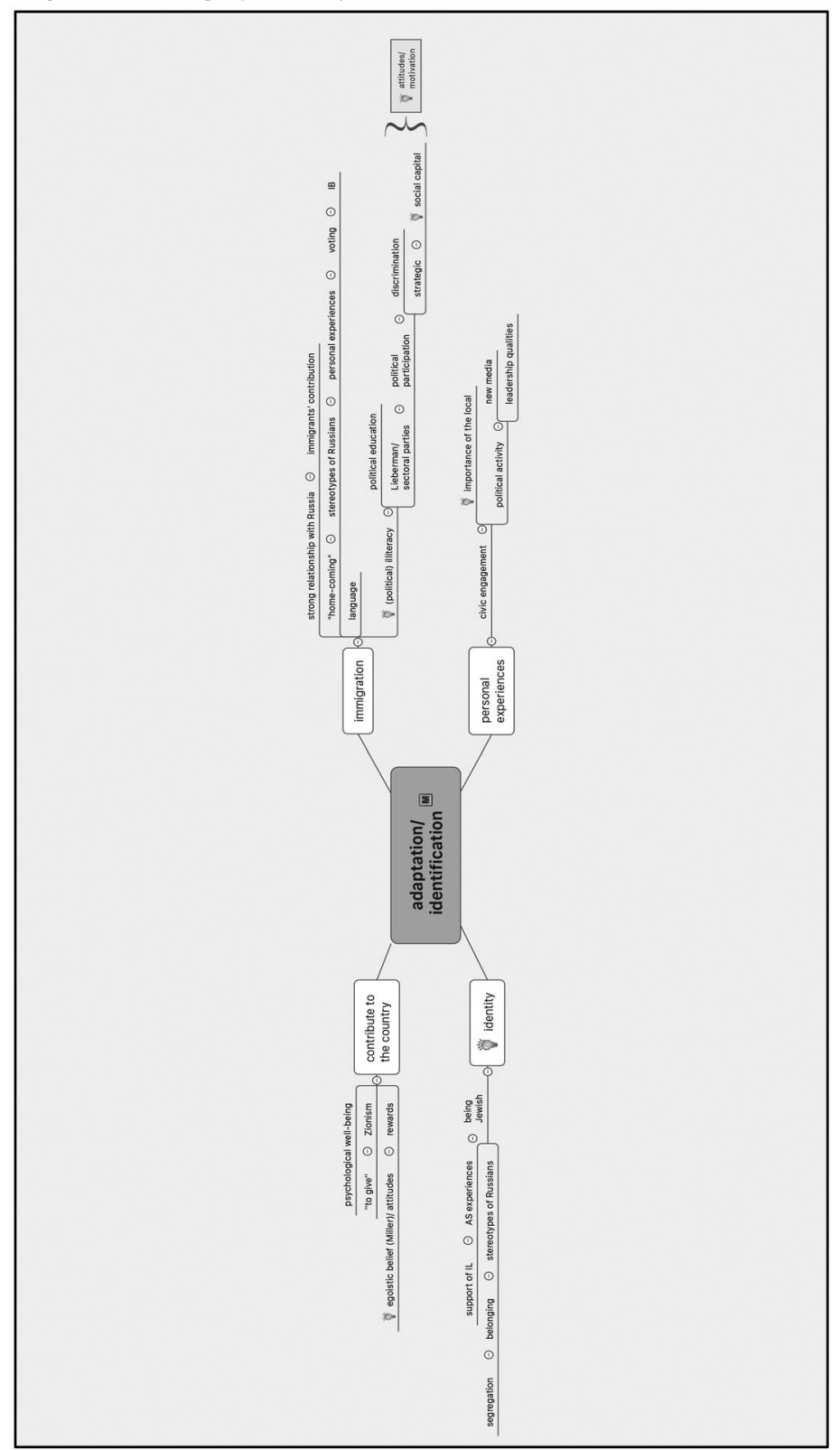

Source: Author's Own Presentation 
a relation (Breuer 2010: 284). Figure 3 shows an example of categories, as developed during the coding process.

When I approached the material that way, I hypothesised that the interviewees use talking about their civic engagement as a strategy to justify their particular view of Israeli citizenship. This version of citizenship, in turn, exactly as I assumed at that point, seemed to serve to give them a sense of belonging. During further analysis, I found more and more hints that my assumption might be right; I had found my key category: belonging.

At this point at the latest, Strauss's coding paradigm alone was no longer helpful. In order to grasp those references to the macro-level, I decided to extend Strauss's coding paradigm because I felt that the concentration on the conditions, strategies of action, individual actions, and the outcome of those actions of the individual would limit the analysis (Kelle 2005). 



\section{A Coding Paradigm of Belonging}

In Pierre Bourdieu's overall conception of human action I have found a useful basis to identify the dimensions of empirical analysis. The present chapter aims at providing a theoretical-operational framework for the analysis of the interview material in order to find answers to the questions raised in the introductory chapter. At the end of the chapter, I will suggest an integrated framework of Pierre Bourdieu's concepts as an extension of Strauss's coding paradigm. Yet at the same time it is more than this: namely an alternative different approach to immigrant adaptation from the angle of the immigrants" "subjective positioning", which recognises the individual as actively constructing their sense of belonging. This does not mean that the structural factors of immigrant adaptation will be left out; on the contrary, I suggest a holistic approach here.

\subsection{BOURDIEU'S CULTURAL THEORY OF ACTION}

Bourdieu's central themes circle around the issues of an individual's belonging, or, sense of place, legitimisation, and symbolic power. His sociological thinking has been described, depending on the purpose the various authors claim for using Bourdieu's ideas, for example as an "economy of practices" (Smart 1993: 388), a "dispositional philosophy of action" (Savage/ Silva 2013: 112), or as a means for the analysis of social inequalities and the "subtle inculcation of power relations" (McNay 1999: 99). Bourdieu's social actors, actively (re-)produce the social world they live in. In his overall work, Pierre Bourdieu developed five interconnected concepts in order to understand and analyse the relation between the 
individual and society, between subjective and objective structures. ${ }^{1}$ This notion is nicely described with the formula "[habitus $\mathrm{x}$ capital] + field $=$ practice" (Bourdieu 1987: 175).

In order to make Bourdieu's rather theoretical concepts applicable as categories for the analysis of interview material, I suggest here to integrate Bourdieu's concepts with methodological approaches from discourse analysis. The objective structures are grasped analytically with the help of a sociology of knowledge approach to discourse (SKAD) (e.g. Keller 2011a); SKAD particularly takes into consideration collectively shared knowledge, e.g. in the form of patterns of interpretation. Social practice is understood as discursive practice and analysed with reference to Helen Haste's lay theory approach (Haste 1992). Among other things Haste emphasises the impact the situational context has on the individual's argumentative strategies.

In the following, I will briefly discuss Bourdieu's concepts with regard to my research interest and suggest an operational framework to (re-) integrate these concepts with different approaches from discourse studies.

\subsubsection{Social Space and Symbolic Order}

Social space, i.e. a given society, is the entity of objective structures or cultural codes. Lamont and Lareau define culture as "institutionalised, i.e. widely shared, high status cultural signals (attitudes, preferences, formal knowledge, behaviours, goals and credentials), used for social and cultural exclusion" (Lamont/ Lareau 1988: 156). Individual "sets of properties" (Bourdieu 1985: 724) constitute the social world (Bourdieu 1985: 723). Social actors are positioned within these objective structures along dimensions of the accumulation of capital, in particular the overall amount of capital, its composition of the various forms of capital, as well as individual trajectories or past experiences (Bourdieu 1986; also Atkinson 2010: 2). Against the background of their objective position in a given social space, individuals develop a set of dispositions to act, reflecting the "central structural elements (political instability, kinship rules, and so on) of their society" (Nash 1999: 185). These dispositions guide the individual's social

1 According to Silva and Warde, Bourdieu most systematically integrated these concepts in his Réponses pour une anthropologie réflexive (Bourdieu/ Wacquant 1996), (Silva/ Warde 2010: 5). 
interaction. Through their actions they "necessarily reproduce those structural elements although in a modified form" (Nash 1999: 185). Accordingly, Bourdieu conceives the social space as a "space of relationships" (Bourdieu 1985: 725) between social actors. In other words, the material order of possession of relevant forms of capital mirrors the symbolic order of power relations in that given society (Bourdieu 1985: 723). The relationships between social actors in a particular social space are determined by the distribution of power among them: the composition of an individual's capital, his or her resources, determine his or her objective position in a given society. Their objective position, again, determines their "chances of achieving legitimation" (Crossley 2001: 85). The social group in power, in turn, determines which forms of capital are considered valuable at a certain time, i.e. what kind of composition of an individual's capital is required for achieving a legitimate objective position to exercise power. Members of a given society usually do not question this power. It is rather generally accepted as a means of guidance about what is regarded legitimate and valuable by those social groups-Bourdieu rather speaks of social classes in order to emphasise the relative stability of a given social hierarchy—-who are more distant from power.

\subsubsection{Forms of Capital}

The concept of capital is central in Bourdieu's theoretical framework of social action; and it has already been mentioned with regard to social space. Depending on its particular form, capital needs to be individually acquired, or embodied, over time rather than being transmitted directly within the family. ${ }^{2}$ Accordingly, Bourdieu speaks of capital as "accumulated history" (Bourdieu 1986: 183). The accumulation of capital occurs against the background of an individual's "respective distance [...] from the realm of material necessity" (Crossley 2001: 85). In other words, an individual needs to have the time and opportunity to accumulate non-economic forms of capital. In this context, Prieur and Savage speak in this regard of capital as "accumulated advantage" (Prieur and Savage 2011: 569). In order to illustrate this, Bourdieu compares the social world to a game (e.g. Bourdieu and Wacquant 1996 [1992]): the amount and composition of a social actor's

2 The exception from this rule is economic capital. 
capital - one's stakes in the game - defines one's chances to pursue one's interest of improving one's objective position in a given society (Bourdieu 1985: 724). This means the composition of a social actor's capital gains particular importance in a concrete field; here, capital is both the product of and the resource for individual agency (Bourdieu/ Wacquant 1996 [1992]: 129). It is important to mention here that social actors, according to Bourdieu, do not see what they do as a game as such, as something they are not necessarily involved in, but as a meaningful and important (Bourdieu/ Wacquant 1996 [1992]: 148).

Bourdieu distinguishes four forms of capital: economic, cultural, social, and symbolic; to a certain degree each of them can be converted into the other forms (Bourdieu 1986; Siisiainen 2003): ${ }^{3}$

Cultural capital Cultural capital—or "Informationskapital [informa-tional capital]", as Bourdieu refers to it from a backward perspective (Bourdieu/ Wacquant 1996 [1992]: 151) — is closely linked to formal and informal education both in Bourdieu's writing and the concept's application in empirical studies. Cultural capital is divided into its three sub-forms: inherited or embodied (e.g. particular cultural skills and knowledge), objectified (e.g. school certificates), and institutionalised (e.g. titles) cultural capital (Bourdieu 1986). It involves particular cultural competencies, skills, and habits, cumulating into "the cultivated naturalness" of particular social classes (Bourdieu 1987). Thus, cultural capital is by definition a struggle over cultural codes, over "legitimate culture" (Prieur/ Savage 2011: 568).

Critics mainly refer to ambiguities and gaps in Bourdieu's notion of cultural capital. Lamont and Lareau describe the development of the concept in Bourdieu's writings: being introduced as an "informal [...] competence" (Lamont/ Lareau 1988: 155), through being an institutionalised feature, mirrored in the possession of formal knowledge e.g. in the form of diploma

3 In the empirical literature, in different research contexts further, sub-forms of capital have been introduced: e.g. "socio-political capital" (Fanning et al. 2010) in the context of political opportunity structures for immigrant candidates in Ireland, or "discursive capital" as suggested by Gavriely-Nuri (2012) studying "cultural codes" in Israel. However, I agree with Smart (1993) to reduce the operationalisation of existing forms of capital to the basic forms Bourdieu had suggested in order to prevent confusion. 
(ibid.), then becoming an "indicator and basis of class position [...] being mobilized for social selection" (ibid.), and finally becoming "a power resource" (ibid.). In this context Kingston criticises that, due to the vagueness and ambiguity of the concept, "too many conceptually distinct variables have come to be placed under the big umbrella of cultural capital, creating a distorted sense of what accounts for academic success" (Kingston 2001: 89). Finally, Bennett and Silva argue that in particular cultural capital became practically applicable only after Bourdieu had added a specification of the sub-forms of cultural capital (cf. Bennett/ Silva 2011). In order to deal with these points of criticism, Lareau and Weininger stress that Bourdieu's concept of (embodied) cultural capital contains particular "techniques and "skills"' (Lareau/ Weininger 2003: 593), or, as Edgerton and Roberts put it, "adaptive cultural and social competencies" AND the "possession of relevant intellectual and social skills" (Edgerton/ Roberts 2014: 4). In a similar vein, Erel applies migrants' cultural capital as "adaptive [...] competencies": "first, migrants do not only unpack cultural capital from their rucksacks, instead they create new forms of cultural capital in the countries of residence. They use resources they brought with them and others they develop in situ to create quite distinct dispositions. Second, migrants engage in creating mechanisms of validation for their cultural capital" (Erel 2010: 649) "as capital alternative or oppositional to frameworks of national belonging” (Erel 2010: 643).

Social capital According to Bourdieu, social capital is "the aggregate of the actual and potential resources which are linked to possession of a durable network of more or less institutionalised relationships of mutual acquaintance and recognition - or, in other words, to membership in a group-which provides each of its members with the backing of the collectively owned capital, a 'credential' which entitles them to credit, in the various senses of the word" (Bourdieu 1986: 51; see also Smart 1993).

As mentioned above, most empirical studies employing the concept of social capital refer to Putnam's version. While Putnam constructs social capital, in particular the aspect of social trust in social relationships, as a necessary dimension for social integration, Bourdieu uses the concept, together with other forms of capital, to describe social conflict (e.g. also Siisiainen 2003; Braun 2001). 
Symbolic capital Symbolic capital can be translated into social prestige or standing - as an individual, but also as a would-be member of a particular social group. The purpose of symbolic capital is to produce a "meaningful distinction" or legitimate social hierarchy, and the question of what is legitimate is subject to constant social struggle (Bourdieu 1986; 1985). This form of capital in particular is linked to collectively shared cultural codes; these codes define the possession and composition of other forms of capital that an individual needs to transform these into symbolic capital (Bourdieu/ Wacquant 1996 [1992]: 146). The general recognition of the value of symbolic capital is a prerequisite for the transformation of other forms of capital into symbolic capital. Over time, as culture may change, the particular composition of symbolic capital may change. The direct link to a concrete cultural context reveals, or, rather, puts a veil on the arbitrariness of who has a high standing in a given society (Bourdieu/ Wacquant 1996 [1992]: 151).

\subsubsection{Habitus}

Bourdieu introduces the concept of habitus in order to bridge the conceptional gap between the abstract notion of society and the individual that actually lives in that society. The individual's objective position in social space - the social and cultural context - deeply influence his or her ways of perceiving the social world. From Bourdieu's cultural perspective, the process of an individual's socialisation is the "situated internalisation of cultural schemes" (Edgerton/ Roberts 2014: 15), of embodied experiences connected to this position. By linking objective and subjective structures, Bourdieu's concept of habitus is able to put individual action into context: habitus refers both to an individual and a collective history (Bourdieu 1986; see also Reay 2004; Webb et al. 2002; Nash 1999; for empirical examples see Rapoport/ Lomsky-Feder 2002; Reay 1997). In the process of socialisation, the individual generates power resources (habitual dispositions, including the different forms of capital) in the various fields of social interaction; these power resources, again, can be mobilised later on in current fields of action. Habitus is an "objective opportunity structure" (Bourdieu 1985: 726-7), an "interplay between [an individual's] past and present" (Reay 2004: 434), and at the same time it structures what an individual expects of his or her future through "embodied structures of expectation" (Edgerton/ Roberts 2014: 7). Bourdieu developed his idea of 
the habitus providing social actors with a "practical sense" (Bourdieu/ Wacquant 1996 [1992]: 154) as a critique of the overly intellectual conception of human action (Bourdieu/ Wacquant 1996 [1992]: 153; see also Edgerton/ Roberts 2014; Crossley 2001). In contrast to assumptions made by Rational Choice Theorists, for instance, habitual dispositions guide individual actions as an underlying, mainly unconscious basis. As Sweetman put it: "as the embodiment of social structure, habitus allows us to act" (Sweetman 2003: 532).

As a reply to critics who see Bourdieu's conception of individual action as a "mere reduction of an individual to his or her positions in social space" (Lahire 2003), I agree with Crossley that it is a "matter of emphasis" (Crossley 2001). The objective position in social space is only one side of the coin - the individual's subjective positioning and representation is just as important. In this context, I argue that by using all of Bourdieu's concepts in an integrated framework, one avoids such a "reduction". In this sense, an individual's habitus is not only a "structured structure" but functions also as a "structuring structure", actively reproducing the existing social order in daily interaction, or social practice. The perception of an individual's position is hence a central "contribution [...] towards constructing the view of the social world" (Bourdieu 1985: 727).

Apart from general critique of Bourdieu's concept, many authors state the ambiguity not only of the habitus but also of all of Bourdieu's concepts throughout his work. However, especially his conception of individual action has been under attack. There are three main points of critique of the concept: the first point is that there is little innovation in the habitus, but that dispositions learned through the socialisation process in early childhood remain unaltered. Bourdieu meets this criticism by arguing that the habitus enables the social actor with a "practical sense", and that besides it is understood as a "dynamic" and "generative principle" (McNay 1999: 101).

4 In Jenkins's reading of Bourdieu (2006), habitus or the subjective perception of one's social environment and subsequent action is completely determined by external conditions. As a result, the individual expects of his or her life only what seems probable from past experiences, and thus simply reproduces the status quo in a given society. Certeau even speaks of Bourdieu's habitus as a "prison house" (Certeau 2008: 84; cited after Webb et al. 2002: 58), lacking "any possibility of a self-conscious, dynamic cultural literacy" (Webb et al. 2002: 59) that would 
A second major point of criticism is that Bourdieu states that there is a temporal dimension in the acquisition of a habitus (Noble/ Watkins 2003: 525; see also McNay 1999). As mentioned above, Bourdieu states that the early years of socialisation are formative; in the process of socialisation

include a "self-reflective understanding of the person's own position and resources" (Webb et al. 2002: 57), an "awareness of the rules, regulations, values and cultural capital" (ibid.). I share the point of view that — despite that criticsBourdieu opened up his concept of habitus to subjective reflexivity by introducing what he calls "hysteresis effect" and "socio-analysis". Nedelcu states that "Bourdieu [...] has pointed out, however, that habitus 'is not destiny', but rather the product of socialisation; thus, it tends to reproduce past behaviour within a familiar context but gives way to innovation when faced with novel situations." (Nedelcu 2012: 1345). Once internalised, the individual actually uses repertoire of rules most of the time unconsciously to act and react in common situations and is at the same time able to creatively, i.e. consciously adapt it to new situations (Krais/ Gebauer 2010; e.g. also Noble/ Watkins 2003). In this context, Sweetman hints to the "generative capacities of dispositions" not only in times of crisis as suggested by Bourdieu, but as the post-modern result of a demand for reflexivity in various spaces of everyday life, such as the workplace, the community, or consumer culture, in order to understand the "habitus as a continuum of actions", ranging from rational or strategic choices through routinised to unconscious forms of action (Sweetman 2003: 538). In other words, dispositions are either being reinforced through encountering similar situations, or they are being transformed, adapted, if necessary. Several authors stress in this context the "negotiated [or discursive character of a] situation at the ground [i.e. interpersonal] level [of communication or interaction]" (Crossley 2001: 82; see also Bourdieu 1985). In the same token, Nash's empirical description of an "educated habitus" (2002a), which he defines as a "set of mental dispositions to process symbolic information" (Nash 2002a: 45) must be understood as a reflective aspect of the habitus. However, it would definitely help the concept to stress more the "generative role of agency" (Crossley 2001: 96), i.e. to introduce the whole continuum of actions, ranging from rational making of plans and strategies through routines to completely autonomous because embodied forms of action, which would meet the need to take into account the "new demand for reflexivity" (Sweetman 2003; Atkinson 2010; Crossley 2001) in changing and interwoven societies. 
individuals unconsciously adapt and internalise the culturally accepted ways to act (in terms of structural categories of class, gender or the various social fields). In Noble and Watkins's critique, this internalisation remains a "passive process" through "transmission, internalisation, inculcation and conditioning" (Noble/ Watkins 2003: 525; e.g. also Lahire 2003). A third criticism - related to the question of whether a change in the individual habitus is possible - concerns the possibility of social change. Most authors accept that "socio-analysis" implies a possibility to make actions conscious to the habitus, namely in situations where it is necessary to develop new facets (Crossley 2001; Bourdieu 1985). Thus - the argument goes - on the biographical level it might be correct that objective structures are reproduced, but on the ontological level this circular process can lead to social change: Crossley argues here that the current status quo in a given society is the "outcome of a historical process" (Crossley 2001: 92). This implies that Bourdieu's ideas on the reproduction rather than the innovation of objective structures, or social change, are, again, a "matter of emphasis" (ibid.) rather than ignorance of determinism.

\subsubsection{Social Field and Practice}

A social field is the concrete social sphere where action takes place; it is governed by objects of particular value or "power resources", particular "formal and informal norms" (Edgerton/ Roberts 2014: 3), whose entity forms a given social space. However, what is valuable, however, in a particular field is negotiated through power relations. But these power relations are naturalised, and thus accepted as pre-existing and taken for granted by the individual (Bourdieu 1986; e.g. also Savage/ Silva 2013; Crossley 2001). Thus, a social field can be defined as a "set of objective historical relations between positions anchored in certain forms of power (or capital)" (Bourdieu/ Wacquant 1996 [1992]: 16). According to Bourdieu, fields are semi-autonomous, but there are homologies between them: in order to pursue their goals or strategies within a certain field, agents have to be capable of mobilising the forms of capital valuable in that specific context (Bourdieu/ Wacquant 1996 [1992]: 127). At the same time, all fields are subordinate to the field of power, or the "field of symbolic or ideological production" (Bourdieu 1985: 731). In this particular field, social actors fight over the hierarchical order of subordinate fields as well as the resources 
needed there (Softic 2016: 136). Bourdieu introduces the term in order to empirically grasp his observation that some social actors are able to apply their power resources; in particular symbolic capital not only in a particular social field but across all social fields and thus occupy particular powerful objective positions at a given time (Barlösius 2011: 112).

In line with one of his central issues, the distribution of power, Bourdieu denies altruistic behaviour: social actors pursue these strategies to maximise their possession and composition of capital in order to increase their chances to define what is valuable or legitimate in a particular field or the given social space as such. The interviewees' civic engagement takes place in the political field. Softic defines the political field as the ,arena, in which the intrinsic value of resources, but also their distribution is at least negotiated" (Softic 2016: 139). In this context, Bourdieu states that - as in any other social field - in the political field, borders between established and lay social actors preventing the latter from reaching dominant positions in the respective field (Bourdieu 2013: 42). With regard to immigrants entering the political scene, it can be assumed that they face obstacles with regard to the forms of capital, the required experience and the knowledge they own, i.e. their particular habitus. As outlined above, social fields provide the arena for struggles over the legitimacy of these distinctions (Bourdieu 1985). The social order can be challenged within the schemes and expectations available to a particular individual or practical social group (Bourdieu 1985: 734; cf. also Dumais 2002) by applying subversive strategies in order to call the existing social order into question.

A main point of criticism regarding the concept of field is, again, its vagueness and, at times, its interchangeable use as both structure and mechanism (cf. Savage/ Silva 2013: 115), depending on the purpose it serves in the specific context. In the present study, I conceptualise the field as a structure and mainly concentrate on the social field as the actual arena where social struggles - i.e. struggles over an individual's or social group's objective position - are fought.

The habitus realises itself in a particular field, and in relation to that particular field by drawing on embodied dispositions as the basis for agency or social practice. Dispositions are understood as a general repertoire of options to act which the individual adapts to the concrete situation by filling them with content in every particular situational context (cf. Haste 1992: 30). By means of their power resources, social actors are provided with a "feel 
for the game" (Bourdieu 1985: 727), because they accept the basic cultural principles or "objective structures" as given (ibid.). This practical sense comes with a "sense of place" (ibid.) or a "sense of limits" (Savage/ Silva 2013): learned dispositions function according to a practical logic, preconsciously excluding unfamiliar or "unthinkable" practices from the repertoire of possible actions and reactions (Reay 2004). Because social actors "play" according to the "rules of the game", they become accepted members of a social group; or, as Savage and Silva (cf. 2013: 113) put it, the realisation of an individual's habitual dispositions is thus central to the maintenance of social space-_the game itself". As a result, a qualitative distinction, a social hierarchy, between the different positions in a particular field can be established in social interaction because individuals "recognise [...] [them] as significant" (Bourdieu 1985: 730): social actors "make [emphasis added] the distinctions" (ibid.) through their actions.

\subsection{THE INTEGRATED FRAMEWORK}

According to Bourdieu, a social actor occupies an objective position in relation to other social actors in a given society, the social space, depending on the different forms of capital they have at disposal. These resources are acquired in various contexts or fields in the life course and to a large extent their composition is determined by the individual's objective position. However, an individual's subjective positioning, again in relation to others, is not necessarily identical with their objective position in social space. However, the individual may present their position differently in the various contexts. Against this background, Bourdieu states that social actors aim at improving their objective position, and the field is the social arena to do so. In order to illustrate this, Bourdieu applies the metaphor of social actors playing a game, and their resources are their stakes. The social actors reproduce or modify their resources while playing that game, the social practice.

The analysis of habitual dispositions aims at understanding which power resources the interviewees - being immigrants or children of immigrants have and perceive themselves to have at their disposal for taking part in everyday social interaction. The field analysis aims at understanding which of these power resources they regard as valuable, i.e. which resources they 
mobilise in a particular (thematic) field. The analysis of social practice, finally, aims at revealing the interviewees' strategic use of their power resources in claiming a subjective position within a given field, and consecutively, a given social space, here: Israeli society. In the concrete social practice of the interview, the interviewees reproduce, yet, also modify their power resources.

In the present study, I assume that the interviewees, against the migration background of their families, refer to more than one cultural system when adapting to the objective structures of Israeli society referring to the cultural system they have been socialised in in their families. Their resources can be analysed along different dimensions: as it is the case with objective structures, there are also subjective structures, or power resources-habitus and forms of capital - that the interviewees have embodied prior to migration or in their immigrant families and in the Israeli context. These resources may be experienced as contradictory and mismatching or compatible. I assume that the interviewees bring the issue of resources up in their narratives as they reach the level of consciousness. In this context, I further assume that contradictions between the two cultural systems will at times rise to consciousness in the narratives. How the interviewees handle those contradictions and present them in their narratives is the content of analysis of social practice.

Bourdieu's concepts form the theoretical-methodological frame of the present study; they are not being applied separately but as an integrated framework. This integration aims at applying a holistic approach to the position of talking, as taken by the participants in the study. A framework of Bourdieu's concepts shall help to show that the interviewees do not act independently but in the context of their existence within a particular social space, Israeli society. Apart from Bourdieu and Wacquant (1996 [1992]), ${ }^{5}$ Nash (2002b) applies a "realist" framework examining habitual dispositions against their realisation in particular fields of practice. His framework aims at looking at the individuals, and their habitual dispositions in a given social

5 In this context, I am aware of the ambiguities and disruptions in Bourdieu's overall work. However, as Wacquant (1996 [1992]) argues, the development of the overall conception covers a period from the 1960s onwards and is dynamic in integrating new empirical insights as well as critique from colleagues (see Wacquant 1996 [1992]: 22-3). 
space and from a holistic perspective. In a critique of education research, which in their eyes concentrates solely on Bourdieu's notion of cultural capital in order to better understand socio-economic inequality through the education system, Edgerton and Roberts refer to Nash's "structuredisposition-practice explanatory framework" (Edgerton/ Roberts 2014: 2) as an alternative approach.

In the present study, I have also decided to take a holistic approach. I will provide an analysis of the cultural context (objective structures) and of the individual dispositions (subjective structures) of the participants. Yet I will pay particular attention to how the two levels become linked in the particular situative context (social practice), i.e. which resources and strategies the interviewees apply and which goals they aim to achieve. The interviewees' subjective positioning can be contrasted with the analysis of their objective position in Israeli society. As a final step of the analysis, I aim at making statements about how they discursively construct their "sense of belonging" against their objective position as well subjective positioning. In other words, I will take the perspective of the interviewees and provide an analysis of how they actively position themselves in order to make sense of their position in Israeli society.

\subsubsection{Analysis of Cultural Codes}

A central issue in Bourdieu's concept of social space are cultural codes. As I have stated before, I claim that the analysis of (public) discourse in this context is of growing importance, or, as Adele Clarke and Keller put it, to look "beyond the knowing subject" (Clarke/ Keller 2014: para. 57). To determine the cultural codes in the form of public discourse the interviewees have embodied analytically in the interview material, I suggest here to apply a sociology of knowledge approach. Recent developments in the tradition of a sociology of knowledge have shifted the construction of knowledge from social to communicative (Keller 2011b). The approach provided by a sociology of knowledge allows to make statements about social processes of the (re-)production and institutionalisation of knowledge on the societal level and also about power relations in these processes. Gavriely-Nuri (2012) makes a similar suggestion with what she terms "discursive capital". 
The Sociology of Knowledge Approach to Discourse (SKAD) is based, among other things, on Foucault's theory of discourse, ${ }^{6}$ aiming at the analysis of the "discursive constitution of knowledge or [...] [analysing] regimes of power and knowledge" (Keller 2007: 1). Keller points here to the "emphasis on the active and interpretative efforts of social actors in the (re-) production and transformation of symbolic orders in discourses" (Keller 2011a: 36). Discourse is defined here as "statements and respective practices of statements [...] following the same principle of formation" (Keller 2007: 1); it is a "strategic game [...] [or] a battle] about the interpretative power" (ibid.) - a definition very similar to Bourdieu's definition of social space. In this regard, the approach also adapts Bourdieu's idea of symbolic battles over "the legitimacy of symbolic order" (Keller 2011a: 35). SKAD aims at capturing "contested social reservoirs of knowledge", in contrast to subjective sense-making; and it aims at capturing the "inter-discursive context", in contrast to looking at closed [...] semantic structures of textbased approaches (cf. Keller 2011a: 78). In detail, SKAD aims at making statements about social actors and their "subjective positions" (Keller 2011a: 73), their "power resources" (Keller 2011a: 74), their "ways of incorporation [of discourses]" (Keller 2011a: 73), "social contexts" (ibid.), "power effects in their everyday representation" (ibid.) as well as "[their] updating" (Keller 2011a: 74) through "processes of collective knowledge production" (ibid.).

In the present study, I will focus on the cultural codes the interviewees use as references to what they present as being common sense in Israeli society as well as the cultural codes they refer to as an alternative cultural system of reference against the migration background of their families - the reasons to do so will be analysed as suggested below. This includes an analysis of the interviewees' objective position, i.e. the position they talk from about the symbolic order of Israeli society. I will analyse the interviewees' subjective embodiment of objective structure along categories in order to "reconstruct[...] typical or typecasting elements of structure" (Keller 2011a: 79):

- the public discourse(s) the interviewees engage in,

- "patterns of interpretation" and

- "topoi" (ibid.), as well as

6 For an introduction into SKAD see e.g. Keller 2007. 
- individual interpretation of these patterns.

- In a second step, I will analyse whether, and if so, how the interviewees reproduce these patterns of interpretation in practice, i.e. the interview situation, and for what purpose.

\subsubsection{Analysis of Power Resources}

Referring to the points mentioned above, I operationalise habitual dispositions as power resources. Those resources may then be applied by the interviewees in a particular field to claim a certain social position for themselves and to distinguish themselves from other individuals or social groups.

Previous empirical studies are generally rather vague in their operationalisation or practical application of Bourdieu's concepts. This is particularly true with regard to the exploration of habitual dispositions. However, there are a number of reasons for this vagueness. On the one hand, Bourdieu himself made very few comments on how to actually apply the concept in empirical research. To overcome this conceptual vagueness, some authors argue in favour of employing his concepts as a method rather than a theory (Reay 2004; 1995; Nash 1999; Bourdieu/ Wacquant 1996 [1992]). ${ }^{7}$ Reay, for example, sees the potential to "reveal the taken-for-granted inequalities embedded in everyday practices" in the concept of habitus (Reay 1995: 353). Accordingly, she defines it as a "method for analysing the dominance of dominant groups in society and the domination of subordinate groups" (Reay 2004: 436). Nash suggested applying the concept in order to "name [...] forms of classification, perception and discrimination", and thus try to explain social practice (Nash 1999: 177) to show the "ways in which the social world is in the body" (Reay 2004: 432). In a similar vein, Barlösius emphasises that Bourdieu's habitus functions as a system of classification in order to establish social distance or "distinction" (Barlösius 2011: 67; see also Bourdieu 1987 and Bourdieu 1985). Bourdieu's very conception of the habitus suggests that it is not derived from direct observation but rather indirectly: e.g. from the observation of practice and thus the realisation of habitual dispositions in a particular situation (Reay 1995; Nash 2002b; Rapoport/ Lomsky-Feder 2002). In doing so, the concept of habitus is being

7 This solution would erase at least some of the critique on the concept (see above). 
made applicable through the analytical distinction between an individual's habitus and his or her lifeworld as the "stream of incoming experience" (Atkinson 2010: 8) which can be observed.

With regard to capital, Bourdieu suggested analysing the forms an individual owns in three dimensions: the individual's overall amount of capital, the composition of the various forms of capital and the time needed to accumulate this specific composition (Bourdieu 1987: 195-6).

Social capital is operationalised as more or less durable personal relations the interviewees are able to rely upon or hope to rely upon in the future. For the present study it is interesting to determine who the people behind these relations are, in particular what their objective position in Israeli society and relative position to the interviewees is, and what exactly the interviewees expect from being acquainted with these people, i.e. how the interviewees present their relationship with these individuals.

Cultural capital is operationalized as its three sub-forms: inherited or embodied (e.g. particular cultural skills and knowledge), objectified (e.g. school certificates) and institutionalised (e.g. titles) cultural capital (Bourdieu 1986; Bennett/Silva 2011). Because of the migration background of the participants' families, I will place particular emphasis on embodied cultural capital. ${ }^{8}$ With regard to Bourdieu's remark about this being "Informationskapital" (see above), I will look at adaptive strategies (cf. Erel 2010) the interviewees may apply in order to make value of their families' cultural capital. I will also look at processes of incorporation of Israeli cultural codes made visible in the interviews. Guiding categories for the analysis of the interviewees' power resources are:

8 An alternative concept to cultural capital in the respective literature is literacy. Literacy is either conceptualised as "cultural literacy" (Schirato/ Yell 2000) or "political literacy" (Cassel/ Lo 1997), in the context of civic engagement understood in terms of particular "civic skills" (Verba et al. 1995). However, I prefer Bourdieu's concept of cultural capital to that of skills, mainly because this way I can show that and how this particular resource can be and is used by the interviewees in a strategic way. 
- narratives about relevant past and present experiences,

- forms of capital,

- reflections about their objective position,

- future expectations,

- moments including socio-analysis: reflexivity, talking about unknown situations, qualifications etc.

In a second step, I will focus particularly on the analysis of how the participants in the study use these resources in the discursive practice of the interview situation. In this context, I will also look at how the participants position themselves in Israeli society as the social space under observation.

\subsubsection{Analysis of the Field and Discursive Practice}

As outlined above, habitual dispositions are realised in a particular field. Field analysis according to Bourdieu should be performed in three steps (Bourdieu/ Wacquant 1996 [1992]: 136):

- relation of the field at hand to the field of power,

- objective position of actors and institutions in the field at hand,

- analysis of the social actors' dispositions.

I am particularly interested in how the interviewees apply their power resources against the background of their objective position in Israeli society and also in the strategies they pursue with the application of these resources in a particular context. I will analyse the use of resources with the help of Haste's considerations on lay theory (Haste 1992). The methodological strength of Haste's concept is linking a motivational approach with the discursive nature of arguments while speaking about this motivation. She argues for an approach which takes into account that and how meaning is negotiated in dialogue and discourse and against the background of a concrete social situation (Haste/ Torney-Purta 1992; see also Billig 1997; 1989). In this context, Haste criticises a concept which understands a person's belief — e.g. as suggested by approaches of authoritarianism — as a pattern that, once formed, is constant and more or less unchangeable and informed by an underlying principle (Haste 2004). Haste adapts Bourdieu's thinking as well as ideas from discursive psychology and suggests 
understanding belief — similar to Bourdieu's habitual dispositions - as providing a "set of schemata and scenarios of how the world works and how the individual is located in that world" (Haste 1992: 28), which is actively developed and modified through social practice. She states that belief is not fixed, but relates to a) the situational context, and b) the public discourse in which the speaking individual is situated (Haste/ Torney-Purta 1992). A person's belief is, thus, seen as dialogue and discourse: people hold contradictory views and act within a social and cultural context that is negotiat(ed)(able) (ibid.; see also Billig 1989; Potter/ Wetherell 1987). Haste and Torney-Purta argue that those usually unquestioned or, as Bourdieu would say, "doxic" dispositions are brought into the sphere of discourse in the context of an interview situation. The particular situational context more or less forces the interviewees to justify their arguments. ${ }^{9}$

Social practice is operationalised as discursive practice in the context of the study. Haste (1992) argues on the basis of Bourdieu's thinking that the individuals can fill their dispositions with varying and even contradictory content - depending on their current goal in a given social interaction. The social actor's representation or line of argumentation thus has to be viewed against the background of the development of this repertoire of dispositions in the process of the development of the habitus (early and recent personal experiences and their individual processing) as well as the situational context (current events, the actual situation of realisation, argumentative goals or, to speak with Bourdieu, strategies, etc.).

In agreement with Bourdieu, I assume that by way of argumentation and justification the interviewees are more or less forced to consciously reflect upon those resources taken for granted in everyday life. I further assume that the interviewees strategically use these resources discursively as different communicative strategies-e.g. making a statement, justifying a past action, post-rationalising a past decision-in order to position themselves. I operationalise discursive practice as the line of argumentation presented in the interview narratives, including the analysis of justifications and possible contradictions between different sequences about the same issues or when speaking about different issues in the course of the interview. Guiding categories of analysis are:

9 As Haste (1992) shows with her study on lay theory, this must not necessarily be a discursive interview (Ulrich 1999). 
- issues relevant to the interviewees when talking about their civic engagement, issues linked or rejected,

- argumentative strategies, justification, contradictions, the purpose these strategies are applied for,

- the situational context of the argument,

- references made to cultural codes,

- power resources the interviewees claim to have or not to have at their disposal,

- subjective positioning within a particular field.

Figure 4: A Suggested „Structure-Disposition-Practice” Explanatory Framework

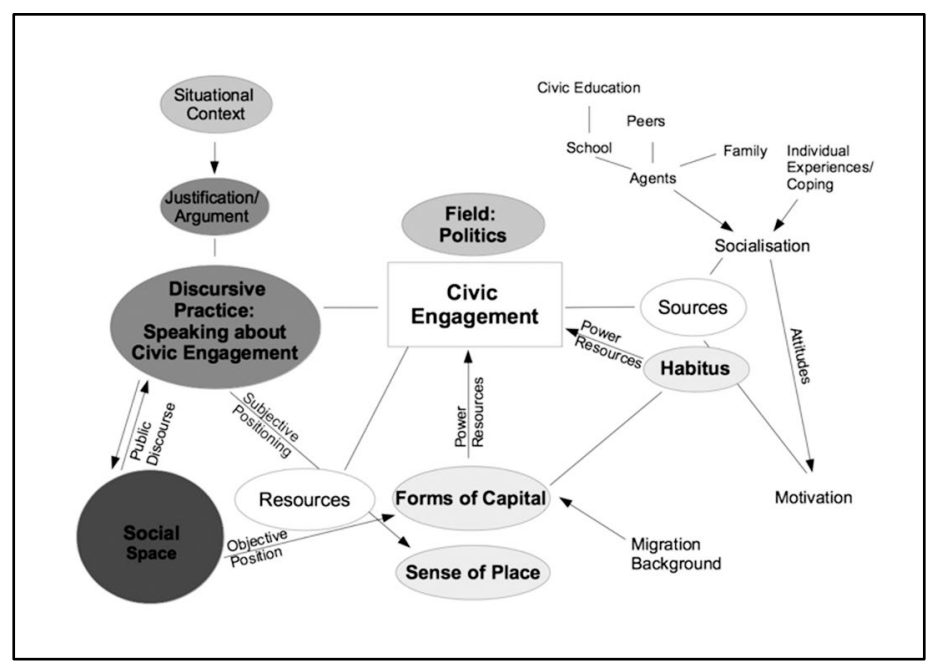

Source: Author's Own Presentation

In a final analytical step, based on the empirical findings, I will explore the interviewees' construction of a sense of place. Here the guiding categories are:

- power relations resulting from the interviewees' positions,

- "ideologies of superiority" (Reay 2004; 1995), i.e. distinctions made.

Figure 4 shows the suggested explanatory framework. 
In the present study, I aim at developing a material theory of how Israelis with an FSU family background who engage with an extreme right political party lingering between the discursive images of being a mainstream or a sectoral party, construct a sense of belonging to Israeli society. 


\section{Theoretical Sensitivity II: Framing the Study}

As a relevant frame of the present study, I have considered literature on Israeli society and the Yisra'el Beitenu party. Thus, in the following sections, I will review previous research in these areas.

\subsection{FEATURES OF ISRAELI SOCIETY}

Everyday life in Israel takes place against the background of growing social tensions and cleavages. Fishman states that Israeli society has transformed from a "consensual society with common values" in the 1950 s and 1960 s to a "tribal society with very few if any common values". The only commonality is seemingly the relationship with Palestinians inside and outside Israeli borders in recent years (Fishman 2004: 54). Ben-Porat and Turner define Israel as "a developmental state with problematic borders, a [divided] civil society [...], and a dominant military stratum" (Ben-Porat/ Turner 2011: 5).

The present section looks at the key features necessary to understand present-say Israeli society and the transformation Fishman (2004) describes.

\subsubsection{The Political Culture}

Bagno identifies two main approaches to the definition of a society's political culture: an attitudinal approach emphasising the evaluative aspect of external stimuli on the basis of individually incorporated shared values 
and an attitudinal-behavioural approach defining "attitude as an active response provoked by an external event-stimuli [sic!]" (Bagno 2009: 26). In the former case, the definition of a society's political culture as shared values is obviously linked to the society members' political socialisation. Here, political culture is historically formed - and thus possibly transformed — and transmitted through formal and informal institutions over generations. In their classical study on civic engagement or "civic culture", Almond and Verba define political culture as "the political system as internalised in the cognitions, feelings, and evaluations of its population. People are inducted into it just as they are socialised into nonpolitical roles and social systems" (Almond/ Verba 2016: 14). In the attitudinal-behavioural approach, political culture carries an individual aspect since it integrates individual experiences and perceptions of public events and, thus, accounts for "attitudinal differences" (Dowse/ Hughes 1986: 227). Dowse and Hughes refer to political culture as "specifically political orientations toward the political system and its various parts and attitudes toward the role of the self in the system" (ibid.).

These orientations have implications for individual political behaviour as well as the society striving for "coherence in the operation of its institutions" (ibid.). In this context, Dowse and Hughes also stress the ideological dimension of political culture, defined as a "set of ideas having special characteristics" in order to establish clarity, internal coherence and consistency over internal cleavages (Dowse/ Hughes 1986: 236). Concluding from her identification of the various approaches, Bagno identifies "political culture as a concept which mediates between the political system and its environment, providing a framework within which political beliefs, historically considered, can be located, and as a factor which will influence and constrain future patterns of development in a political system" (Bagno 2009: 26).

Back in the late 1980s, Kahane and Rapoport observed antidemocratic tendencies in Israeli society, as for instance a "withdrawal from democratic ideas" on the basis of the political system's perception as corrupt and inefficient, "partial rejection of democratic institutions", and a growing number of young Israelis supporting right-wing authoritarian values such as strong leadership over democratic elections (Kahane/ Rapoport 1990: 221). The authors argue that the political culture in Israel has to be considered against the background of socio-political conditions that include a constant 
security threat, a meta-narrative of the traumatic history of Diaspora Jewry, insecure economic development, or a large immigrant population "lacking a civic democratic tradition" (ibid.). However, Kahane and Rapoport consider these alone an "insufficient explanation" for "antidemocratic trends" in Israeli society, but rather to be their result (Kahane/ Rapoport 1990: 223).

Still for today, several authors have described an atmosphere filled with "individual and collective anxieties", as Kahane and Rapoport already put it in 1990 (p. 221). Against this backdrop, one can identify particular "political beliefs" in Israeli political culture.

Zionism From a historical perspective, the emergence of Zionism is closely linked to the development of modern nationalism and the foundation of nation states in Europe. Zionism can be read as the European Jewish version of nationalism and has been described as a "Jewish national liberation movement" or the "generator of Modern Jewish nationalism" (Ram 1999: 329). Of the various versions, Theodor Herzl's political vision of a Jewish State (1894), an Altneuland (1902) - a new Jewish national state in one of the oldest places of Jewish settlement (British Mandate) Palestine — laid the basis for the secular and national political Zionism that pulled European Jews to the Middle East.

In this context, secular political Zionism envisioned a particular notion of the "new Hebrew" who is young, male, healthy, white, i.e. of European origin (e.g. Roberman 2007; Almog 2000). Basically, this "new Hebrew" reflected the physical and mental condition of those who emigrated to Mandate Palestine - the contribution of women silenced in this maledominant notion - and was constructed as a counter-image of the weak and poor "Shtetl Jew", commonly described in Jewish diaspora and Israeli literature. Shohat "shows [...] [that] the Eurocentric [Zionist] concept of a single 'Jewish History' cut non-Ashkenazi Jews off from their origins" (Shohat 1999: 5).

After independence (in 1948), the premises of political Zionismsettlement in Israel or the return from the diaspora, the adoption of an Israeli

1 Carlo Strenger. Zionism? Post-Zionism? Just Give Arguments. Haaretz Online (English Edition), December 20 2007; Retrieved from http://www.haaretz.com /print-edition/opinion/zionism-post-zionism-just-give-arguments-1.235552. 
identity and an ideological commitment to the land and the collective, "expressed mainly through military service, or the decision to stay over leaving" (Lomsky-Feder/ Rapoport 2001) — served as one of the pillars of Israeli citizenship.

In the last decade or two, the dominant ideology of political Zionism has been challenged by several developments: among other things the "social upward mobility" (Fishman 2004: 58) of lower social classes, in particular that of Sephardim² (ibid.), a growing pluralism characterised by the growing demand of segments of Israeli society peripheral to power to gain recognition (Livio 2012) and tendencies to avoid military service (ibid.). Finally, the arrival of large numbers of immigrants - in particular from FSU countrieswho "lack the Zionist history of life" (Fishman 2004: 61) have additionally challenged the Zionist "national ethos of home-coming" (Golden 2002; e.g. also Lomsky-Feder/ Rapoport 2001; Golden 1996) by refusing to accept the previously dominant politics of immigrant absorption (Lomsky-Feder/ Rapoport 2002; 2001), i.e. assimilation to Israeli-Hebrew culture (Eisenstadt 2008). In this context, Strenger ${ }^{3}$ (2007) even calls the current reference to Zionism in public discourse "anachronistic", and Kaplan adds "Zionism fulfilled its historical mission" (Kaplan 2013: 149).

As a preliminary result of these developments, Ram observes that more recently "classical" Zionism has been accompanied by two new classspecific forms in the context of global and local or national processes: a "post-Zionism", promoted mainly by secular, political left, higher educated segments on the one hand, vs. a "neo-Zionism" of the lower social class, Jewish national, religious and political right segments of Israeli society on the other hand (Ram 1999: 329). However, this is not a fixed status quo. With regard to scientific work (in particular historical science), in Kaplan's view there had been a "post-Zionist" development as well, examining "other

2 From Hebrew "sephardi", "Spanish", referring to more recent immigrants from Muslim countries in North Africa and the Middle East after Israeli independence, whose ancestors had fled Spain after the expulsion of Jews in 1492 and found asylum in Muslim countries.

3 Carlo Strenger. Zionism? Post-Zionism? Just Give Arguments. Haaretz Online (English Edition), December 20 2007; Retrieved from: http://www.haaretz.com /print-edition/opinion/zionism-post-zionism-just-give-arguments-1.235552. 
aspects of Israeli society" and in particular applying a "de-mythologizing attitude" (Kaplan 2013: 149). At the same time, he already observed the emergence of a "post-post-Zionism" which, instead of critically reviewing societal developments that were justified with Zionist ideology, is driven by a "desire to rediscover" (and recreate) a Zionist society (Kaplan 2013: 1501).

As a result, support for Zionism as the dominant, uniting idea of Israeli society has been in decline; one sign of this is a growing willingness to leave the country (Dowty 2004). However, in this context Ichilov stresses the "absence of a more general [...] Israeli identity" (Ichilov 2004: 101) which would leave room for non-Jewish citizens to identify with Israel not just as a Jewish state, instead creating an "atmosphere of alienation and distrust" (ibid.). On the contrary, right-wing political circles, including the government of Prime Minister Netanyahu, aim at strengthening Jewish dominance by demands to introduce a loyalty oath to the Jewish character of the state and its symbols with regard to internal affairs - clearly aimed at Israel's non-Jewish, in particular Palestinian citizens - and the demand to recognise Israel as a Jewish state as a precondition for peace talks with regard to foreign affairs.

Israeli citizenship Ben-Porat and Turner describe Israeli citizenship as "a peculiar combination of late nineteenth-century developments in nationalism and Zionism and twentieth-century wars and settlement" (Ben-Porat/ Turner 2011: 2), displaying "political struggles [...] defined fundamentally by an attempt to reconcile the two conflicting principles of a 'Jewish and democratic state"" (Ben-Porat/ Turner 2011: 1). Israeli citizenship implies two aspects with the Law of Return (1952) as the legal basis for the attribution of social, civil, and political rights at its centre: inclusionary for people of Jewish descent and exclusionary for various "others", e.g. Palestinians outside pre-1967 borders, foreign workers or asylum seekers (cf. Ben-Porat/ Turner 2011; e.g. also Peled 2007). Smooha coined this political order an "ethnic democracy" and defined it as a "political system that is democratic for the dominant group but excludes, on the basis of ethnicity, other groups from the democratic process" (Smooha 2001: 24; see also Smooha 1989). Accordingly, Peled identifies three dimensions of Israeli citizenship: a liberal dimension with regard to the distribution of rights in order to "distinguish" between Israeli citizens and non-citizens, a Republican 
one with regard to the citizens' contribution to the community in order to "legitimise" the existing social hierarchy and an ethno-nationalist dimension in order to "discriminate" against the non-Jewish, in particular Palestinian citizens (Peled 2011: 278; see also Shafir/ Peled, 2011; 2002).

However, the legitimisation of the status quo has entered a crisis (Levy 2011; Peled 2011; Lerer/ Amram-Katz 2011; Lebel 2007; Ben-Porat/ Mizrahi 2005) as Israeli society has become more pluralistic on the one hand, and various societal cleavages have become more blatant on the other hand: ethnic (Ashkenazim vs. Sephardim), religious (religious vs. secular), national (Jewish vs. Palestinian), political (left-wing vs. right-wing) and social (established vs. newcomers) (Fishman 2004: 54; see also Ben-Porat/ Turner 2011; Kimmerling 2005; Ichilov 2004), or have just emerged like racial ("white" vs. "non-white" Jews) (Elias/ Kemp 2010; Ben-Eliezer 2008). The introduction of a loyalty oath for non-Jewish Israelis, in particular Palestinian Israelis, as a prerequisite for basic civil, social, and political rights, as suggested by the Yisra'el Beitenu party, may be interpreted as an attempt to win back this legitimisation. While back in the 1980s right-wing extremist parties were banned when they publicly demanded such an oath, it has recently become more publicly acceptable, for instance in the form of the so-called "Lieberman Plan" (Waxman 2012: 22). In this context, in particular the status of Palestinian citizens has increasingly been eroded. The massive, partly violent protests of Palestinian citizens that took place in October 2000 in Upper Galilee play a central role in both the perception of these citizens by the Jewish majority as well as concrete legislative acts concerning them (Waxman 2012; Peled 2007). Resulting from those developments, there is an ongoing debate whether to speak of Israel as an "ethnocracy", with a Jewish majority ignoring the rights of their national minorities, rather than of an "ethnic democracy" (Ghanem 2011; Peled/ Navot 2005; Yiftachel 1999; Dowty 1999).

Cultural codes Undoubtedly, the collective memory of the Shoah and the "shared belief" of Israel being under siege (Bar-Tal 2000) are two of the major "cultural codes" (Gavriely-Nuri 2012) in Israeli society. GavrielyNuri defines "cultural codes" as a "compact package of shared values, norms, ethos and social beliefs" (Gavriely-Nuri 2012: 80). Cultural codes are inherited directly (through social interaction and personal experience) and through indirect exposure (e.g. the media) (ibid.). Familiarity with those 
codes, i.e. the ability to decode them, provides a symbolic resource to exercise symbolic - i.e. interpretative - power (Gavriely-Nuri 2012: 82; see also Bourdieu 1985).

Psychological analyses of Israeli society quite regularly point out the impact the perception of being threatened has on how Israelis perceive the world. Bar-Tal and Antebi coined the term "siege mentality" 4 for the phenomenon they observed: "a mental state in which members of a group hold a central belief that the rest of the world has highly negative behavioural intentions toward them" (Bar-Tal/ Antebi 1992a: 634). "Siege mentality", like other central collective beliefs, is rooted in a long-term (emotional) collective memory of contact with one or many out-groups perceived as negative or hostile. Connected to this are beliefs of an existential collective threat, of facing this threat alone, and "that all means are justified for group defence" (ibid.). In concrete terms, the Israeli "siege mentality" currently consists of the belief that Israel as a state and the people inhabiting it are threatened in their very existence by the Arab states in the region. This perception is furthered, for instance through political socialisation, or mass media and public discourse in general (e.g. Bar-Tal 2001). ${ }^{5}$

This belief has implications for the political culture: Mustafa and Ghanem (2010) explain the rise of a "new extreme right in Israel"including the Yisra'el Beitenu party — at least partly with the collective belief of being under siege. Zertal links the collective perception of "the whole world [being] against us" among (Jewish) Israelis directly to another major cultural code of today's Israeli society: the practices of commemoration of the Jewish victims of the Shoah. She states:

"[i]n organizing the trial [of Adolf Eichmann in Jerusalem, 1961] as a historic, continuous morality play, [...] [Ben Gurion] created the teleological, indispensable link between the agony and death of the Jewish Diaspora and the establishment and the right to exist of the State of Israel, including its daily practices, especially the

4 The authors explicitly distinguish a "siege mentality" from other psychological constructs like paranoia or ethnocentrism on the basis of an "emphasis [...] on the rest of the world" (Bar-Tal/ Antebi 1992a: 634).

5 However, not all individuals show the same strength in their beliefs; Bar-Tal and Antebi (1992a) found the highest correlations with religiosity, hawkish political orientation and nationality, i.e. being Jewish. 
militaristic ones. [...] Defence of one's country became a sacred mission endowed with the weight of the ultimate catastrophe" (Zertal 2000: 112).

By a similar token, Zuckermann identifies several "central axes of fear"historical persecution of Diaspora Jews, the Shoah, and the constant security threat against the background of ongoing military conflicts with Israel's neighbours-(Zuckermann 1999: 63) and emphasises in this context "the dialectical relationship between psychologcial needs, functioning as the „glue“ of the socio-political system, and that very same system, which ideologically ,arouses“, reproduces and affirmatively reinforces those needs“ (Zuckermann 1999: 61-2).

Commemoration practices have, above all, served the political goal of enhancing patriotism and loyalty through the potential sacrifice of the citizens' lives to defending their country (e.g. Rapoport/ Lomsky-Feder 2007; Zertal 2000) - it is no coincidence that the national commemoration day (Yom haShoah) is the day before Independence Day. Those practices had not been installed at the end of World War II and after the rescue of the survivors from Nazi concentration camps, though, because Jewish victims clearly contradicted the image of the "new Hebrew" (see above) installed by political Zionism (Zuckermann 1999: 69). Zertal adds: "collective mourning and grief for the murder of a third of the Jewish people [...] literally could have shattered the realisation of the vision of a new state and its struggle for existence. [...] Thus, there was an almost concerted effort to "disremember" the recent, unbearable past." (Zertal 2000: 100).

Accordingly, public remembrance of the Shoah was mainly supposed to serve two political purposes: in order to argue that living in Israel, returning from the Diaspora, was the only safe option for Jews, on the one hand, yet, on the other hand, in order to rhetorically draw parallels between the recent past, the existential threat of annihilation of European Jewry by the Nazi regime, and the present, the acclaimed existential threat to Israel's existence by its Arab neighbours (Zertal 2000: 106-7). Correspondingly, after the capture of Eichmann and his trial in Israel and in the aftermath of the SixDay War (1967), "Israeli militarism and security consciousness were 
boosted" (Zertal 2000: 111); ${ }^{6}$ and the new narrative of Israel's "fight against the Arab "enemy" (Zertal 2000: 112), based on the commemoration of the murdered victims of the Shoah as a warning, was "embraced as the cornerstone of Israel's collective identity” (Gulie Ne'eman Arad 2003: 5).

However, these practices of commemoration have also been contested. In addition to the processes of social change in Israeli society described above, a further factor contributing to "growing reservations about the centrality of the Shoah in Israel's national life and political culture" (Gulie Ne'eman Arad 2003: 6) has again been the mass immigration from FSU countries. Rapoport and Lomsky-Feder (2007) found that the interview participants in their case study adapted the Shoah narrative dominant in Israel and the connected Israeli-Jewish identity in the process of their absorption. At the same time, though, as a social group, they maintained an alternative narrative about Jewish life in the Diaspora. Hereby, the interviewees challenge the dominant Israeli view of the weak Jew living in exile and replace it with their notion of the heroic and victorious (Jewish) Soviet soldiers fighting in WWII, which was an integral part of Soviet practices of commemoration and which the immigrants had experienced themselves (cf. Rapoport/ Lomsky-Feder 2007; see also Roberman 2007). In this context, the interviewees also tended to "normalise" personal antiSemitic experiences (Rapoport/ Lomsky-Feder 2007).

Against this background, military service has played a crucial role in the lives of Israeli citizens, and it has implications not only in the military but also the civil sphere. Livio shows how the "mishtamtim (literally, 'shirkers')" (Livio 2012: 78) - those (Jewish) individuals who dodge mandatory military service for various reasons - damage the still highlyvalued contribution to the symbolic collective in the eyes of the (Jewish) majority (Livio 2012: 80). Service in the Israeli Defence Forces (IDF) is an important context for the citizens' political socialisation. One of the claimed goals of mandatory military service has been, as the $1^{\text {st }}$ Israeli chief of staff, Yadin, put it, to "raise conscientious Zionist soldiers" (cited after Ichilov 2004: 123).

6 In this context emerged also what Kimmerling (1993) described as "civil militarism" for the Israeli context, the interwovenness of the civil and military spheres. 


\subsubsection{Disintegration of Israeli Society}

As described above, cleavages within Israeli society can be directly linked to the (growing challenge of the) legitimisation of the current social order, and they often overlap with economic gaps between the segments in question. Those cleavages are not abstract but have direct effects on daily interactions. Usually they find expression in negative stereotypes used in social interactions to humiliate those still engaged, but at times they can also be channelled into concrete exclusionary acts against people perceived as "the others". In the early days of modern Jewish settlement in Palestine and of the newly-founded State of Israel, the political, social and economic dominance of the "Zionist bourgeoisie" (Fishman 2004: 58), i.e. Jewish pioneer settlers of European origin and their descendants (Ashkenazim), over Sephardim was questioned as little as the dominance of a particular form of nationalism in the form of secular political Zionism. This social hierarchy was legitimised by the distinctly greater contribution and risk-taking of the dominant group, in particular with regard to military sacrifices and political responsibilities (Levy 2011: 40). However, in accordance with the decline of Zionism as the unifying idea as well as additional developments like the decline of trust in Israel's military power and years of economic crisis (ibid.), various rifts and cleavages have surfaced: on the one hand among Jewish Israelis (e.g. Shetrit 2010), and on the other hand between Jewish and nonJewish, in particular Palestinian, Israelis.

national/ Palestinian citizens The fact that British-Mandate Palestine was not waste land but largely inhabited had been largely ignored by the Zionist settlers who came to establish their Jewish state. Accordingly, those non-Jewish natives were not foreseen to have a place in the "ethno-territorial Jewish project" (Rabinowitz 2001: 305) before and after Israel's independence. Instead, there has been (growing) emphasis on the character of the state as Jewish over democratic (i.e. the granting of equal rights to all its citizens), while the collective identities of national minorities have been all but ignored (e.g. Ichilov 2004; Rouhana 1997). ${ }^{7}$ Rabinowitz shows that

7 A particular case of national minorities in Israel are Druze and Bedouin citizens. Druze often become mixed up with the "Arabs", though they are a non-Arab community with their own religion. There exist special Druze departments and 
in particular Palestinians Israelis have actively been othered in terms of culture: they have been referred to as rural (vs. urban Jewish Israelis), uneducated/ uncivilised (vs. Jewish millennia-old high culture), or shorttempered (vs. Jewish deliberateness) for the purpose of constructing a(n) (Jewish) Israeli identity against them (Rabinowitz 2001: 317-9). While selfperceptions of the group have been largely ignored by the Jewish majority who have referred to them simply as "Arabs", in particular after the events of October 2000 (see above), the self-definition of Palestinian Israelis has changed and they have demanded the recognition as a national minority to guarantee particular rights, (e.g. Waxman 2012; Peled 2007). In combination with Israeli Jewish perceptions of Palestinian Israelis being a constant security threat, Waxman points to the shock that Jewish Israelis have experienced in the course of such public demands (Waxman 2012: 17).

ethnic/ "Mizrahim"8 Ben Meir and Bagno-Moldavsky find that the perception of an Ashkenazi-Sephardi divide has weakened, yet not vanished (Ben Meir/ Bagno-Moldavsky 2010: 52). However, until recently, the ethnic divide had been the most visible conflict line in Israeli (Jewish) society. Arriving in Israel after independence, Jews from Arab countries were supposed to assimilate to the hegemonic Jewish culture of European settlers, ${ }^{9}$ i.e. "to be "cleansed" from their "Arabness" (Shohat 1999: 6).

Moreover, against the background of Rabinowitz's work about the othering of Palestinians (2001), the very terms Oriental/ Mizrahi, or Arab, which are used to refer to those Jewish segments of Israeli society, already assume a low social and cultural status for this group. Shohat finds evidence in Zionist texts "rejecting the non-Ashkenazis as 'savage' and 'primitive", (Shohat 1999: 6). In this regard, Sephardic Israelis were expected to occupy the lower stages of the social hierarchy, with the highest stages occupied by Ashkenazim. Again, linked to their social position is their economic lower social position of this societal segment: in the context of the realisation of

they enjoy cultural and religious autonomy as well as particular social and economic benefits (Ichilov 2004: 103). With regard to their citizenship status, it is noteworthy that Druze in Israel are allowed to do military service.

8 Hebrew, "Oriental"

9 A prominent example is the adaptation of the genocide of European Jewry (Shoah) as an all-national collective event. 
the "ethno-territorial Jewish project", Palestinian cheap labour workers were supposed to be replaced by Jewish ones (Shohat 1999: 9-10). However, since the 1980s or early 1990s more confident self-definition of Sephardi Israelis as "Mizrahi" has become noticeable based on several processes. For instance, the younger generations of immigrants from Muslim countries have shown economic and thus social upward mobility (Fishman 2004: 58). Besides, they have gained political influence, namely in the framework of two political parties: the Likud, and the ultra-orthodox SHAS (cf. Shetrit 2000).

A more recent renewal of the emphasis on an Ashkenazi-Sephardi divide-based on the emphasis on a claimed cultural superiority of Europeanness or, more precisely, "Russianness"-has been reinforced by the mass arrival of FSU immigrants.

social/ veteran Israelis vs. newcomers The Zionist discourse of homecoming clearly undercuts the economic reality in Israel, which has been marked by a crisis in the 1980s and a slow recovery. Besides, the current social hierarchy of the established at the top and the newcomers at the lower stages has been contested in particular by the mass immigration from FSU countries. The Israeli public generally acknowledges the positive impact of new Israelis from FSU countries in various fields, such as science and technology (Dayan 2004: 7-8). However, they also perceive a negative impact in other fields, such as politics or crime (ibid.). ${ }^{10}$ In this regard, on the everyday level quite persistent negative stereotypes have emerged like that of "Russian prostitutes" and "criminal" (Dayan 2004: 7; see also Glöckner 2011: 205-7). From the angle of cultural identification, a further aspect contributing to the development of stereotypes is the relatively high number of non-Jewish immigrants in the context of this wave of immigration due to families of mixed marriage who are not considered Halakhic Jews by the Rabbinate. ${ }^{11}$ Again, those people were not intended to be part of the

10 Khanin states in this regard that FSU immigrants have "managed to change the previous right-left balance" (Khanin, 2011: 155).

11 Since this recognition as a Halakhic Jew regulates various status passages in the life course, above all marriage and funeral, the denial of that status limits those citizens' life choices in these regards and in everyday practice constructs a minority on religious grounds - not to mention that the regulation of cultural 
Zionist project and although the integrative power of Zionism as an ideology has weakened in other areas, it is still powerful with regard to regulating immigration.

political In classic terms, there are two main political camps in Israel: the political left-wing, and the political right-wing; besides there being a growing political centre. Left-wing politics has usually taken a territory-forpeace position in peace negations with Palestinians and with regard to internal affairs rather a welfare-state and social-equality oriented positionto name only a few examples. Right-wing politics, in contrast, has rather advocated a peace-for-peace position in the negotiations with the Palestinians and a free market economy, but has also put more emphasis on national security than on other political issues, as Gutwein ${ }^{12}$ points out.

However, former clear-cut differences between the political camps, in particular with regard to the solution of the Israeli-Palestinian conflict, are becoming blurred. Lieberman's Yisra'el Beitenu party, a clearly extreme right-wing political party, for instance, crosscuts the traditional right-wing

rights according to an individual's religious status is in sharp contrast to the dominance of individual secularism among Israelis with an FSU family background. Non-Halakhic citizens are even collectively separated in official data as "others" from the Jewish segments of Israeli society (Central Bureau of Statistics 2016; 2010). Only those who have a Jewish mother are Jewish according to the Halakha, the complex of Jewish religious law. However, the Law of Return, which organises immigration to Israel, allows entrance of nonHalakhic Jews (having a Jewish father, or a Jewish grandparent) and of nonJewish spouses and children and moreover grants basic civil rights, including Israeli citizenship, to both groups. The group of individuals who are granted immediate citizenship by the Law of Return differs from the Halakhic definition and has historical-political reasons. The Law of Return has aimed at granting shelter to Diaspora Jewry in the aftermath of the Shoah and is thus guided by the definition of who was considered Jewish in the Nazi-German Reichsbürgergesetz of 1935 .

12 Daniel Gutwein. How the left elevated Lieberman. Haaretz (English Edition), 2009. Retrieved from: http://www.haaretz.com/print-edition/features/howthe-left-elevated-lieberman-1.269990 
positions ${ }^{13}$ - and has been quite successful with this strategy in national elections.

racial/ "Ethiopian Jews" Falashmura, Beta Israel or Falasha", are usually not a subject of research, but if they are, the empirical results reveal that those usually socially weak segments within Israeli Jewish society are confronted with hostile, even racist, attitudes toward them (cf. Amit 2011). Pedahzur and Yishai (1999) find in their study on xenophobia ${ }^{15}$ in Israel that the social groups they examined are targeted on the basis of different factors: Palestinian Israelis due to the unsolved Israeli-Palestinian conflict, Falashmura on the basis of race, and foreign workers particularly because of the economic competition. However, those factors also influence the hierarchy of the social groups targeted, for instance, hostile attitudes are far more often expressed toward Palestinian Israelis than toward foreign workers or Falashmura. Like other studies have shown (see above), the degree of religiosity of the respondents and their perception of fear also have a negative influence. For the case of Falashmura, Pedahzur and Yishai explain hostile attitudes toward them by simply stating "that they are so different from the Jews from other countries in skin colour, culture, social tradition, and religious practices" (Pedahzur/ Yishai 1999: 102). Other authors term the phenomenon more precisely as cultural racism (cf. Elias/ Kemp 2010; Ben-Eliezer 2008); and Elias and Kemp put the statement into context: "entry and absorption difficulties encountered by the sizeable population of Ethiopian Jews have led to the emergence of racial divides and intra-Jewish colour-based forms of racism" (Elias/ Kemp 2010: 74).

As a result of their low economic status and social exclusion, Falashmura are at the very margins of Israeli society (e.g. Amit 2011). Elias and Kemp find that in return, second generation youth chooses a rather transnational way of coping: they tend to adopt a "'black[...]' (instead of Israeli [...]) [identity and, with it,] [...] black Diaspora cultural symbols (e.g. music, hairstyle, fashion, and forms of social protest) completely foreign to them in Ethiopia” (Elias/ Kemp 2010: 82).

13 Ibid.

14 Amharic, "stranger" (Ben-Eliezer 2008: 936)

15 Xenophobia is defined here as "not only rejection of what is strange; the socially weak can be victims as well" (Pedahzur/ Yishai 1999: 102). 
However, the younger generation has also begun to claim their rights as citizens. $^{16}$

religious/ Jewish ultra-orthodox Although the Jewish religion is of high significance here, and many public institutions are based on it, the significance of religion has also been contested in recent years. According to Ben Meir and Bagno-Moldavsky, the secular-religious divide has replaced the former divide along ethnic lines as the most severe within the Jewish segments of Israeli society (Ben Meir/ Bagno-Moldavsky 2010: 52).

\subsubsection{Political Attitudes of Young (Jewish) Israelis}

According to classical theories of political socialisation, young people become socialised on political issues both directly and indirectly in different contexts - above all in face-to-face interactions at school, in peer groups and various other environments, both national and global and, I would argue, also local and regional ones. When it comes to growing up in Israel, Ichilov states that children are exposed to conflict as the "dominant message at the global sphere" (Ichilov 2004: 11) which has become "part of the people's daily routines" (ibid.) while at the same time the "traditional bounds of citizenship", namely unity and solidarity, erode, as has been described (Ichilov 2004: 30). In this context, Ichilov agrees with Bar-Tal (2001) in stating that constant exposure to conflict (e.g. the Palestinian-Israeli conflict) transforms into collective narratives or societal beliefs, in particular about threat (Ichilov 2004: 51).

These narratives, or "stories", evoke strong negative collective emotions and are the basis for learning "predispositions for prolonged conflict" (ibid.; cf. also Halperin/ Bar-Tal 2011; Bar-Tal/ Antebi 1992a). Against this background, Ichilov (2004) examines young Israelis' notions of a "good citizen" and finds that a majority supports loyalty to the state as well as

16 Isabel Kershner. Second-Generation Ethiopian-Israelis March toward Acceptance. June 9 2012; Retrieved from:

http://www.nytimes.com/2012/06/10/world/middleeast/second-generationethiopian-israelis-march-toward-acceptance.html 
obedience to political authorities (Ichilov 2004: 127) ${ }^{17}$ She also finds that the young peoples' answers "reflect the major rifts within Israeli society", in particular with regard to the Israeli-Palestinian conflict and connected cleavages between political left and right and Jewish and Palestinian Israelis (Ichilov 2004: 128).

Concluding from results of the longitudinal IEA study on young peoples' perceptions of citizenship, Ichilov states a decline in "tolerance toward 'others"' (e.g. national minorities), efficacy and trust in political authorities, and "civil identities" for the Israeli case (Ichilov 2004: 153). At the same time, young (Jewish) Israelis perceive a growing threat, above all of the erosion of "bonding forces" to be caused by rifts within Israeli society (Ichilov 2004: 155). Also, an increasing number of young people find the use of military power legitimate in order to reach political goals; they support anti-democratic tendencies-e.g. depriving non-Jewish citizens of particular civil rights or emphasising the character of the State of Israel as a Jewish state (Ichilov 2004: 153). However, her results also show that young Israelis have become increasingly politically engaged and actively take part in both conventional forms of engagement, such as political discussions, demonstrations or in various organisations as well as unconventional or even illegal forms of protest (ibid.).

Other empirical studies confirm a "consistently high level of generalised interest in social and political issues" (Enosh/ Katz 2004: 12) among Israeli adolescents with about 15 per cent of them stating interest in foreign policy and about 55 per cent in social issues in 2004 (ibid). Whether this increase in political action also results in an increase in political literacy, i.e. knowledge of facts, remains questionable against the background of the reported intolerance and support of national(ist) or antidemocratic tendencies, however.

\subsubsection{The Political Adaptation of FSU Immigrants}

There have been three large waves of Jewish immigration from Russia or the Soviet Union: in the period of the Yishuv, the Jewish resettlement of

17 Those from Kibbutz settlements usually display a more balanced view and also stress a citizen's obligation for active engagement in one's community (Ichilov 2004: 127). 
Palestine in the context of secular Zionism before Independence, the Prisoners of Zion or Otkazniki movement of the 1970s and 1980s and the "Great Russian Aliyah" (Khanin 2011) after the collapse of the Soviet Union.

Arian et al. dedicated that 2010 Israeli Democracy Index to the $20^{\text {th }}$ anniversary of FSU immigration and an examination of the political attitudes of those segments of Israeli society. Besides, the study is set against the background of two large military operations, the 2006 Lebanon War and the 2009 "Operation Cast Lead" in Gaza. Their study shows that positive attitudes toward democracy among the respondents are in decline: though they generally support state institutions, in particular IDF (Israeli Defence Forces), they are dissatisfied with their own political influence or representation as a social group (Arian et al. 2010: 55), the perceived high level of corruption of political elites (Arian et al. 2010: 61), and political leadership in general which is perceived as weak (Arian et al. 2010: 58). In this context, 74 per cent (veteran Israelis: 61 per cent) support the idea of a strong leadership (ibid.). With regard to the rights' aspect, almost half of the respondents (48 per cent) reject "harsh criticism" of official policies, such as military operations, (Arian et al. 2010: 63) and 77 per cent (veteran Israelis: 47 per cent) support the encouragement of "Arab emigration", and the limitation of civil rights of national minorities, in particular Palestinian citizens (Arian et al. 2010: 64). Halperin et al. find that Israelis with an FSU background tend to answer more often in exclusionist terms than veteran Israelis and explain this at least partly with "political 'hawkish' attitudes" and in particular "well-rooted negative Russian sentiments toward Islam" (Halperin et al. 2009: 1001).

These figures must be interpreted against the context of two developments: the generally increasing public acceptance of open prejudices and discrimination, and IB's "loyalty" slogan (2009) as a consequence and further catalyst of that acceptance. Generally, the authors state a decline in social trust against the perception of growing cleavages within Israeli society, yet at the same time an increase in the expression of belonging of the particular FSU community (Arian et al. 2010: 81). ${ }^{18}$

18 In this context, Khanin identifies three main models of the group's political integration: the cooperation of Russian political elites with mainstream political parties, either as "satellite lists" or "intra-party lobbies" (Khanin 2011: 58-9) or 
Most studies link those attitudes directly or indirectly to the immigrants' "Soviet legacy" (Khanin 2011: 56). The supposedly "imported" political culture consists of particular features, e.g. the preference of strong leadership over democratically elected representatives, patriotism, low levels of political participation/ mistrust in political elites and "suspicious of political authorities", economic liberalism vs. social contestation (Philippov/ Bystrov 2011: 261) and the maintenance of the "post-Soviet concept of the "enemyimage" (Arian et al. 2010: 65). Correspondingly, Philippov and Bystrov sum up the recent increase in voters' turnout rate and of the FSU immigrants' general influence on (political) life in Israel with the words that "they [FSU immigrants] are on their way to creating the appropriate patterns of active citizenship" (Philippov/ Bystrov 2011: 260); however, they also claim this "imported" political culture to be an "excuse for voting for the most radical parties", in particular the Yisra'el Beitenu party (ibid.). In this context, empirical studies on the political "attitudes" of FSU immigrants - and, as implied there, their children-suggest a certain stable set of attitudes, described as more right-wing and conservative in comparison to other Jewish layers in Israeli society - especially when it comes to the peace process and territorial concessions (e.g. Philippov/ Knafelman 2011; Philippov/ Bystrov 2011; Arian et al. 2010; Goldstein/ Gitelman 2004). Remennick (2007) described the phenomenon as "integration without assimilation". Yet, Bagno's study (2011b) suggests that the political attitudes of immigrants approach those of the Israeli majority over time.

In the literature, there are two major positions about how to perceive the (first generation of) new Israelis' persistence. One of them is arguing that this standing matches the latest developments of growing pluralism and visibility of minorities in Israeli society (cf. Dayan 2004). However, researchers who take a more pessimistic position on the phenomenon argue that, on the contrary, this is a sign of the group's perception of themselves as part of the dominant Jewish majority and, moreover, "the elite within [this] majority" (Shumsky 2001). Connected to that "elite"-perception is that of one's (cultural) superiority over ethnic and national, in particular Muslim minorities (cf. Lerner 2010; Shumsky 2001). What Khanin describes as a "preservation of [the] mentality and values of 'Russian' Jewishness and less

the establishment of "independent community-centred" (Khanin 2011: 59), "sectoral" (e.g. Bagno 2011a) parties. 
of 'Russian' language and culture" (Khanin 2007: 115), the perception of "Russia as a [supranational] civilisation" (Lerner 2010: 29), serves as the necessary link to understand the increasingly extreme positions with regard to granting civil rights to ethnic and national minorities in Israel, in particular Palestinians (cf. Lerner 2010; Lomsky-Feder et al. 2005; Shumsky 2004; 2001). Concluding from this, at least for the first generation of FSU immigrants, it is safe to say that those restrictive attitudes have a cultural dimension, personally experienced in their (post-)Soviet everyday life, which is added to the perception of threat against the background of the security situation.

\subsection{THE YISRA'EL BEITENU PARTY}

The current section reviews literature on the Yisra'el Beitenu party. The respective literature on the Yisra'el Beitenu party focuses on three main aspects, namely its status within the Israeli party system—or, to speak with Khanin, whether IB is a "Russian party with an Israeli accent" or an "Israeli party with a Russian accent" (Khanin 2010: 105-6) - its location within the Israeli political continuum between left-wing and right-wing ideologies as well as the context of the party's constantly growing electoral success between 1999 and 2009.

\subsubsection{Is Yisra'el Beitenu an Extreme Right-Wing Party?}

In his historical overview of Israeli political extreme right-wing parties, Pedahzur challenges Ehud Sprinzak's "classic definition" of what is understood as right-wing extremism in Israel (Pedahzur, 2000; 2001). This "classic" concept had evolved after the Six-Day War (1967) and used a traditional definition based on the analysis of the historical phenomena of "revolutionary fascism" in Europe and the "American postwar radical right" (Pedahzur 2001: 26), and was built exclusively on issues of "land and security" (Pedahzur 2001: 25). On the basis of his observation that about 20 per cent of the then Knesset members favoured antidemocratic or xenophobic ideas, Pedahzur argues in favour of replacing Sprinzak's concept with a more contemporary approach based on the analysis of today's European extreme right-wing movements and parties. He defines right-wing 
extremism as a syndrome of several features, namely nationalism, racism ("old" and "new"), xenophobia, anti-democracy or favouring a strong state (cf. Pedahzur 2001; e.g. also Mudde 2002; 1995). Pedahzur concludes that the observed transformation of the right-wing political camp also has immense influence on the political party scene in Israel: the emergence of a multi-party camp, united by a "shared ideological vision" about how to deal with the Palestinian-Israeli conflict but divided by others, reinforced the "polarisation within Israeli society", causing "more conventional parties" to "[adopt] the political manners and style" of the political parties on the rightwing edge (Pedahzur 2001: 39).

Pedahzur shows that the Israeli right-wing extremism has "transformed" from an "old" form (1970s-1990s), mainly represented by the KACH party, founded by Rabbi Meir Kahane, and predominantly playing on nationalist and racist tones. The "new" form which has emerged on the Israeli political scene is nowadays represented by SHAS and Yisra'el Beitenu. ${ }^{19}$ Along with features represented already by the "old" form, Pedahzur identifies new features, such as xenophobia, anti-establishment, or anti-democratic tendencies. In particular, IB demands a fundamental modification of Israel's “judiciary or criminal justice systems" (Pedahzur 2001: 31), incriminating it as "administrative dictatorship" over the elected government (Pedahzur 2001: 35), as well as the provision of the president with much more power, comparable to the political power the Russian president wields (ibid.). Accordingly, IB's 1999 election campaign - the first general election the party participated in-focused on "mobiliz[ing]" feelings of "deprivation" and "frustration", based on the perceived "persecution of the Russian community in Israel" by the police and other institutional organs (ibid.).

The typical voter of the Yisra'el Beitenu party is, according to Bagno's findings, secular, younger, an immigrant male whose ethnic origin is his first identity, afraid of Arabs as a group, lives in an area affected by (recent) military operations, holds right-wing or hawkish political views and is attracted by the party's programme rather than by a concrete candidate (Bagno 2011a: 31). Besides, IB's immigrant voters are "least satisfied with the quality of democracy", as mainly mirrored in their perceived low political

19 Although Pedahzur mainly focuses on SHAS - IB had been founded only two years before the publication of his article-, his analysis reveals some interesting aspects about Lieberman's party as well. 
efficacy, low political interest and low political literacy; accordingly, they are expected to use their vote more as a "protest" (Bagno 2011a: 27). ${ }^{20}$ This finding can be seen as a proof of Pedahzur's finding (2001) of IB presenting itself as an anti-establishment party (see above). Accordingly, Bagno states that when those voters with an immigrant background actually become politically active, they, more than their veteran Israel counterparts, "make instrumental use of [this] participation" (Bagno 2011a: 28). Khanin attests to the party a "substantial political protest potential" (Khanin 2010: 107). IB has made extensive use of this protest potential and based its electoral campaigning on an "unprecedented attack on members of the Israeli law enforcement and the bureaucratic establishment", and in this way won the "solidarity of both immigrants from the FSU and other origins as well as veteran Israelis" (Khanin 2010: 107; see also Pedahzur 2000). This strategy obviously pays off despite the fact that the party has been part of that "establishment" since 2006 and left the governments several times for strategic reasons only.

There are two major positions to explain the recent electoral success of extreme right-wing parties in Israel: while some authors see the reasons basically in social and economic processes, in particular the state of the welfare state and failures of the political elites to respond adequately, ${ }^{21}$ others explain the phenomenon with processes and transformations within the political field itself (e.g. Mustafa/ Ghanem 2010). Pedahzur embeds IB's appearance and electoral success into the broader process of the "transformation of Israel's extreme right" (Pedahzur 2001; 2000). In his analysis of the "supporting conditions for the survival [and emergence of new] extreme right-wing parties in Israel", Pedahzur develops an explanatory model, including conditions on several levels: the bottom of his pyramid is the Israeli political culture, followed by the analysis of social cleavages, structural factors (i.e. the threshold vote or legal controls), with the top formed by the very party scene (Pedahzur 2000). The most important

20 This gives reason to worry since Torney-Purta and Klandl Richardson (2004) emphasized the importance of those three factors as much of a precondition for political engagement.

21 Daniel Gutwein. How the left elevated Lieberman. Haaretz (English Edition), 2009. Retrieved from: http://www.haaretz.com/print-edition/features/how-theleft-elevated-lieberman-1.269990 
feature of the country's political culture is what Smooha had called "ethnic democracy" (Smooha 2009; 2001), ${ }^{22}$ which Pedahzur sees as the "precondition for ethnic conflict" because it "[encourages] radical political expressions towards the minority" (Pedahzur 2000: 8-9). In this regard, the Yisra'el Beitenu party - according to Peled an "extreme right-wing party headed by a West Bank settler, Avigdor Lieberman" (Peled 2011: 278) particularly plays on an ethno-nationalist component of Israeli citizenship, and "gained notoriety" (ibid.) with Lieberman promoting his plan of a territorial exchange of Jewish settlements in Judea and Samaria with Israeli territories inhabiting large populations of Palestinian Israelis, namely near the 1967 Green Line and in Southern Galilee.

A further level of Pedahzur's model (Pedahzur 2000) is represented by various cleavages in Israeli society, in particular social rifts. These cleavages are important for the analysis because one fundamental feature of the "new" right-wing extremism in Israel is the parties' development of a "twodimensional platform", on which social cleavages serve as one issueparticular notions of how the Palestinian-Israeli conflict should be solved form the other-instead of previous parties relying on only a single issue. Consequently, when it comes to the level of the party scene itself, those political parties are most successful in managing to persuade the electorate of their ideological vision and are able to "[represent] their constituencies" simultaneously (Pedahzur 2000: 21). Lately, SHAS and Yisra'el Beitenu have been most successful in this respect.

\subsubsection{Is Yisra'el Beitenu an "Ethnic Party"?}

In order to categorize the Yisra'el Beitenu party, Bagno refers to Chandra and Wilkinson's differentiation between "ethnic structure" and "ethnic practice" (Chandra/ Wilkinson 2008): while ethnic parties relying on the former approach put emphasis on "descent-based attributes" in order to mobilize specific groups, ethnic parties utilizing "ethnic practice" for the same purpose emphasize rather "time-sensitive" categories (cf. Bagno 2011a: 20). "These categories [imply] the exclusion of others, but at the same time go for an explicitly national agenda in order to catch-all possible eligible

22 On the discussion of the concept itself, see for example Berent 2010; Danel 2009; Peled/ Navot 2005; Ghanem et al. 1998; Peled 1992; and Yiftachel 1992. 
votes" (Bagno 2011a: 21). ${ }^{23}$ Another feature Bagno mentions in this context is a "catch-all ethnic party's" "loyal[ty] to the establishment" (Bagno 2011a: 22) — a feature Pedahzur (2001) would strongly disagree with with regard to IB. The remains of the "ethnic party" can be found in IB's use of the Russian language in its media campaign for the 2009 general elections as well as in the Russian-speaking candidates on the party's electoral list. Though both components may as well serve the opposite argument of the immigrants' and the party's political assimilation to the Israeli scene since, first, Russianspeaking candidates can be found on the lists of other major parties as well (though not as many at the top of the respective list as with IB), and second, other major parties also made use of Russian language-campaigning since Israelis with an FSU background have become a major political force. This development meets the interests of the party's potential constituents, as Glöckner states: "RSJ [Russian-Speaking Jewish] voting patterns in the elections of 2003 and 2006 rather indicated that the model of pure 'Russian' parties has passed its peak, possibly underlying the fact that for many of the RSJ immigrants the socio-economic situation had improved very much in the course of the last decade" (Glöckner 2011: 83).

Accordingly, Khanin tells the history of the Yisra'el Beitenu party as a history of "[ideological] transformation": based on his findings that $2 / 3$ of IB's electorate in the 2009 general elections consisted of Russian-speakers and $1 / 3$ of veteran Israelis without such a background. Khanin states that the party's “major dilemma [was] to find a modus vivendi between [its] nationwide aspirations and [its] predominantly Russian community character" (Khanin 2010: 105). ${ }^{24}$ Khanin sees a major cause for IB's electoral success in the "charismatic Lieberman" himself, appearing as the representative of various peripheral social groups, as well as the successful launching of the "concept of a "population and territories exchange"" which can be understood as a "neo-centralist alternative" to both left-wing and right-wing political approaches of how to reach a peace agreement with the Palestinians (ibid.). In order to pacify the obvious contradiction of keeping

23 On the concept of a "catch-all ethnic party" see Enyedi 2008; Mudde 1999; and Roper 1994.

24 On the question of how far this "Russian community character" was still predominant in 2009; Bagno (2011a) found that in the latest of these elections IB was no longer perceived as an immigrant party. 
its Russian-speaking electorate while gaining electoral support of veteran Israelis, the Yisra'el Beitenu party has "regular[ly] updat[ed] its political image [as well as its] political tactics" (Khanin 2010: 107) and has transformed from an "“all-Israeli' right-wing party [with an] electorate [...] coincidently Russian-speaking [via a] Russian non-sectarian party [via a] Russian party with an Israeli accent [toward a (currently)] originally Russian nationwide party" (ibid.). Correspondingly, Khanin finds that the party's ideology has gone through an evolution as well: while in its first election campaign in 1999 the party shared a moderate right-wing ideology with the Likud and a social welfare orientation with the then still-successful FSU immigrant-based Yisra'el Ba'aliyah (YBA), it performed a strong "rightwing shift" when entering the National Union bloc in 2003, but returned to a more moderate "centre-right" ideology after leaving the bloc in 2004 (ibid.).

Through all these switches and transformations, the Yisra'el Beitenu party has not only been able to "preserve most of its camp's strong rightwing Russian and veteran core", but also to compensate losses from this camp by gaining a more moderate electorate in 2006, mainly through wandering voters from the Likud, YBA and the Kadima party (ibid.). By 2006, the party had managed to "balance internal ideological controversies" between an "Israeli Russian-Jewish community which voted either for the ideological right or which was social welfare-oriented centre and would have otherwise voted for an immigrant party", a "right-wing Liebermanist core", and a "more moderate mainstream" party (Khanin 2010: 109). According to Khanin, it had done so mainly by combining a "kind of centre party" ideology 25 -filling an "ideological vacuum" left by the political failure to achieve peace of Sharon's plan to disengage from Gaza - with a "strong rightist rhetoric" (Khanin 2010: 109-10). In addition to this, the party made "effective use of the historical momentum" (Khanin 2010: 119), mainly through "capturing the feelings of public anger about Palestinian Israeli demonstrations" (Khanin 2010: 114) in support of Hamas in the context of the military operation "Cast Lead" (2009) in Gaza. Olena Bagno would

25 With the announcement of the so-called "Kissinger-Lieberman-Plan or Lieberman-Plan", the party had practically accepted "a territorial compromise between Jews and Arabs in the lands West of the Jordan river [and, implicitly, also] the establishment of a Palestinian state." 
disagree here: she emphasises that in its 2009 electoral campaign the Yisra'el Beitenu party made only implicit use of exclusionist elements, but did not openly attack Palestinian Israelis or other ethnic or social groups (Bagno 2011a) with slogans like "No loyalty, no citizenship". ${ }^{26}$

As a consequence, in 2009 Lieberman's party had not only made major transformations of its public image and its ideology, but it had also experienced "substantial [yet, wanted] changes of its electorate" (Khanin 2010: 114) since through these transformations it had also become attractive for veteran Israelis for whom Lieberman had stopped being a "persona non grata" (Khanin 2010: 113). The Israeli political centre had started to see his sharp rhetoric as mere framing of ideas which in the 2006 elections had still been unacceptable, simultaneously, Lieberman had become a symbol for the representation of peripheral groups of Israeli society (cf. Peled 2011).

\subsubsection{Yisra'el Beitenu's Electoral Success}

Electoral campaigns must not be underestimated, and IB's electoral campaigns have accordingly undergone important transformations. In her paper, Meller analyses the Yisra'el Beitenu party's electoral campaigns on TV for the general elections of 1999 to 2009. From her analysis, she concludes that the party has employed the "metaphor of nation as home and family" - as already the party's name suggests - as a conscious reference to Israeli or Zionist history (Meller 2010: 3) and important values in Israeli political culture in order to "remove [...] ambiguity" about Israel as the "home of 'Russian' Jews" (Meller 2010: 7). Meller understands the party's 1999 campaign as "a statement [both] against competing Russian parties [as well as] against the Israeli establishment" (Meller 2010: 7-8), ${ }^{27}$ this meets Pedahzur's definition of the new Israeli right (see above; e.g. also Pedahzur 2001). In the 1999 elections, IB functioned as a "bridge [toward] a home" for those Russian-speaking Israelis who wanted to "relinquish their identity" (Meller 2010: 8; cf. also Shumsky 2001). Interestingly, the campaign

26 Partija "Yisra'el Beitenu" ("Our House Israel"). Online Platform. http:// www.ndi.org.il (Russian).

27 Lieberman, according to Khanin (2002), refers to the Israeli establishment as "oligarchs", after the economic elite which evolved in Russia and other former Soviet Republics in the aftermath of their independence. 
presented Lieberman "as a fierce leader" - an image which will remain in the later campaigns - and placed the issues of social welfare and national security on the party's central agenda (Meller 2010: 9). Meller interprets IB's decision to run within the extreme right bloc "National Union" in 2003 as "an integral part of [its and its voters'] socialisation in Israeli society" (Meller 2010: 11): the parties of the bloc shared the vision of an "anti-Arab and anti-concessions and [...] hawkish defence plan" (ibid.). Again, the issue of national security was stressed, and Lieberman was presented as a "protective paternal figure" (ibid.). In 2006, the party again ran as a "standalone party"; in its campaign, the party promised to "resolve the demographic problem"-again, a national security issue - in order to "reaffirm [IB's] position on the Jewish identity of the state" and to overcome the perceived disintegration of the Jewish Israeli society in order to "unite against a common [external] enemy" (Meller 2010: 12). Finally, Meller sees the success of the party's 2009 campaign in mainly two factors: the partyrelated "carefully constructed discourse" around the party leader, Lieberman, as well as the context-related "consistent shift to the right" of Israeli society (Meller 2010: 15), and a respective adaptation of the party's agenda.

In her analysis of IB's 2009 electoral campaign, Bagno finds that the party "exclusively [builds on] issues related to Israel rather than on ethnic policy issues" (Bagno 2011a: 24) despite the fact that their candidate list for the elections includes "many immigrants" and suggests the opposite. Above all, security or the perceived lack of it is an issue; the party's programme/ platform as well as its campaign centre around security concerns. The party's messages in the campaign — namely, "Lieberman - I trust him", "No loyalty, no citizenship", "Only Lieberman understands Arabic" - call upon implicit "feeling[s] of personal insecurity induced by external forces" or "disloyal forces" (Bagno 2011a: 26-7), whereas concrete exclusionist demands on ethnic grounds are rather implicit or introduced in the public discussion of those messages (Bagno 2011a: 26).

Alongside the developments described above, most authors mention the influence of current events on IB's electoral success in 2009, above all the military operations against Hamas in Gaza ${ }^{28}$ which had ended only three weeks before the 2009 elections, and in the cause of which IB was able to put its major issue of personal and national security on the agenda. Arian et

28 Referred to as "Operation Cast Lead" in public discourse. 
al. reflect that the territorial conflict between Israel and the Palestinians has been "[superimposing] itself upon all other political divisions" ever since the 1967 Six-Day War (Arian et al. 2011: 280). In its cause, security issues have dominated the "mindset of Israeli voters" and divided Israeli society along the "foreign policy cleavages"; besides, security became "interlocked with the religious-secular split and nationalist attitudes" (ibid.). Not surprisingly, security issues (along with social issues) dominated the electoral agenda of the political parties and by putting them on the agenda they best met the public opinion (Tsfat et al. 2011: 233). IB was most successful in doing so and accordingly received the best media coverage of its electoral campaign - though 83 per cent of those news reports contained "criticism on ideological grounds" (Tsfat et al. 2011: 238-9). Yet, Khanin (2009) ${ }^{29}$ states that IB's success in the 2009 elections cannot be explained by the "Gaza effect" only since even left-wing politicians criticize that the military operation was stopped prematurely. However, he emphasizes that Lieberman made the strongest statements about it; and in addition, it seems that his long-term critique of Israeli Arabs pays out in this context because it meets the disappointment of many Jewish Israelis by the open support or solidarity with Hamas (cf. also Waxman 2012). Last but not least, Pedahzur and Brichta point to the role the utilisation of local government structures can play in a party's electoral success, especially with regard to new political parties which aim at entering parliament through (existing) local structures. Local government structures represent an "important resource" for those parties since they establish a "linkage" to the national level (Pedahzur and Brichta 2000: 55).

To sum up, according to Meller, IB's campaigns mirror the party's as well as its Russian-speaking voters' political integration or "Israelization" (Meller 2010: 16): having started with a founding body of Russian-speaking Israelis and electoral campaigns in Russian with Hebrew subtitles, by the next general elections in 2003, they (as part of the bloc) could count on the support of non-Russian-speaking candidates and the party's growing ability to attract non-Russian-speaking voters. This trend continued in 2006 and led to TV ads completely in Hebrew (with Russian subtitles, as had become

29 Vladimir (Ze'ev) Khanin. Феномен НДИ: станет ли Либерман новым Бегиным? IzRus, 08.02. 2009. Retrieved from: http://izrus.co.il/obshina/article/2009-02-08/3683.html 
standard for Israeli political parties) in 2009 (Meller 2010: 16). Meller sees the party's ongoing integration of the electoral campaigns going hand in hand with the political adaptation of its Russian-speaking electorate, referring to the electorate's "development of a collective identity" from a more "introvert political and social inclination in the Russian community [...] [toward the predomination of a] general-national Jewish identity" (ibid.; cf. also Shumsky 2001). ${ }^{30}$ Accordingly, asking about the party's public image shows that a majority of both FSU immigrants and veteran Israelis think of IB "not [as] an immigrant party", and among IB voters the number of people sharing this view is even higher (Bagno 2011a: 25). ${ }^{31}$

30 Yet, Meller is not consistent in her general evaluation of the party and its voters' integration, since in her final conclusion she still sees major elements of a "Soviet political culture" defining the voters' approach to the Israeli reality (Meller 2010: $16)$.

$3173 \%$ of the respondents in the 2009 INES survey with an FSU origin and $64 \%$ of veteran Israelis expressed this view, and correspondingly $78 \%$ of IB voters with an FSU origin and 88\%of veteran Israelis (Bagno 2011a: 25). 


\section{A Material Theory of Belonging}





\section{The Interviewees' Objective Position in Israeli Society: Jews, Russians, Israelis?}

The participants in the present study do not talk about their civic engagement in a vacuum. Social action, here: civic engagement, takes place in a particular social environment, here: the political, field, against the background of objective opportunities or restraints and individual power resources. In the present chapter, I will briefly discuss the participants' objective position in Israeli society as the social space within which the present study has been undertaken. I consider the participants in the study members of the social group of immigrants from the former Soviet Union, arriving in Israel after its collapse. The consideration of Israelis with an FSU family background as a social group is for methodological reasons rather than based on assumptions about the group's identity. As outlined above, according to Bourdieu, members of a social group share a similar objective position in a given social space based on their possession of capital. Having said this, it is likely for members of that social group to share particular experiences of opportunity and restraint in the process of incorporation.

The short description shall mark the starting point for an analysis of the interviewees' objective position within this social space. As outlined above, time is essential for the accumulation and validation of capital as well as the development and reorganisation of habitual dispositions. In this context, I will provide an analysis of the power resources the interviewees present to have at their disposal during time. 


\subsection{THE OBJECTIVE POSITION OF FSU IMMIGRANTS: MAJORITY OR MINORITY?}

Israel is an immigration country, encouraging in particular "return migration" from the Jewish diaspora. Immigrants from the former Soviet Union have arrived in Israel under the Law of Return (1952) which regulates (Jewish) immigration to Israel. The objective position of those immigrants can be analysed along two dimensions: their legal status, i.e. citizenship status (Delanty 1997: 9), and their social status. According to the Law of Return, immigrants are granted immediate Israeli citizenship and the allocation of full political rights (e.g. Israeli passport, active and passive voting rights); and they receive full economic rights (e.g. access to welfare).

The recognition of diploma or formal education in general — and thus the immigrants' economic incorporation - has been easier in Israel than in other countries of Jewish immigration from the former Soviet Union (Glöckner 2011; 2005). Glöckner (2011) states that in Israel —unlike in other receiving countries - FSU immigrants have joined the dominant group (Israeli Jewish citizens). Like every other (Jewish) citizen of Israel, military service is mandatory for FSU immigrants - its length however, depending on age and family status upon arrival — and they are obliged to pay taxes.

Thus, legally, immigrants and their families who arrived in the country from countries of the former Soviet Union (FSU) have become Israeli citizens. However, there is collective discrimination against a particular group of immigrants - in theory not targeted against those from FSU countries, but in practice it concerns mainly them as a social group - under the Law of Return and their family members with regard to their cultural.

In the hegemonic discourse Jewish immigrants are considered homecomers. Those new citizens are expected to integrate quickly and smoothly into Israeli society, "be committed to the Israeli national ethos" (LomskyFeder/ Rapoport 2001: 1) and become "real Israelis" (Golden 2001). However, Jewish immigrants - though sharing more or less of a common cultural heritage based on "Jewish Law" (Fromm 1989 [1922])—bring experiences different from those who stayed "at home" and are newcomers in the specific cultural context of Israeli society. Their social status in the

1 On home-comers cf. also Schütz 1945 
context of established-newcomer relations, suggests a more peripheral position.

\subsection{ANALYSIS OF POWER RESOURCES I: "MOVE UPHILL"}

Most of the interviewees have lived in the reality of migration and incorporation. They mention economic problems at home, and usually they connect these difficulties with their family's migration background. Zeev, for instance, tells me his parents "don't have time for us [Zeev and his little sister], they are working all the time" (Zeev, p. 7); in a similar token, Katya states: "[my mother], she is working a lot, so, my grandmother looked after me" (Katya, p. 9).

But the interviewees refer to those experiences differently, depending on the extent to which they have made those experiences and their individual strategies of coping and the issues they emphasise in their narratives. Crosscutting these individual factors, there are differences between those who have already started their professional careers and those who are still in school, i.e. with respect to the length of their stay in Israel. The former would hardly speak of any difficulties in their families. Katya, for instance, immigrated as a 10-year-old girl with her mother and grandmother from Moscow in 1993, has lived in Bat-Yam near Tel-Aviv, ("the centre" [Katya, p. 1]), ever since. She finished school, did her military service, received higher education and started working; she had spent more than two thirds of her life in the country, has a mixed circle of friends and speaks of herself as "Russian-Jewish Israeli, this is the end of the immigrant era" (Katya, p. 1). Her emphasis is rather on her present personal achievements and experiences of success and living "a normal life" (Katya, p. 21) than difficulties in the context of migration experienced in the past.

For those interviewees still in school and living at home, those difficulties are still a central part of their everyday experience. Their families often live at the periphery of the country — not Katya's "centre" — with regard to geographical as well as economic concerns. Boris's story shall serve as an example here. Boris was finishing school at the moment of the interview; he grew up in Hadar, a geographically lower neighbourhood in the northern Israeli city of Haifa with a higher percentage of more recent immigrants as 
well as low-income families than elsewhere in the city. He is aware of living at the periphery, saying of his place of residence: "immigrants who made it [economically] move uphill" (Boris, p. 2). ${ }^{2} \mathrm{He}$ is well aware of the economic difficulties in his family, his parents' hard work in order to advance economically, and the does not complain about their absence, but simply states it is that way. Yet, Boris personally experiences the consequences of the difficult economic situation in the family, not only in terms of money but also with regard to his sense of belonging:

Boris: "My grandmother and grandfather were not very interested in looking after me. Why? Because I am not Jewish (.), like, in Ukraine I was Jewish, here I am not, actually, in Israel (.) [I am] Ukrainian, there [in Ukraine] I am (Jewish)“ Interviewer: "(Mmh)“.

Boris: "Here it goes according to the mother, and my mother is Ukrainian, so my grandparents were not very interested in looking after me ((because)) I am, well, again, I am not Jewish.“ (Boris, p. 2)

In Boris's story, the family's financial situation links what is happening on the collective level (e.g. hegemonic discourse on home-coming, stereotypes about recent immigrants) with the individual level of dealing with the consequences of migration. The child is directly confronted with the consequences, and finally accepts that he does not belong ("I am not Jewish") and thus is not as worthy to be "look[ed] after". In Boris's view, this even divides his family. Summing up, Boris states: "I was more a street kid, hanging out with friends" (Boris, p. 2).

In single cases, like Avi's, the issue of physical violence at home is brought up. Avi, now living in Natserat Illit, grew up in Hadar as well. Even before their immigration to Israel, the family was in financial difficulties. Originally from Moscow, after his parents' divorce and his mother's remarriage, the family "was forced to move to Kharkiv [Ukraine]" (Avi, p.

2 However, the interviewees perceive their everyday life at the periphery differently. Lukas, who like Boris has almost finished school and lives with his family in Hadar, tells me of a quiet everyday life. The family already has improved economically and moved a little "uphill", both parents work, but his mother has already found the spare time to become actively engaged in their neighbourhood (Lukas, p. 10). 
1). In 1993, when Avi was eight, Avi's family, including his grandparents, immigrated to Israel for economic reasons ("[The decision to immigrate] didn't derive from any value, any value, any Zionist value" (Avi, p. 1) and settled in Natserat Illit. Yet, the financial situation of the family did not improve until his stepfather finally found work. The family moved to Haifa, and Avi's little sister was born. Avi does not speak much about the situation at home. Regarding his step-father, he simply summarises: "we did not have a good relationship, we had [physical] fights, I was hospitalised" (Avi, p. 2). Also, later, already as an adult, Avi refers to second-hand experiences of physical violence: when he speaks about his own civic engagement later on, he tells similar stories about young people from families with an FSU background growing up in Natserat Illit. In their relatively weak objective position as newcomers in Israeli society, the interviewees experience subtle discrimination of immigrants in everyday life. Acts of discrimination are exercised by individuals against individuals but also perceive them as members of a particular social group, new citizens.

This is neither a particular Israeli problem nor a problem concerning especially Israelis with an FSU family background. As previous empirical research shows, especially in economically weak or peripheral areas, social problems interfere with ethnic cleavages (e.g. Gonzalez-Sobrino 2016; Barth 1969). Correspondingly, especially those interviewees living in peripheral towns or neighbourhoods directly experience social cleavages in their everyday lives and they fight those cleavages on the street. Emmanuel, who immigrated with his family in 1998 from Novosibirsk as a five-year-old and also lives in Hadar with his parents and his little sister-tells me about an incident on the street:

\footnotetext{
“They called me a 'stinking Russian' on the street, they also humiliated my little sister, [...] they think of themselves that - if arrives here some immigrant and he doesn't know the language nor has he work nor connections, meaning he is no one, so you can do with him whatever they want (..), and till today they simply think of themselves that they are much better and this, this is simply humiliating." (Emmanuel, p. 1)
}

Elsewhere in his story, Emmanuel clarifies who "they" are: "those from Morocco" (Emmanuel, p. 5), Israelis of Mizrahi origin. Again, there is a difference between those - usually the younger ones-for whom social cleavages are an everyday reality because they live in a particular 
neighbourhood and those who have "move[d] uphill". The latter rather consider those experiences as past and hardly mention incidents in this context. However, there is a commonality between the younger and the older in their strategies of coping with those incidents from a backward perspective. Basically, the interviewees fight a cultural "war with words" (Brekle 1989) in their narratives. Mizrahim are presented as culturally different and even inferior because of particular values of "honour, $[\ldots]$ and the status of women" (Emmanuel, p. 28; Avi, p. 22) ascribed to them. Emmanuel has adapted the hegemonic discourse about the weaker social status of Mizrahi Israelis and the justification of that status on grounds of a claimed cultural inferiority. Yet, the style of Emmanuel's narrative- he tells it in the $3^{\text {rd }}$ person-suggests the encounter he tells me about is not a very recent experience but one he looks at already from a distance. And indeed, he tells me about another incident later in the interview: The positive experience confuses him and makes him reflect about the truthfulness of the stereotypes he holds toward Mizrahim:

"I hated those people my whole life, and now, like, I suddenly have some friendly relationships with them - and this I understand, you begin to understand that not everything, not all of them, well, again, you understand that the majority, that anyway they run around [...] 'you are bad Russians'.” (Emmanuel, p. 9)

As Boris's story already suggested, the interviewees also experience a more abstract form of subtle discrimination. In the hegemonic discourse, and particularly the media, recent FSU immigrants have been suspected to have fled their home countries for economic reasons rather than "coming home" to Israel for ideological reasons, i.e. based on Zionism (e.g. Remennick 2007; Dayan 2004). The lack of ideological reasons for immigration to Israel - to make Aliyah, i.e. to ascend, as would be the corresponding ideological term — clearly violates the "Israeli national ethos" (Lomsky-Feder/ Rapoport 2001) of home-coming. Due to the successful overall incorporation of Israelis with an FSU family background in the long run, it is probable that this has become less of an issue in public. But especially the older participants in the study are aware of that discourse. Accordingly, Vicky directly refers to the discourse of home-coming when she stresses the particular "Zionist" atmosphere at home. As an eight-year-old child Vicky moved with her family from Belarus to Israel in 1992. Vicky's statement 
suggests that the emphasis on being Jewish has entered her home only after arrival in Israel; yet it can be read as a means to prove her right of immigration:

"We didn't talk about politics, but we did talk, we talked about that is important that we are in Israel, ehm, (...) and (...) that we are happy and that we are well here and that we are here to stay, [...] so maybe that those are my roots, that from there I already developed my opinions.” (Vicky, p. 17)

Katya adds:

"[Back in Russia the atmosphere at home was] maybe less [Zionist], maybe it was less ideological, ehm, to go to Israel because we are Jewish, but (..) it was not the ideology of the 1970s when people fled the SU because they were strong Zionists, but I can ensure you that here [in Israel] I, here, me and mother —ok, grandma, grandma, she was always very anti-, anti-nationalistic, she, she never was connected to Russian, Christian, Jewish, whatever-so [about] the Aliyah I can't tell, but here I altered into being very, very Jewish." (Katya, p. 18)

The narratives reflect a constant reference to the hegemonic discourse of home-coming and Zionism; and Vicky's and Katya's statements have to be understood as a discursive reproduction of this discourse. Both present their lives in Israel after immigration as an adaptation to the "national ethos". By doing so, both prove - in contrast to Boris - to those who have raised those accusations, the invisible audience they talk to here, that they belong.

From that position of belonging, Katya reflects upon the individual reasons of such discriminative behaviour and manages to reconcile her negative past experiences with a present feeling of having moved beyond:

Katya: "Here [in Israel], I was offended when I was called "Russian" because there [in Russia] I always knew I was Jewish (..), that is why here, here it bothered me very much (..) but I have overcome this, too."

Interviewer: "What does that mean, to be 'Russian'? How did you deal with that?" Katya: "How I dealt with that? I was always (.) directly becoming emotional and to explain: 'why do you call me like that, I am Jewish, and my mother is Jewish, and all my family is Jewish, and me, (.) who are you to say that to me', so, I took that very, 
like, very, very (.) emotional, but, ehm (..) - again, that came from kids, usually, that did not come from, from-, well, adults, I was a kid back then".

Interviewer: "Yes, but you also said, your mother either was called 'Russian'?” Katya: "Y_yes, (..) but also, (..) — people who, ehm (.) (laughing) — are less successful in life, suddenly see someone who comes to the country as a stranger (.), who comes to the country and slowly gets along better than those people - which is also very natural [that they] say (.) "he takes my place", that is very natural, that is natural self-defence of people, now I understand that, so, now I don't care about them (..), ehm, (..)indeed, generally, the Aliyah of the 1990s was, was, also helped the country-well, Aliyah always helps, immigrants always help, because they raise the level of the population that already lives - that is not true only (.) from my point of view, I believe it is true also (.) for other countries, not only Israel.” (Katya, p. 23)

Katya's qualification at the end of her quote ("I believe it is true also (.) for other countries, not only Israel") suggests that the experience she tells is in the past ("that came from kids, usually, that did not come from, from-, well, adults, I was a kid back then") and that Katya has developed a way of coping with those experiences. Yet, the story also reveals that the she had not expected confrontation with or questioning of her sense of belonging ("I was offended", "I was always (.) directly becoming emotional [crying?]"). ${ }^{3}$

Both Katya and Vicky connect the experienced confrontation in Israel with personal experiences of anti-Semitism back in the former Soviet Union. They present those experiences as a similar confrontation of not belonging in their narratives. Vicky remembers how she learnt that she was Jewish and what it meant; it is easy to get her sarcasm:

"At home I heard talking that we are Jewish and that we are different. In our class were only two Jewish kids, we had the knowledge that we both were Jewish and that we need to take care of each other, but also the kids in class helped us to know because they told us." (Vicky, p. 11)

Katya describes strategies of hiding her Jewishness:

3 Katya's example confirms that an individual's sense of belonging contains an emotional component; this emotional component will be revisited throughout the interviews. 
"To Judaism we [Katya and her mother] became connected already here [in Israel] (6), ehm, wow, I really—actually not (.) though—wow, that's funny, that's really funny-, when, ehm, my mother had taken the decision that we come here and I already knew that we would leave-I was in school, I was in $1^{\text {st }}$ grade, nine years old, ten-(..) the moment my mother would say something to me (.) on the street (.), ehm, well, 'listen, we leave, you need to, in school you need to do so and so', I would always say to her: 'Mama, schschschsch! Don't talk about that! Schschschsch! Keep that a secret, so no one knows!'. I don't have a clue where that came from, but obviously it came from some built-in fear (..) that it is forbidden to talk about that we are Jewish, forbidden to talk about that because of all that repression - my greatgrandfather, the father of my grandfather, he was in prison from 1937, they released him when Stalin died [in 1953], that is just — what did he sit for? Because they had found a picture in his home, ehm, (..) a picture of [Mikhail Nikolayevich] Tukhachevsky, ${ }^{4}$ that is one of, one of (..) the leaders of (..) - if I remember correctlyof the Whites. A picture, because of a picture you take a human being to prison and you leave a woman with three children at home, why? (.) In private talks, it always came up that one must not talk about that we are Jewish — also our family name does not sound exactly Jewish (.), it does not sound Jewish at all, my father's family name sounds more Jewish, but I added it only here in Israel, ehm (..), so, so, there was such a thing (.) - a nine-year old girl who did not suffer from anything carries an inner fear, which is very sad. I don't want my children to carry the same fear, I don't want them to fear to say they were Jewish, or, Israelis, or, whatever (.) — it's very, very sad (..) at school I didn't tell anyone that we would leave before, before the last week, simply because I was afraid—of what?“ (Katya, p. 22-3)

The children in both families grew up with a feeling of being "different" and not "belonging" that they finally embodied in the form of a particular habitus. Yet, in contrast to findings of previous empirical studies (e.g. Rapoport et al. 2002), those interviewees do not "normalise" their personal experiences with anti-Semitism. Instead, they use the reference to those experiences, not only their own but their families', as an argumentative strategy to claim their right to be in Israel.

4 Tukhachevsky was a marshal of the Red Army and part of Stalin's inner circle until 1937. He was executed in 1937 during Stalin's Great Terror (cf. Harris 2016; Snyder 2010). 


\subsection{ANALYSIS OF DISCURSIVE PRACTICE I: "SABRAS" VS. "RUSSIAN WHORES"}

A minority of interviewees positions themselves as established citizens and looks at the newcomers. Igal's story shall serve as an example here. When I explain to Igal-living in Natserat Illit and waiting to enrol at the local college - I will anonymise his name, he answers directly: "make it an Israeli name, I am Sabra" (Igal, p. 1). ${ }^{5}$ His biographical background differs from the others with regard to personal experiences in the context of migration. Igal neither shares the personal experience of leaving nor that of starting over; his parents had immigrated to Israel already in the mid-1980s, before the Great Aliyah. In his family, the issue of adapting to a new cultural environment was hardly discussed. Igal became interested in his mother's experiences only when she became a member of the Knesset:

"Regarding your question [about Igal's parents], regarding what happened to my mother during Aliyah, at the beginning it didn't interest me, with the time it began to interest me, so I started to ask my mother questions about her Aliyah, how it was, how here, how there, how it can be that a new immigrant-it's possible to say she is an old immigrant of course, but - how it can be that an immigrant is-like, in my head, it dawned on me-when my mother was elected to be a member of the Knesset, I didn't believe it, even when she had been a member of the Knesset for some time I simply was totally shocked, I didn't believe that my mother, the mother that I see at home, that suddenly she has become a member of the Knesset, [although] her Ivrit - there is nothing to do about it, her Ivrit is not smooth, it's a tiny bit bumpy, here and there she makes mistakes-, so how can it be that such a mother suddenly is elected to be a member of the Knesset? Since then I started to ask questions." (Igal, p. 34-5)

Two things are striking in Igal's story. First, he becomes interested in his mother's biography only after she has been successful, after she "suddenly [has been] elected to be a member of Knesset" though, in Igal's eyes, she still is "an immigrant". Those two pieces of experiences - an "immigrant",

5 In Israeli discourse, speakers address someone as a Sabra who-in contrast to recent immigrants - was born in the country in order to make a qualitative distinction between those who have grown up, even partly, in the Diaspora and those who have been raised in the culture of the newHebrew (e.g. Almog 2000). 
an outsider, entering the Parliament, one of Israel's centres of political power - obviously do not match in his view ("I simply was totally shocked"). Second, Igal is not as interested in his father's story because he "has stayed in his position [as a factory worker] ever since his arrival" (Igal, p. 38). Thus, while his mother is a constant reference in his story, Igal mentions his father only towards the end, and only when I ask specifically about him.

Against this background, Igal talks about Israelis with an FSU family background:

"The Russians, the Ukrainians, or all the Soviet Union, they come to Israel for social reasons, for economic reasons, they do not come because of Zionism, that means that Judaism is already not essential, not (...) - 'give me money, give me economic, don't talk to me about a Jewish state, that does not interest me, I don't care about it, don't want to (...) — give me my money, I don't care if we'll have a Prime Minister who is an Arab, my pleasure, the main thing is I'll get my money, that is what I care about.' This hurts us a lot, it hurts the previous Aliyot a lot. [Igal goes on talking about separate TV programmes in Russian], now, I don't say this concerns only Russians, it's also Arabs and everyone, there are TV channels in every language, if there is one, two, three, I don't have a problem with that, but now it's eight, nine-I [i.e. the immigrants] go to a coffee shop, and I don't need to know Ivrit, I simply, there is always someone who speaks Russian, so I can talk in Russian, I don't need to know Ivrit.“ (Igal, p. 25-6)

Igal's demand to speak Ivrit as a means of assimilation stems from his everyday experience. He links his personal experience of an (assumed) lack of proficiency in Ivrit with the argument that using Ivrit in everyday life, i.e. adapting the host society's language/ culture, is the ultimate sign of being a member of the Jewish collective. By adapting a "hegemonic position [(]national, collectivist, Zionist, Israeli, [...] Ashkenazi (European descent), secular, male[)]" in Israeli collective identity (Ram 1999: 335), Igal aims at distancing himself from FSU immigrants of the 1990s and presenting himself as "normal" and, thus, belonging. Correspondingly, Igal refers to the newcomers as "the Russians". Though the term is common in public discourse, it also cuts off those citizens from the Jewish/Israeli collective. In order to show he belongs to that collective, Igal adopts his mother's biography and even speaks from her position ("This hurts us a lot, it hurts the previous Aliyot a lot"). Yet, he is not able to adopt her position 
completely because he lacks knowledge and personal experience of the background of Jewish life in the Soviet Union and the aftermath of its breakdown as well as their process of incorporation. Accordingly, he must admit: "this [the assimilation of FSU immigrants] is the only thing we [Igal and his mother] argue about" (Igal, p. 26). However, later on it becomes clearer why Igal aims at distancing himself from those "Russians" so eagerly:

"When they arrived, there started all kinds of rumours: Russian [girls] are whores, they go to Arabs, and so on. Now, why does this happen? Because in the last waves immigrated gentiles, Russian gentiles, they are not Jewish, now, when they arrive in Israel, and they get connected to an Arab who is Christian, for them this is not problematic, because a Christian Arab and a Christian Russian [girl], this is not a problem, no problem, it's ok. But that Israeli Sabre like me who looks at this from the side, I understand this, but some people don't understand this, they only see a Russian, they immediately generalise him as Russian, it doesn't bother them, Jewish, gentile, they don't care, they see a Russian, now when they see a Russian, they generalise all the Russians, all together." (Igal, p. 28)

Igal tells the incident in the third person as if talking about somebody else. But it is as likely that he speaks about a personal experience where he was "see[n as] a Russian", and, thus, his own sense of belonging, his Jewishness, questioned. The argumentative strategy Igal applies here is twofold: on the one hand, he adopts his mother's biography and places his story in the context of former waves of immigration. In line with public discourse, Igal claims immigrants of these waves had come to Israel for ideological reasons and adopted the "Israeli national ethos". ${ }^{6}$ On the other hand, Igal adopts the public discourse about "Russians" and the stereotypes raised in this discourse, but not without qualification: in order to bridge the gap between discourse and his personal experience of being linked to that social group in everyday life, Igal claims some of the newcomers were "Russian gentiles, they are not Jewish" - adopting here another line of the same discourse questioning the newcomers' Jewishness - and those stereotypes were to be ascribed to them alone. At the same time, however, Igal reproduces the

6 Igal does not use the term otkazniki (e.g. Beizer 2005), however probably because he does not know. It is also not clear whether his parents arrived in this context. 
generalisation of stereotypes he has criticised before ("all the Soviet Union, they come to Israel for social reasons, for economic reasons, they do not come because of Zionism, that means that Judaism is already not essential").

In summary thus far, it is possible to make some general statements about the interviewees' objective position as members of the same social group in Israeli society. Yet, there are a number of individual factors-e.g. age at the time of the interview, place of residence, socialisation, social network, etc., and not to forget the temporal aspect which make it impossible to draw general conclusions about each individual member's objective position in Israeli society and the political field in particular.

Thus, the objective position of the study participants within the Israeli society is a composition of resources true for the social group of FSUimmigrants and resources rooted in individual social action. On the one hand, they, as a collective, have shared the same political and economic citizen's rights and duties as Israeli-born citizens since their arrival but have lacked resources and social status as relatively new citizens. On the other hand, individual social actors have made individual experiences and integrated them into their habitual dispositions and acquired different forms of capital on an individual basis. At the same time, first individual members have acquired the necessary resources, earned that social status due to individual achievements and become part of the Israeli elite in various fields (cf. Glöckner 2011), and as a consequence, the social group as a whole has improved its social status. 



\section{Talking about Civic Engagement: "The Dirty Game of Politics"}

In this chapter, I will show how the interviewees talk about becoming engaged with the Yisra'el Beitenu party.

Enjoying full political rights, I assumed it was unlikely that the interviewees had faced legal barriers - in various empirical studies this is referred to as political opportunity structures (e.g. Fanning/ O'Boyle 2010; Fanning et al. 2010; Bloemraad 2006) - to become engaged; and the interviewees do not mention any legal restrictions either.

However, previous empirical studies on the civic engagement of immigrants show that they need a certain degree of adaptation to the host society in order to have access to culture-specific resources. In this context, de Rooij concludes immigrants become engaged in less -time and cost intensive areas (de Rooij 2012: 459). With regard to the participants in the current study, this does not apply: as listed above, the interviewees engage in a variety of forms of civic engagement, most of them in their spare time. However, with regard to Fanning and O'Boyle's description of a particular "socio-political habitus" (Fanning/ O'Boyle 2010), which is not necessarily related to migration, the interviewees can add their own experience.

The second question is, however, how the interviewees strategically apply their power resources in these stories, i.e. how they present them and for which purpose. Civic engagement takes place within the political field (e.g. Bourdieu 2013), which is close to the field of power and directly subordinate to the latter.

Thus, one may assume that people who are actively engaged with a political party, which, additionally, is legitimised by being part of the 
government, speak about their relation to the execution of power. And the interviewees do, yet, not predominantly speak in terms of personal influence, but with regard to serving a community.

\subsection{ANALYSIS OF POWER RESOURCES II: ROLE MODELS}

The empirical findings presented above already suggest that the participants in the present study have compensated the lack of some forms of power resources - relative to the host society's - at their disposal throughout the length of their stay. However, it also shows that the interviewees as individual members of the social group differ a) in the composition of their resources based on the individual mixture of collectively shared and individual predispositions, experiences and their individual processing, and b) in the emphasis on different aspects.

One of the aspects receiving particular emphasis in this context are individuals, usually in their families, who serve the interviewees as role models. Generally, the family plays a minor role in the narratives. The interviewees speak about their civic engagement in terms of individual achievement. One reason may be that most of them are adults, and have left home for studies or work, and thus there are other people outside the family, peers, who are close to them.

When the interviewees do speak of their family, they usually refer to their home as supportive and involving good relationships with their parents providing a particular atmosphere of trust, respect and support in the family. This atmosphere does not necessarily have to be political, but it usually provides the interviewees with a sense of belonging. Rapoport and LomskyFeder describe a similar relationship between the participants in their study and their parents; the family is also the place where a sense of belonging, in particular the knowledge of being Jewish, is cultivated (Rapoport/ LomskyFeder 2002: 239).

With regard to their civic engagement, most of the interviewees emphasise the support they have received at home. At the same time, some interviewees speak about family members who serve them as role models. The fact that the interviewees bring up family members who serve them as role models for civic engagement is in line with Torney-Purta and Klandl 
Richardson's finding (2004) who show that the way in which political issues are brought up in the core family has a positive impact on the children's or adolescents approach to civic engagement. This is particularly true for the interviewees' grandparents. Both, Avi and Katya, speak of their grandparents as citizens who actively defended the values they believed in, yet in different ways. Avi's grandfather was a writer back in the Soviet Union, and at times censured; he continued writing occasional articles for one of the local Natserat Illit newspapers after his immigration to Israel. Avi describes a close relationship with his grandparents, in particular his grandfather, whom he visited as often as possible after his mother's remarriage (see above). One possible reading of Avi's story is that his grandfather serves as a fathersubstitute for his grandchild. Yet, the important thing for Avi is that his grandfather "raised me in a Zionist mood" (Avi, p. 21), and continues serving as a moral authority in Avi's head:

"Something sits in my head, and this is disturbing me, I tell you the truth, that there is a situation that I will leave this country, like [...] the moment that I already see, ehm, that really is, like, if I had kids, or if I had already, ehm, some economic basis, and I see that this is not, it doesn't move anywhere [...] if my grandfather would hear me now, auwa, 'what, are you crazy?!', he would say, 'what happened? You will stay here, this is the country, this is the country, what happened? If everybody talked like that, what will be? Nobody would stay here!' He is right, so this maybe comes from home, too" (Avi, p. 19).

Katya's grandmother-Katya states the two have many discussions as she also lives close to her granddaughter - is a similar moral guidance. Katya observes similarities of her own life with that of her grandmother's: both share the experience of serving in the military - her grandparents were both partisans (Katya, p. 9) - and being politically interested: "she knew everything about politics, so it was simply impossible, impossible, ehm, even to argue with her" (Katya, p. 12). More than with her mother, Katya talks with her grandmother about these experiences. Interestingly, in this context the reference to the Knesset as one of the centres of political power (see above: Sabras) returns in Katya's story. Katya tells me how "proud" (Katya, p. 12) her grandmother was when she started working there as a parliamentary assistant. The Knesset in her narrative, just like in Igal's, is more than merely a workplace, it is a symbol of power. 
Against this background of success, Katya claims to prefer "Russianspeaking" (Katya, p. 38) over referring to herself as "Russian", adopting the hegemonic discourse just like other interviewees refer to themselves. Her family's history as well as her own achievements so far are for Katya a resource for gaining self-esteem and symbolically preserve her "culture" over completely adapting to the Israeli mainstream. Accordingly, Katya reflects on her sense of belonging:

"[Being Russian is] nothing to be proud of, I, it's, it's, it's a part of me, it's a part of my culture, a part of [what defines] me, I, I can't live-I am not proud of it, because to forget my past is, is, is bad, it means what, what does it say about me, yes my grandmother was, my grandparents were, they were soldiers in the Soviet army, (..), and my mother grew up there, and my father is still there, so what, I'll forget all of this and say 'no, I am not, not Russian, and I want to forget all this?' It's wouldn't be right, and also, also you see that I come from this background, and people also tell me this explicitly: 'one can see that you, that you, that you are Russian', yes, my way to dress, [...] it is a matter of growing up.“ (Katya, p. 5)

This adds another layer together with her argument of being Jewish (see above). Katya's identity of being a "Russian-speaking" Israeli is carefully constructed and reflects a long process of fighting and coping.

In contrast to grandparents who give some of the interviewees a general compass or sense of belonging, politically engaged mothers have a direct impact on their children's political orientation. Two other participants, Igal and Lukas, talk about the influence their mothers' active engagement has on their own activities: both had been recruited by their mothers and helped them organise local activities in the framework of IB. But the interviewees' recruitment was not the starting point, rather do those interviewees reflect on the fact that they have learnt to see the world through their mother's eyes in a long-term socialisation process. As Igal puts it:

"[T]he whole family shares the same political attitude, an attitude which originates of course [...], my mother gave this attitude, my mother planted this attitude into us, now, my mother comes with a certain talk, so we simply continue to talk like this, there is no argument, because we all believe the same way, we can't argue, argue about what, you understand? [But] I love arguments, I get crazy to sit with an Arab and talk with him about the state of Israel: 'to whom does this country belong, to me or to you?', I 
always do that, always - , the thing is that because - , of course, I respect the person that I stand up against him, but because my education is a little bit higher than his, in this specific subject of course, yes, no doubt about that, he has higher education than I do in many subjects, but in this specific subject-, so we start to argue, in the end when I get into some ecstasy, when I get excited, he simply stops talking. Because he doesn't know, he doesn't know, and this is exactly what happens here, educated people know what happened in the world, and they know what happened in this specific country in the course of the year, and these Palestinians that are born now, those children don't know, they simply don't know where they live, they live at war with Israel, so they simply fight Israel, why do they fight Israel, they don't know, they don't have a clue, they are told that the Israelis took the territories from them, this is not true, they don't know that, and they don't care, this is what their mother told them, me on the contrary - if my mother had a different attitude, I - , everybody tells me, 'Igal, you are influenced by your mother', the truth is, yes, I am not ashamed of that." (Igal, p. 25-6)

Igal implies that his mother's strong opinions have not left any room for alternative political views. But his statement also illustrates that he is not interested in hearing alternative political views when he has the opportunity to engage in discussions with people who think differently but is absolutely convinced his mother's opinions are a historical truth he must spread. Igal's conviction can be explained with his positioning in Israeli society: in order to present himself as a Sabra, Igal can adopt the extreme right political discourse in terms of the Israeli-Palestinian conflict he has been instructed in at home.

\subsection{ANALYSIS OF DISCURSIVE PRACTICE II: "IT [...] COME[S] NATURALLY"}

In this section, I will show how the interviewees talk about their motivation to become engaged. In their empirical study on party activists, Bruter and Harrison (2009) identified three different types of activists: moral, social and professional-minded ones. All three of those can be found among the participants in the current study. Yet, some interviewees consider it more important than others to talk about the source of their motivation: a particular community. 
Looking back to the beginning of his engagement, Max, a member of the Knesset for the Yisra'el Beitenu party at the time of the interview, claims it was "natural" for him to become engaged:

Interviewer: "Did you talk about politics at home, with your mother and grandmother?"

Max: "No, there are things that come naturally, there are things that you do not discuss and do not, not (...) - well, my mother, she is a teacher of Russian language and literature, she, she helps me with other issues which on a certain stage I need advice upon in order to decide whether to proceed or not. Why? Because - if a person takes a decision that yes, he is going to run for office, maybe. When decisions are takento help the weak - when decisions are taken — to become engaged with an NGO-I think it is worth it to have some discussion in the family, [whether] 'yes' or 'no'. It [informal engagement] should come naturally - there is spare time, there is time that one can give to support others - it should come from inside a person, not like he is [discusses whether] 'yes' or 'no'. Why? Because you cannot make plans about these things, impossible to say 'I start here and finish there', that is why - it is such a huge change of your life once you start - in the end, yes, it crosses your mind that you spend more and more time - in the beginning it should come naturally, if somebody starts to do that, he should like it, not like he forces himself or feels obliged before someone else. That is how I see it, I do not see anything special in this, something that needs to be discussed at home, to do or not to do - in the beginning at least." (Max, p. 21-2)

The motivational source, as he describes it ("it should come from inside a person"), is not something acquired during one's socialisation process, it is a character trait. Max is striving to present his engagement coming entirely from inside against the background that he has particular qualities, "leader qualities".

But at the same time, he states his motivation to become engaged involves the feeling of moral obligation as a citizen, an internal predisposition which is learnt ("it should [my emphasis] come naturally"). Accordingly, he makes a qualitative distinction between different forms of civic engagement: every citizen should become engaged in their communities, and those who have particular character traits, should start political activities. Expressing the feeling of such a moral obligation involves a more or less abstract social unit towards whom this obligation is felt, and 
indeed, the community is a common reference in the narratives. The community involves different contexts or levels of abstraction. It can be the interviewees' concrete social environment; community in these cases is related to "issues in everyday life" and concrete personal experiences. Some interviewees state their active engagement has been motivated by a pressing issue in their community (cf. Haste/ Hogan 2006). Max and Ben for instance have become engaged in their college student's councils, a rather temporary and random community.

Yet another group of interviewees state they have become politically engaged as a consequence of recent events, i.e. because they were upset because of something in the news (cf. ibid.). In this context, the so-called Gaza flotilla of the summer of 2010 is of particular interest. There were literally dozens of demonstrations to show support to the Israeli Defence Forces (IDF) every weekend in the course of the event. Zeev decided to help organising spontaneous demonstrations on behalf of the IDF in his school. ${ }^{1}$ Zeev states he felt obliged to publicly express solidarity with the IDF and organised pupils' demonstrations on Fridays in his hometown Haifa: "It's important to show support to the IDF, we did well [what we did in Gaza], we are at war with them [i.e. the people in Gaza]" (Zeev, p. 14). Igal adds: "every Israeli wants to support [IDF], every Jewish Israeli" (Igal, p. 15).

Another local event was the discovery that Natserat Illit's mayor was corrupt in 2009. Igal, like Avi a student of media and communication at the nearby Jezreel Valley College, talks about how his mother-the representative of the Yisra'el Beitenu party in the Knesset - took the lead in local demonstrations with him helping her with the organisation. While in the case of demonstrations in Natserat Illit, community occupies a concrete space and people, the city or the city's inhabitants who feel upset about their mayor, pro-IDF demonstrations take place against a rather abstract conception of community. Against the background of these statements, community is directed toward a more abstract sense of belonging, an "imagined community" (Anderson 2006 [1983]). In Zeev's and Igal's cases, this community-"we"-is that of Jews.

1 The IDF is seen as apart from the government, and support for the former is still high (Arian et al. 2010; Ben Meir/ Bagno-Moldavsky 2010) — in contrast to support for the latter (Arian et al. 2010; Ben Meir/ Bagno-Moldavsky 2010). 
Sometimes is the idea of community refers to a specific local context or particular personal encounters; this particularly concerns participants from Natserat Illit. Avi tells me he was upset about what he perceives as social problems the local, in particular immigrant youth in Natserat Illit suffers from. He explains his motivation to become actively engaged with his personal experiences:

"I went through a lot, now I am here, and I said [to myself], I have already grown up from the same processes being 16, 17, and I see that the young people here need, and I speak to you basically about Russians." (Avi, p. 4)

Community in Avi's case then implies an emotional attachment to a certain group based on concrete shared experiences-here: a common migration background. In his case, emotions of grief, frustration and anger cause him to feel responsible. In this context, Avi's story suggests a feeling of social responsibility, a moral obligation to become engaged when facing problems in his community. Yet Avi also emphasises that he wants his engagement clearly understood as community work, not political activities: "I didn't want [to mix my activities with politics] until now, if you like, it's fine" (Avi, p. 11). Katya, on the other hand, states that her community work only started when she began to work for a political representative. She tells me how excited she was when she returned from her job interview, having found out that her potential future position was more than "being a secretary":

"Maybe this sounds like hypocrisy, but, ehm, when I came to the job interview [...], and [the MK] began to tell me about the work, I began to understand that this is not just about being a secretary and not just, ehm, to answer telephone calls, that doing that work I can find other tasks for myself, I drove home and all the way back I couldn't listen to radio nor anything else, I arrived at home, and just said to my mother: 'Mom, I, you don't know how much it is possible to really help people at this work, and you simply don't believe', [...] ehm, it, it, it, it brings such a huge feeling of satisfaction (4), this is not hypocrisy, I really told her this, she was shocked and told me: 'this is what you are thinking about when you want to enter politics?'.“ (Katya, p. 8)

Accordingly, she describes her job as that of a "legal advisor" rather than that of an "assistant" and, consequently, as if she was actually working in a 
legal office, like her father wanted her. Avi's and Katya's community is not the temporary one which Ben refers to. Both show concern about the immigrant community of "Russians"; thus, it symbolises emotional attachment. By referring to her social group and stating that in her job she is able to help, Katya manages to reconcile her own decisions with her father's expectations, and thus to re-establish the good relationship she claims that they have. Furthermore, in order to justify her staying in her current position before him but also before herself, Katya returns to her father's warning but turns it into an argument in favour of her involvement in politics - gaining actual power:

"[Y]ou can actually change something - the moment I say that I am calling from an MK's office [...], [a]nd that is why I chose, right for now, to accept that [being engaged with the Yisra'el Beitenu party], because I also want to learn the rules of the game." (Katya, p. 8)

Katya even risks her good relationship with her father about her political engagement and tells me about the "exhausting argument" with her father: "[A]lways remember that this is politics and that this, simply can, can simply be as not, not, not, not so much white and pure as you may imagine it" (Katya, p. 9). Katya's father, who stayed in Russia after her parents' divorce, warned her about the "dirty game of politics" and at the same time made her understand that he expected her to become a lawyer like himself and Katya's grandparents (Katya, p. 3). Accordingly, the argument is not so much about the specific party but about political activity in general. Scepticism about politics in general and involvement in particular is quite common among post-Soviet citizens, and consequently among the respective immigrants in Israel (Ben Meir/ Bagno-Moldavsky 2010; Arian et al. 2010; Bagno 2009). Katya understands and partly shares her father's concerns about her professional future and a stable income and also that she might "get hurt in the dirty game of politics".

However, in the narrative she emphasises the advantages, i.e. the contribution to her community she will be able to make ("it is possible to really help people at this work"), over possible disadvantages or negative personal outcomes. However, the narrative also reveals an instrumental form of motivation, namely that of making a political career. The line of Katya's argument at that point is also of a strategic nature. In her story about the job 
interview she tells me it was important for her to finally have found a job after a considerable time of unemployment. Katya does not share her parents', here her father's, scepticism about politics but rather looks at the job opportunity pragmatically. Talking about her current position from a backward perspective, she states she would like to "learn the rules of the game" (Katya, p. 4) and therefore meanwhile accepts to work in politics in general and for the Yisra'el Beitenu party in particular.

The game metaphor also occurs in other interviews, in particular when it comes to the resources one needs to play this "game". This can be social connections necessary to enter that "game", i.e. people who function as gatekeepers, but also particular skills like the ability for representation or impression-making on others. 


\section{Serving the Country: "The State of Israel Demands"}

The following chapters deal with the analytical question of how talking about civic engagement with the Yisra'el Beitenu party is discursively framed by patterns of interpretation of Israeli citizenship. In the narratives, the interviewees' construct of Israeli citizenship is based upon certain conditions: the fulfilment of a citizen's duties, namely serving the country and being loyal to the Jewish state grants a citizen rights; and the notion of who a good citizen would be is central. I will show how the interviewees, based on the argument of being a good citizen, position themselves in a dominant position within the Israeli society along the dimensions of duties, participation and identity or, in Bourdieu's words, a sense of belonging. Against the background of the assumption that the social group in power defines who gains legitimate access to the Israeli society in the form of providing or denying Israeli citizenship at a given time, I argue that the interviewees' reading of Israeli citizenship is their strategy to successfully construct such a dominant position. Having said this, the empirical analysis aims at showing how the participants in the study embed their narratives about civic engagement into the broader context of how they present Israeli citizenship and their roles as Israeli citizens, respectively.

The current chapter looks into how the interviewees present Israeli citizenship in general and the dimension of service of the country in particular, and how they embed narratives of their own service of the country into this reading. 


\subsection{ANALYSIS OF HABITUAL DISPOSITIONS I: "YOU GET [WHAT] YOU GIVE"}

In the context of the study, citizenship is understood as the "membership of a political community" (Lister/ Pia 2003: 8), featured by four core dimensions in a particular relationship: (political, cultural, economic) rights, duties, participation, and identity (Delanty 1997: 9). In the narratives, all four of these dimensions can be found and they are presented in a particular relationship. The insight of how the interviewees theorise Israeli citizenship on the one hand and how they construct it as everyday practice on the other hand is essential for understanding how they construct their subjective position within the field of Israeli citizenship and, consequently, within Israeli society. Pinson shows that the Jewish and the Palestinian students in her empirical study construct their understanding of citizenship along various discourses. They employ individualistic approaches which stress the granting of rights to the individual citizen as well as those approaches which rather stress the relationship of a citizen within a particular citizenship space which comes with certain obligations, in particular military service (Pinson 2004: chapter 7). In contrast to Pinson's findings, the participants in the current study construct citizenship first and foremost in terms of perceived obligations: they construct Israeli citizenship around the fulfilment of duties, upon which the individual citizen earns certain rights. Ilan claims:

"So, to say, as much as you give to the state as much you get, like, (...) to me this sounds very logical, right? If you (..) are a citizen who fulfils his duties, you deserve full rights; if not, you deserve part of it, if you don't give anything to the state [...] why will I pay taxes, me, who, why do my military service, do everything, and (..) somebody else will receive social benefits, pension, insurance, and all these things on my money." (Ilan, p. 14)

In other words, a "just distribution of goods", including citizen's rights, in Israeli society should be organised according to an individual's contribution, not according to an individual's needs.

The first dimension of citizen's duties, as presented by the participants in the current study, is that of service of the country. Ilan, the lawyer, puts his argument on a legal basis: 
Interviewer: "[...] Is military service mandatory as well?"

Ilan: "It's the law in the state of Israel!"

Interviewer: "But those who--"

Ilan: "You don't want to serve in the military, like, you have a problem with that [military service], and I understand that some people have a problem with that, like, do national service, serve the country in some other way." (Ilan, p. 15)

The "law" regulating military service in Israel is the National Defence Service Law (1986), but this "law" is not the common argument to join the army in the interviews. Instead, the obligation due to the law is presented as a moral motivation and at the same time as "natural" (Helman 1999: 395). Zemlinskaya describes the link between service, loyalty and citizen's rights in her empirical study on draft resistance: "[i]t [military service] is perceived as an expression of loyalty to the state and as such it defines the hierarchy of belonging to the state" (Zemlinskaya 2008: 12). The interviewees have internalised that public moral discourse about a citizen's obligation to serve and do not question the obligation to join the army. It is usually against their personal experience of military service that service of "all Israeli citizens" is demanded, disregarding the differences in opportunities and approaches of different societal and/ or ethnic groups in the country. Indirectly, Katya claims "every citizen in the state" (here: student) undergoes the same procedure, so everyone "want[s] so badly to serve in the army" (Katya, p. 27). The interviewees just accept it as given to get enlisted after school and not doing military service is usually not considered an option. Some interviewees, however, explain their motivation to serve with their migration background. In this context, Lukas explains why he got enlisted despite his rejection as unfit due to physical health issues:

"It is very important to me to protect this country because we live here, although I was not born here, in my eyes it is very important because this country helped me a lot, like, helped my family, like, helped, helped me to make a place for myself here (.), helped my mother to find work, like, my brother grows up here, I grow up here, grew up here, so, it is very important to me, like.” (Lukas, p. 6)

A further issue in the context of their reading of citizenship is how the interviewees relate their civic engagement and active participation to the other dimensions of duties, rights, and sense of belonging. The interviewees 
distinguish between an abstract understanding of citizenship in terms of citizen's duties, in particular contribution by doing military service and concrete political participation in the form of civic engagement (cf. Pinson 2004). However, participation is presented as not mandatory and thus as subordinate to a citizen's duties: accordingly, in the narratives civic engagement in contrast to the interviewees' military service is not presented as a major issue but serves them rather as a point of departure to present themselves as a good citizen (Ichilov 2004). As will be shown below, the interviewees talk about their civic engagement as something that "happened" rather by chance than something they did consciously and regard as service.

But, not for all of them it is as clearly a citizen's duty to contribute. Emmanuel reflects about the confusing contradiction between the abstract hegemonic discourse of home-coming and directly experienced "hatred" of "Russians", as in the story about his little sister's humiliation. His emotional reaction then displays a feeling of humiliation, and consequently the rejection of the idea of contribution: "look, it's not that I want it too badly because personally I, a country that looks at me strangely, why should I risk my life?" (Emmanuel, p. 29).

\subsection{ANALYSIS OF HABITUAL DISPOSITIONS II: "I WENT THROUGH SOME KIND OF BRAINWASH"}

The interviewees connect the notion of mandatory military service, which they perceive as the most important way of serving their country first and foremost with formal socialisation agents, above all civic education lessons in school. However, in practice those lessons are described as the frontal teaching of slogans rather than discussions about sense and nonsense of having citizen's rights and duties. Katya puts it that way:

"[W]hy did I want so badly to serve in the army? Because - again, this is not because of deep faith in that party or another, it's simply because I felt: 'wow, I have to!' (..) Now why? Because I went through some kind of brainwash (laughing), yes, maybe not in the understanding - not in the negative sense of the word, but yes, when everybody - every citizen in the state has to serve, [...] I simply remember myself in school, $[\ldots]$ the country needs to raise a new generation, the country needs to raise a 
new generation, it needs to prepare them already from a young age, so if this is, if this is to speak about youth organisations, ehm, they talk in slogans, so yes [...], again, I can't tell you to what extent this [talk in slogans] is wanted because we live in that reality (...) and every country does this at the end of the day (laughing), it's not that only we do that [...], obviously, obviously it is wanted by the state, because it has to continue its-it has to continue its erection [...], because if it doesn't raise a new generation, it obviously will not go on to exist, so obviously it is right." (Katya, p. 278)

And Vicky, talking about when she started to consciously think about what it means to be a citizen, adds:

"I became more interested in what is really going on with regard to politics during adolescence because I was in a youth movement called the Zionist youth movement, ehm, there I more considered Zionism and actions that need to be undertaken and afterwards also in the army, ehm, I became more interested in why actually we fight so many (...) wars and what leads to what." (Vicky, p. 16)

Yet Katya presents the moral motivation to "want so badly to serve in the army" as something learnt, externally enforced ("I went through some kind of brainwash"). "Brainwash" carries an alternative interpretation: students are not able, not allowed, not wanted to question the idea of obligatory military service, they are not necessarily convinced of the idea but lack thinking about an alternative. However, Katya hurries to add that it was something she was not forced to learn but did willingly ("brainwash (laughing), yes, maybe not in the understanding - not in the negative sense of the word"), as something a good Israeli citizen internalises — or, as Vicky said, "consider[s] [...] to be undertaken". Generally, the messages sent in formal education contexts are received as rather abstract or far from personal experience-yet at the same time powerful. In this context, other authors refer to the perception of military service as a moral obligation towards their country also described like this by native-born Israelis (e.g. Goldberg 2006; Helman 1999); Kimmerling has coined the phenomenon "civil militarism" which means that "socio-political boundaries of the collectivity are determined and maintained by participation in military service, its manipulation, and sacrifice to support spheres that are classified as 'national security" (Kimmerling 1993: 207). Accordingly, Ilan justifies the 
outstanding role military service plays is due to the fact that it links the perceived obligation directly to the "situation that we are in" (Ilan, p. 15), a situation lacking security. Yet, as will be shown, the interviewees' perception of a lack of security has an impact on how they read citizenship and citizen's rights especially:

"We are not Switzerland, we are not Denmark, [for] people from Germany it might be difficult to get [i.e. to understand], like-Germany, of all countries, for foreigners - like, the situation that we are in, the security guys who stand outside [a building] and check your bag every time you enter and all these things, like, there is nothing [to do about it], it's hard, it's very different from abroad, it's very different from Europe [...] it [serving in the military] is the law in the state of-it's the law in the state of Israel.” (Ilan, p. 16)

Zeev simply states: "we have to contribute, we are Jews, we have to fight, why, I have no clue, [...] we did well [what we did in Gaza], [...] we are at war with them" (Zeev, p. 14). For the establishment of the link between the security situation and military service, civic education lessons play a crucial role in the eyes of the interviewees - as Katya put it, the state needs young people or students to be in line with the official state ideology. In Katya's understanding, "official state ideology" means a nationalist approach to security issues which is justified in her view "because we live in that reality".

Finally, the interviewees can draw on the personal experiences they made during military service. On the one hand, the interviewees refer to personal experiences in the past when talking about their own motivation to serve in the IDF or to become actively engaged in a community or political context. On the other hand, they post-rationalise these personal experiences and refer to them in light of public discourse in order to show what they understand by a good citizen. Similar to civic education lessons, military service is described as a major factor for how young Israelis perceive their everyday life in Israel. Ilan says:

"In Israel [...] young people are generally more conservative, more Zionist, and the older ones vote rather for Avoda [the Labour party], Meretz [a rather liberal party], like, more liberal [...] Again, like, the young generation, which is the generation that serves in the military or has to go to the military or is just after the military or is in reserve duty, ok, they know exactly what is going on in the country, like, they live 
this every day, they are at the university, they see what's going on in the media, they, they are more active, like, older people who work, no idea, at the work place or pensioners, or people from the older generation that usually vote Avoda and so onno idea, maybe they see the things a little different, like, it's their right, I get it." (Ilan, p. 24)

Ilan here connects military service with being "more Zionist", and thus indirectly establishes a direct link between being Zionist, doing military service, and fulfilling one's citizen's duty. Besides, he links being "conservative" with the personal experience of military service-which is not surprising against the background of previous findings about the influence of war on political opinion (e.g. Canan-Sokullu 2012) - , but more importantly with being Zionist as a political opinion ("young people are generally more conservative, more Zionist, and the older ones vote rather for Avoda [the Labour party], Meretz, like, more liberal"). In this context, recent military service is not only presented as a particular filter but as a point of view which is more appropriate than that of older Israelis who do not share that insight knowledge. In Ilan's view, the cleavage between political rightwing and political left-wing is simultaneously a generational cleavage. In Ilan's opinion this is due to the fact that "young people face the political reality during their military service" (Livio 2012), ${ }^{1}$ and (also as a causal effect of their recent service) are more interested in politics while their parents' generation either tend to forget their experiences, make their peace with them or may have other, everyday worries. In sum, political rightwingers, i.e. in Ilan's words those who are "conservative", or, "Zionist", "go to the military or [are] just after the military or [are] in reserve duty", are able to see the political reality because they have insider knowledge.

In contrast to the major role other socialisation agents play for the willingness to join the IDF, family is hardly mentioned in this context. Yet in contrast to findings of previous empirical studies on the issue of military service among FSU immigrants and their children (e.g. Eisikovits 2006), the interviewees do not mention any negative attitudes or talk hesitantly concerning their military service in the family (cf. Eisikovits 2006: 295).

1 More specifically: in border control units, as some of the interviewees point out, e.g. Lukas. 


\subsection{ANALYSIS OF DISCURSIVE PRACTICE III: A MATTER OF SOLIDARITY}

Peled identified three layers of Israeli citizenship: a liberal dimension with regard to the distribution of rights in order to "separate" between Israeli citizens and non-citizens, a Republican one with regard to contribution to the community in order to "legitimise" the existing social hierarchy and an ethno-nationalist dimension in order to "discriminate against" non-Jewish, in particular Palestinian citizens (Peled 2011: 278). Having asked secular and religious as well as Palestinian pupils in the Israeli school system about their understanding of Israeli citizenship, Pinson (2004) can empirically confirm the actual existence of a threefold perception of Israeli citizenship across the three groups (secular Jewish, religious Jewish, and Palestinian citizens). Yet the participants in the current study do not make such a distinction with regard to the citizen's duties of different segments of Israeli society. Instead, they apply the same standard for every segment of Israeli society regardless of their actual legal status. In more detail, they apply a Republican reading of citizenship to all Israeli citizens: citizens are obliged to participate (e.g. Dalton 2008; Lister/ Pia 2003), or-in the words of the interviewees - to serve the country in an equal way.

Accordingly, the interviewees' emphasis on military service of all possibilities to contribute can be read against the background of recent developments in Israeli society with regard to diminishing the absolute value of military service in Israeli society and what Levy calls "the violation of the Republican equation" (Levy 2011: 40). In this context, in the Israeli public discourse, the notion of "mishtamtim" (Livio 2012) has appeared, i.e. individual (Jewish) citizens who dodge their military service for various reasons. However, I argue here that the interviewees do not intend to criticise those Jewish individuals in the first place. This is for two reasons: first, "mishtamtim" are not referred to directly in the narratives. Second, and more importantly, the interviewees constantly construct their line of argument about Israeli citizenship against another segment of Israeli society: Palestinian citizens. However, they do that indirectly. Again, one can take Ilan's narrative as an example. Ilan is preoccupied with his hope for a political career. Above all, he aims at presenting himself as ambitious and successful and making an impression: on me in the direct context of the interview situation on the one hand. On the other hand, Ilan also aims at 
impressing his invisible listeners in the Yisra'el Beitenu party. For this purpose, he talks in much detail about his past and present activities within the framework of the party and outside of it. Besides, Ilan emphasises he has done all those things although, first, "this is not an obligation", and second, in particular not for him since he is physically disadvantaged ("I had a stroke, the physicians didn't believe I'll survive” Ilan, p. 2). Accordingly, he is the one delivering the most elaborate statements about how he understands citizenship. Again, quoting from Ilan's interview:

"[Y]ou have the right to get as much as as you give, that is to say as much as you give to the state, as much you get, like, (.) to me that sounds very logical, right? If you are a citizen who fulfils his obligations, you are entitled to full rights, and if you don't [fulfil your obligations], like, you are not [entitled to full rights] but part of them." (Ilan, p. 13)

And he provides a detailed definition of what serving the country means to him:

Interviewer: "In what way is it possible to serve the country?"

Ilan: "Serve the country? Like a million ways! What does it mean 'to serve'? First of all, start with what you are obliged to do, that's first of all, if you do that, it's already enough."

Interviewer: "What is that in detail?"

Ilan: "Ah, ok, what it means?"

Interviewer: "Aha."

Ilan: "First of all, don't evade taxes, pay taxes like everyone else, go to the armyyou don't want [to go to the] army? Do national service! Ehm, (pause) no idea, if you want [to serve] like just a tiny bit more, donate to some place, to the community that you live in, volunteer somewhere, contribute to your community, where you are, like, this is not an obligation, but it is something that satisfies you- - , when I [studied] in second grade at Tel Aviv University, I volunteered at the [...], at the court, to people who need money, and they come [to the court], and they don't know what they want in life, and they have debts, like, 1,000 NIS, and they are poor, and you (.) help them to fill in the forms and explain to them what to do, hand in the forms, like, (..) - [it's] great satisfaction, like, I, all the time during my studies, all the time- I don't know, all my adult life, I think, I have been volunteering somewhere, ok?” (Ilan, p. 13). 
Ilan puts it straight, service of the country is obligatory - in which form, however, is in his eyes to a certain degree an individual decision. At the same time, his quote implies that there are individuals or segments of Israeli society who do not serve in the military. Yet, unlike Ilan suggests, the National Defence Service Law instructs mandatory military service for Jewish Israelis - making exemptions on individual grounds and giving the possibility of doing National Service instead - but explicitly excludes Palestinian citizens on grounds of security concerns. It is safe to suggest that Ilan, as a lawyer and referring to "the law", is aware that he interprets the regulations on mandatory military service for the sake of his argument. From the quote it has become clear that Ilan knows that those who do not serve in the military cannot be forced to do National Service instead. But, against the background of his own history of civic engagement, Ilan demands some kind of contribution to the "community" from every Israeli citizen and makes the option of alternative service quasi-mandatory. And he utters this demand forcefully; he even directly addresses his imaginary non-serving listener: "you [my emphasis] don't want [to go to the] army? Do national service!".

In this context, Ilan does not explicitly distinguish between Jewish and non-Jewish or Palestinian citizens; yet his wording makes it clear that he has just the latter in mind: Ilan refers to "the law", and to "national service". Besides, by hiding the fact that Palestinian citizens are legally excluded from military service, Ilan implies that those citizens evade their citizen's duty. In other words, he discursively terminates the legal distinction between the Jewish majority and non-Jewish minorities with regard to their duties. Instead, Ilan applies a Republican reading of citizenship to all Israeli citizens, wittingly ignoring that some segments of Israeli society, here in particular Palestinian citizens, have not got any chance of fulfilling this demand. As will be shown below, Ilan is not the only one claiming that the PalestinianIsraeli minority does not fulfil their duties, and service is not the only duty mentioned in this context. It is rather the case that the non-Jewish minority serves the interviewees as the other against whom they can show they fulfil their own duties as Israeli citizens.

It can thus be read as a discursive marker for an "imagined community" (Anderson 2006 [1983]; see also Barth 1969). As outlined above, the concept of community, however random, concrete or abstract, in the narratives implies a moral value demanding the active engagement of those who belong to it. Ilan here connects this sense of belonging to a particular community 
with a particular view of Israeli citizenship as contribution: as it was with civic engagement, contribution is discursively defined as a moral value. Zeev goes even further and adds a scenario of threat to the moral demand: "people who don't serve harm the state, $[\ldots]$ we are Jews, and we have to contribute to the state" (Zeev, p. 11).

The interviewees do not make a direct reference, yet I argue that the presentation of service as regarding all Israeli citizens equally must be read as a reference to one of IB's electoral slogans as well. Picture 1 shows the respective screenshot of the party's online platform. The picture shows someone, obviously a soldier because of the olive-coloured trouser legs and military boots, standing in front of military backpacks.

\section{Picture 1.: “AJust Society Begins With an Equal Society.”}

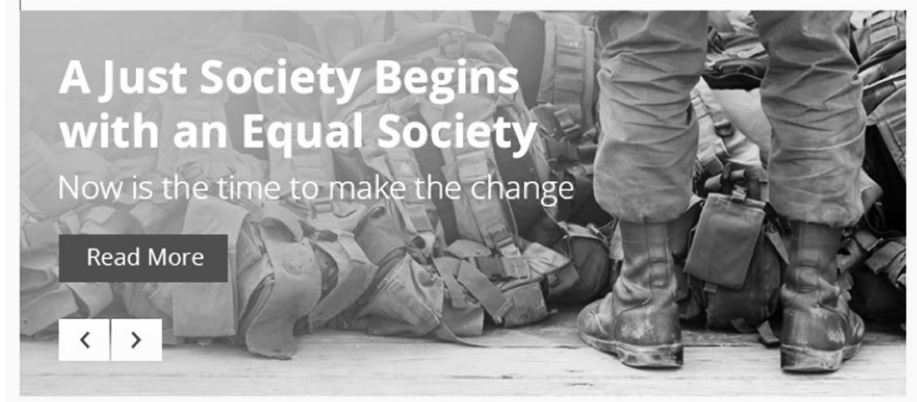

Source: Yisra'el Beitenu Website ${ }^{2}$

Whether that person is male, or female is not clear because one can see only their feet and part of their legs; and this is intentional: in Israel, military service is mandatory for both sexes alike. A slogan reads: "A just society begins with an equal society.". The slogan reflects both the legal discourse of mandatory military service for Jewish Israeli citizens, and the ethnonationalist discourse of military service as a moral obligation of (Jewish) Israeli citizens against the background of a constant threat to security. Yet at the same time the slogan implies that the obligation as well as the legal ruling

2 Partija "Yisra'el Beitenu" (“Our House Israel”). "A Just Society Begins with an Equal Society.” Retrieved from: http://www.beytenu.org/a-just-society-begins -with-an-equal-society/ 
of military service is not limited to the Jewish segments of Israeli society but concerns every Jewish and non-Jewish citizen. It further implies that there are individuals or groups who do not serve and thus do not fulfil their obligation as Israeli citizens; otherwise it would not be necessary to mention the issue in an electoral campaign.

This is exactly how the interviewees argue. Yet it is left open to the potential voter to interpret who is the target group of this campaign. Against the background of the ethno- nationalist roots of that discourse it becomes clear that the target group are non-Jewish segments who do not serve, i.e. Palestinian citizens. Neither the Yisra'el Beitenu party nor the interviewees feel the need to make that explicit any further. 


\section{Loyalty to the Jewish State: "We are [...] a [...] Pitskalle"}

As outlined in chapter 9, the interviewees present serving the state as a fulfilment of one's duties as an Israeli citizen and showing loyalty to the Jewish state as a central issue with regard to citizenship. The repeated emphasis on their perception of the disintegration of Israeli society and its discursive linking to (a lack of) loyalty to the state of Israel is central in the narratives.

The narratives are structured around perceived cleavages and a perceived threat. Gal argues in favour of integrating "the ways in which 'ordinary people associate with citizenship"” (Gal 2011: 215; see. also Joppke 2007: 44) and shows that in the data he used, the respondents clearly link different spheres of rights to different threat perceptions: the perception of economic threat can be linked to the allocation of welfare rights, symbolic threat is connected to the cultural rights dimension and a perceived security threat results in a lower willingness to allocate political rights. In this context, an evaluative hierarchy of threat (Rippl et al. 2007: 111-2) can be derived analytically: on the one hand, perceived cleavages causing an "internal" threat, i.e. within the Jewish segments of Israeli society, connected to symbolic collective values-e.g. as derived from the interviewees' understanding of Zionism - and, caused by the challenge of those values, the existing social hierarchy and the interviewees' objective position within that hierarchy. On the other hand, in the narratives perceived "external" cleavages are presented as posing an existential threat to both individual and collective as well as realistic and symbolic well-being. While nation-wide polls show similar results with regard to the perception of the disintegration 
of whole social groups, the interviews differ from the general picture when it comes to the centrality of the issue of disintegration - in particular the emphasis on a gap between Jewish and Palestinian segments of Israeli society, which has implications on their willingness to allocate rights. This centrality in the narratives can be explained with reference to the political ideology of Lieberman's Yisra'el Beitenu party. In the narratives, this ideological superstructure reinforces a particular processing of personal experiences - in particular on the local level—, which in return serve as an argumentative basis for the reproduction of that ideological superstructure.

Partly, those cleavages are perceived on the basis of concrete personal experiences; in these cases, narratives about cleavages are based on the (factual, emotional, evaluative) description of very concrete encounters the interviewees experienced. As will be shown, in this context, the interviewees find examples and situations from their everyday experience to reconfirm, and, thus, reproduce learned habitual dispositions. Accordingly, there are different contexts against which the interviewees' narratives of threat take place. They cluster around three "argumentative contexts": the context of a perceived disintegration of Israeli (Jewish) society, the larger historicalpolitical context of the Palestinian-Israeli conflict and the situative context of the Gaza flotilla in the summer of 2010.

\subsection{ANALYSIS OF DISCURSIVE PRACTICE IV: "EVERY ISRAELI..."}

The intermingling of current discursive events, (long-term) personal experiences and political dispositions affects the interviewees' view of Palestinian citizens of Israel in particular with regard to their notion of loyalty to the State of Israel. The discursive events (cf. Jäger 2004) the interviewees relate to Iran's former president Ahmadinejad's threat of "wiping Israel off the map", 1 the war against Hisbollah in Lebanon (2006),

1 Glenn Kessler. Did Ahmadinejad really say Israel should be 'wiped off the map'? Washington Post (Online edition), October 5, 2011; Retrieved from: https://www.washingtonpost.com/blogs/fact-checker/post/did-ahmadinejad-really -say-israel-should-be-wiped-off-the-map/2011/10/04/gIQABJIKML_blog.html 
Operation Cast Lead against Hamas in Gaza (2009) or the Gaza flotilla (2010). All four discursive events have been controversially discussed in Israeli public discourse. However, while the first three are against the background of an outer enemy vs. Israel constellation, the last one focuses on an inner enemy, namely Palestinian citizens.

Especially the Gaza flotilla and the subsequent discourse was still so fresh at the time of the interviews I conducted in 2010 that these interviewees made frequent references to it in their narratives. Yet the emphasis the interviewees placed on the reference differs. Igal presents it as a unifying event for the Jewish collective. He claims: "every Israeli wants to support IDF now, the whole world is against us, on the side of the Palestinians, that Turkish Arabs send a flotilla is proof' (Igal, p. 3-4), and uses it as an argument to find proof for his black-and-white dichotomic perception of the world against Israel (e.g. also Lerner, 2010), or what Bar-Tal and Antebi (1992b) refer to as "siege mentality". Zeev and Vicky may share Igal's view on the world around them, but for both of them the discursive event serves as motivation to become active. Vicky says: "sometimes I feel that I want to contribute more" (Vicky, p. 8), and justifies that so far by being a state employee and as such was limited in her political activities, but "actions to strengthen the state allowed" (Vicky, p. 8). Zeev even felt the need to organise such an "action[...] to strengthen the state" and gathers like-minded people at his local school in Haifa to have regular Friday demonstrations to show support to the IDF. He explains his need to show support, stating: "we did well [what we did in Gaza]" (Zeev, p. 14). Zeev does not explicitly speak about who he has in mind with the collective "we" he uses; yet from the context-Zeev speaks about being "at war with them [i.e. the people in Gaza]" (Zeev, p. 14) - the collective "we" can stand for Israelis, Jews or the IDF.

Katya refers to discursive events on another level. She speaks about an argument between herself and her father who stayed in Russia after her parents' divorce, and whom she happened to visit at the time of Operation Cast Lead in Gaza in winter 2008/ 2009. Their argument started against the background of a news report in Russian television about the military operation and Palestinian civilians in Gaza suffering from it. Katya tells me how angry she was with her father for not standing on Israel's side of the story but speaking up against Israeli military actions instead: 
"With my father I did have a serious argument [about politics], actually, actually at the time of Operation Cast Lead, when I visited him for Sylvester [New Year's Eve] (.), he obviously, too, was influenced by some, in some way by all those media reports, and (.) we really had a fight, a real fight, we argued so much that I almost started to cry because (.) he, he simply started to talk in a way that I could not, not, not accept, (..) um: he really started to blame Israel. I took this very hard, I started, I started to get very emotional, and (..) - this was one of the arguments that really, um, I got very angry with my father, and this just does not happen, so I took this very hard, but, um, well, it has been forgotten over time because (..) - again, it's my father, um, arguments about anything connected to internal politics - my father is not involved in what is going on here in Israel, he is only interested in what happens outside, ok, that means, foreign politics.” (Katya, p. 8)

On the personal level, Katya expects her father to agree with her with regard to political events and is upset that this is obviously not the case. She is upset, however, not only because her father "obviously, too, was influenced by some, in some way by all those media reports", but also because it was her father she was having an argument with over an issue that is very important to her and that she is emotionally connected to, and her father does not and cannot share her position. It reveals a feeling of estrangement with a person who is very important to Katya and from whom she seeks advice in important personal matters, and the very fact that she stresses "well, it has been forgotten over time" shows that it is not. However, on the collective level, Katya's quote also implies her concern with Israel's standing in the world and her trust that Israel's government, and in particular the IDF, act morally right (cf. Arian et al. 2010: 91).

\subsection{ANALYSIS OF DISCURSIVE PRACTICE V: "IT HURTS"}

The issue of criticism of official institutions is a very sensitive one for the participants, especially the Israeli Defence Forces (IDF) have a somewhat sacrosanct status among them. In view of discursive events, the interviewees refer to critique of Israel, and in particular its politics towards Palestinians in Gaza and the West Bank as well as military operations. Accordingly, those who criticise one or more of these institutions, are regarded as disloyal. 
However, this perception not only concerns the participants of the present study, IB voters, or Israelis with an FSU family background, but represents a widespread notion in the Israeli (Jewish) public: as Ichilov showed, young (Jewish) Israelis in general perceive a growing threat and increasingly find the use of military power legitimate to reach political goals and they also support anti-democratic tendencies, for example by emphasizing the character of the State of Israel as a Jewish state (Ichilov 2004: 153). Avi states in this regard:

"Israel needs to be bad, I think we need to be bad, [I mean] not to kill, God forbid, blood, God forbid, be bad and say 'you want to blow us up here, you send us a flotilla [the Gaza flotilla raid ]?', just as an example, the latest event, the most current, so, great, no problem, we won't enter with toy pistols, I had shot down the whole ship, like the Russians did over there [i.e. in Chechnya?], let's say, it was these days, that the whole world will hate us, no problem, we will enter, like Ahmadinejad [the then Iranian president, who, according to controversial translation, threatened to wipe Israel off the map, just an example, congratulations, how bad a person is, and this [...], and I hate him because he hates me, and hates us, but I defend [the idea] that we will be bad, because only then they will fear us and leave us alone, there is nothing to do about it." (Avi, p. 14).

This tendency goes on; Zimmermann (2016) states that the notion of what is politically correct to say in Israel nowadays has changed in the way that even the political left agrees that the government or official Israeli politics is no longer to be criticised. In this context, the interviewees are particularly bothered by their incomprehension of what they present as "pro-Hamas demonstrations" in several Palestinian settlements in Upper Galilee taking place in the aftermath of the 2010 Gaza flotilla:

"I saw on TV many demonstrations against [IDF], Israeli Arabs with Palestinian flags, and this hurt me very, very much. Why on earth do Palestinian citizens show solidarity with terrorists who claim to destroy their homeland while in Israel every citizen is supposed to have equal rights and access to various governmental support, only demanding a very basic proclamation of loyalty to it.” (Vicky, p. 19)

Emmanuel adds: 
"Our country is surrounded only by enemies and all say, like, 'we hate Israel and you are goats' and so on (..), Israel cannot do anything about it because they [political leftwing] said 'Stupid, they will annihilate, bomb your busses, but you sit quietly!', and above all, that it works no matter that Iran shouts, Lebanon shouts, they can shout till tomorrow, but there is resistance in this country from within, the Arabs who? I don't talk about those who live in the cities but those who live in the Arab villages, small towns, there are serious and violent protests going on against Israel, there Israeli flags are burnt, and they shout, 'Freedom for Palestine'.” (Emmanuel, p. 22)

When it comes to the perception of threat, Palestinian citizens are explicitly othered in the interviews; all of the interviewees refer to them as "Arabs", "Israeli Arabs", or "Arabs in Israel"; Igal claims in this context: "there is a problem with the Arabs in Israel, they perceive themselves as Palestinians, not as Israelis" (Igal, p. 50). All of these terms disregard the selfunderstanding of the national minority (Waxman 2012; Peled 2007; Rabinowitz 2003), and thus show open misrecognition of particular minority rights. But while the first versions ("Arabs", "Israeli Arabs") leave the interviewees with a lack of understanding; the second term openly excludes Palestinians from belonging to the Israeli reality, and, as a result, Palestinian citizens are presented as a merely tolerated but temporary minority. Igal is aware of the Palestinians' self-understanding, yet on the one hand he ignores it completely and on the other hand, he perceives any identity different from Jewish in dichotomic contradiction to being Israeli. As a consequence, in Igal's view, national minorities are not part of the Israeli $=$ Jewish collective but excluded from it without exception. While not all of the participants argue this strictly, they all draw a symbolic boundary between Jewish and Palestinian citizens.

Having drawn that symbolic boundary between themselves as part of the Jewish collective in Israel and Palestinian citizens, "Arabs", and as such part of the "Arab world", the latter are presented as the ultimate threat to the very existence of Israel and its (Jewish) citizens. In the interviews, the Palestinian demonstrations in Upper Galilee are presented as proof that PalestinianIsraeli citizens do not identify with their Israeli co-citizens but with the Palestinians across the border; as Vicky puts it: "Israeli Arabs with Palestinian flags".

In this context, the interviewees often link passages about a perceived threat with particular: similar to the demonstrations and riots in October 
2000, which left the Israeli-Jewish segments shocked and with a feeling of betrayal (see also Waxman 2012), the interviewees are shocked and feel betrayed by “pro-Hamas demonstrations". Her shock is displayed in Vicky's statement: "[w]hy on earth do Palestinian citizens show solidarity with terrorists who claim to destroy their homeland while in Israel every citizen is supposed to have equal rights"; it reveals both the inability to understand minority demands for particular rights and recognition and the actual misrecognition of these minority rights in her own statement. Instead, she feels betrayed by those who demand those rights. Those demands which had been easy to ignore as long as they were uttered quietly or within the institutional framework, are now perceived as an unexpected and uncontrollable threat to national security; Vicky summarises: "this hurt me very, very much". The inability to understand is also displayed in the interviewees' reactions: they argue for the demand of a loyalty oath for Israeli citizens. Unisono, there are statements throughout the interviews, mirroring Vicky's "[Israel] demand[s] a very basic proclamation of loyalty to it", Igal's "the State asks for a minimum" (p. 1), or, Ilan's "the state demands a minimum [of] loyalty" (Ilan, p. 14).

\section{Picture 2: "No Citizenship Without Allegiance".}

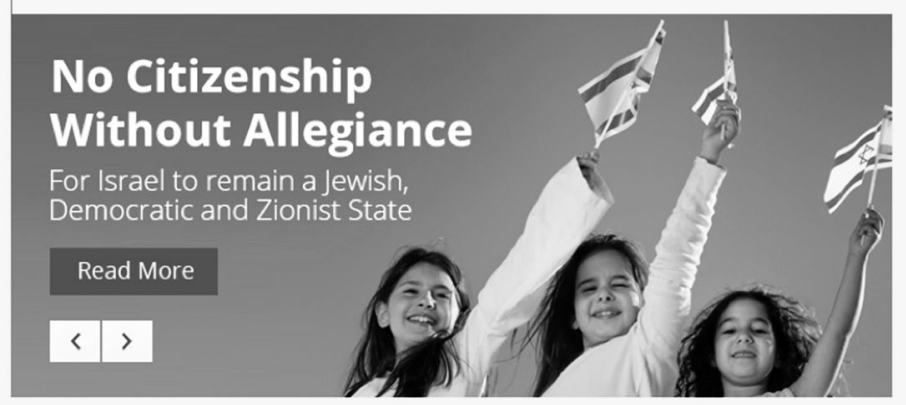

Source: Yisra'el Beitenu Website ${ }^{2}$

2 Partija "Yisra'el Beitenu" ("Our House Israel”). "No Citizenship without Allegiance". Retrieved from: http://www.beytenu.org/no-citizenship-withoutallegiance/ 
As it is the case with the demand for an "equal contribution", the demonstration/ display of loyalty to the Jewish state must be read as a reference to one of the Yisra'el Beitenu party's electoral slogans: "Without allegiance, not citizenship". Even more than the slogan about making an equal contribution, the demand for loyalty echoed in the Israeli public and dominated much of the 2009 electoral campaign for the national elections. Picture 2 shows the respective screenshot of the party's online platform. The picture shows three schoolgirls with long brown hair and dressed in white shirts, waving Israeli flags. The girls smile, in the background nothing but a blue sky. The slogan says: "No citizenship without allegiance"; the subtitle says: "For Israel to remain a Jewish, democratic and Zionist State". The girls-innocent children and not boys who might be bullies-look happy: being loyal is so easy, as if it was some game children play-except that these children do not understand what is at stake in that game: collective deprivation of citizenship for those who do not want to play in the eyes of those who make the rules. It is just as easy for the interviewees to demand "allegiance" - the Hebrew term says "loyalty" (ne'emut); but in contrast to the electoral slogan, they directly address the national minority targeted against the background of personal experiences.

The slogan shows quite frankly how, or, where the Yisra'el Beitenu party positions Palestinian in relation to the very society: outside. IB's loyalty slogan has been harshly criticised as targeting Palestinian citizens and Palestinian citizens only (e.g. Bagno 2011a; Koren 2010); yet at the same time it seems to have found consent in the Jewish segments of Israeli society. This is mainly because of the, at first glaze, rational character of the demand: be loyal, do not harm the state, your homeland that you live in! For most Jewish citizens, this may be a peculiar civic duty since it is such a self-evident one. However, in this context the demand for Israel to remain a "Zionist State" is rather to stress that the Yisra'el Beitenu party is in line with the Zionist values of the State and aims at attracting voters who have had doubt in that. Avi directly links both issues, threat perception as the cause and the loyalty oath as the presented solution He directly addresses Palestinians ("you") as the imagined listeners, throwing his incomprehension and anger at them. However, he is also confused:

"[W]hy do you go towards terror, like why do you go 'Let's do damage' to your state, 'No loyalty', like Lieberman says, 'No loyalty, no citizenship', this is his slogan, but 
the $[\ldots]$ he is right, actually in this he is right, as much as he is corrupt and everything, as much as I don't believe in in this person, but this is true, because from my point of view the same people who throw stones and everything, afterwards I go to eat Shawarma at their place. It's a pity because a people needs a culture, because a people [...] I don't even know how to distinguish, right, it's difficult to distinguish between Jewish and Israeli, there is some [...], you know, sometimes it is asked, asked on, I see it on TV, let's say, someone is interviewed, like we are doing right now, only that's on TV, how do you feel? Do you feel more like Jewish or Israeli? What is this question? Is this something different? In my opinion, it is not something different, and it's not, not important whether you are Jewish or not, you live in Israel, you accept Israeli values? What does this mean? Are you for peace, first of all, with the help of God, if not peace, so at least for the Israelis, you already live in Israel, you serve the country, in the army, you served in the army? From my point of view, you are Israeli, you didn't serve in the army, but you as a person accept the values of [...], what was it? Like, patriotism, some love to the state of Israel, this is what I think." (Avi, p. 21)

Avi's quote displays his hesitation to decide clearly that IB's slogan is the legitimate way, and he appeals to "Israeli values" which he presents not necessarily as "Jewish" but negotiable. After all, Avi's hesitation is rather the exception in the interviews. 



\section{Palestinians as Quasi Non-Citizens: "They Will Stab me in the Back"}

In the previous chapter, I outlined that the interviewees emphasise an existential threat. Based on these findings, I will look at the presentation of threat, in particular the interviewees' presentation of Palestinians as a threat in more detail. In the narratives, this presentation is not limited to Palestinian-Israeli citizens but broadened in two directions: Jews vs. Palestinians (citizens and non-citizens) on the one hand, and "Western" societies vs. "Islamisation" on the other hand. In other words, Palestinians are presented as an existential threat on three levels: on the national level as "disloyal citizens", on the regional level as "members" of the Hamasinternationally recognised as a terror organisation - , and on the global level as "Islamist Muslim immigrants" in Western democracies, including Israel. Throughout the interviews, Palestinians are considered part of "the Muslim world" (Ilan); and on each of the three levels, different stereotypes about Muslims are employed.

\subsection{ANALYSIS OF DISCURSIVE PRACTICE VI: "PEOPLE FROM THE VILLAGE"}

Throughout the interviews, Palestinian citizens are hardly directly presented as a theme. Instead, they are the invisible other against whom the interviewees construct their reading of citizenship, or, rather citizen's duties, as was shown in the previous chapters. Accordingly, talking about Palestinians takes place in dichotomic terms of "them" vs. "us" (Weinblum/ 
Iglesias 2013): non-Jewish, non-contributing, disloyal segments of Israeli society vs. Jewish, contributing, loyal citizens. As shown above, in this context Palestinians appear most probably when it comes to the current state of the Israeli (Jewish) society, its perceived disintegration, the discursive events in the aftermath of (probable) military operations and matters of national security. A very simple explanation for the non-existence of Palestinian citizens in the narratives is that this is a direct reflection of the interviewees' everyday life and their lack of contact with Palestinian Israelis.

However, depending on their personal experiences, and above all, locality, the interviewees stress different levels. The particular locality of Natserat Illit (Hebr.: "Upper Nazareth") serves as a counter-example to the non-existence of Palestinian citizens in the narratives. Natserat Illit was founded in the 1950s as a development town in Upper Galilee at the geographical and socio-economic periphery of the country. Rabinowitz (2003) states, as a Jewish settlement uphill the Christian-Palestinian town, it was consciously put [geographically] above Natserat Tachtit (Hebr.: "Lower Nazareth") alongside other Jewish settlements in order to preserve the Jewish character of the region. Inhabitants of the city do not talk about too little everyday contact with their Palestinian neighbours but negative everyday encounters instead. Vicky, a public servant who has lived in Natserat Illit since her family's immigration, introduces "the problem with Arabs" (Vicky, p. 12) with a declaration of love toward her home town: "I love this city, [...] I belong here, $[. .$.$] it makes me sad" (Vicky, p. 12). In the narratives, the very$ presence of Palestinian citizens or "Arabs" is discursively connected to different social developments which the interviewees perceive and present as problematic and who, more precisely, are presented as their main cause. The interviewees speak about it in the context of the city's location at the geographical, economic and political periphery of the country and a resulting lack of economic resources of the city's inhabitants. Avi, who is engaged with a local NGO to fight social problems of "Russian youth" in the city, describes an intermingling of social problems connected to the migration background of many of the city's inhabitants (cf. also Remennick 2010; 2003). Against the background of personal experiences - his stepfather beat him up when he was still living at home, and a close friend committed suicide because, according to Avi (p. 6), he was desperate about his economic situation living in Natserat Illit-Avi claims: 
"It's not just me who grew up like this, there are many young people who grew up like this, simply they, they are used to misery, so nobody cares because they all grew up like this." (Avi, p. 11)

Vicky adds another aspect: "young people don't always have the money to buy a flat, (...) Arabs do, [...] it makes me sad, [...] I came from Russia in order to live with Jews" (Vicky, p. 13-4).

However, the socio-economic dimension of the "problem" is only the surface of the arguments here. Vicky complains Palestinians from the neighbouring settlements and Nazareth would strategically buy houses in the city young Jewish couples cannot afford. By doing so, in Vicky's eyes, Palestinians "break an unwritten law"; and this "unwritten law", according to Vicky, states that Natserat Illit is Jewish and does not allow Palestinian inhabitants. Jewish inhabitants, according to Vicky, would not even consider moving to Nazareth to live in an "Arab" town, or, as Vicky puts it: "I came here to live among Jews" (Vicky, p. 14). Interestingly, Vicky does not nearly as vigorously claim territory beyond the Green Line of 1967 as "Palestinian", or-at least- "not Jewish" territory, e.g. in parts of East Jerusalem where Jewish families are reported to strategically buy or build houses in order to "free those areas from Arabs" (Lis/ Levinson, 2011). So, the actual "problem" Vicky describes here is the very presence of Palestinians in a territory she considers Jewish ("I came from Russia in order to live with Jews").

Avi argues along similar lines but does so in a much subtler way. He expresses his special concerns about female minors, in particular from FSU immigrant families, being seduced — whether he means sexually abused is not clear-by "people from the village":

"I [...], so to speak in my neighbourhood I see girls, basically Russians, like, immigrants, from the FSU, who, ehm, hang out with Arabs who come from the villages, with a BMW, like, a silvery one, and open windows, without a roof, they [the girls] get on the car, jump into the car, and this is not ok, girls aged 16, aged 14,

1 Jonathan Lis and Chaim Levinson. Top Israeli Officials Set to Inaugurate Jewish Neighborhood in East Jerusalem. Haaretz (English Edition), 25.05.2011. Retrieved from: http://www.haaretz.com/top-israeli-officials-set-to-inaugurate -jewish-neighborhood-in-east-jerusalem-1.363898 
little ones, I am not used to this, and terrific, they haven't got a good education at home, obviously, or something here is inadequate in their heads or [...] it's not ok, we have a law that minors mustn't do that.“(Avi, p. 10-1).

Avi's concern must be seen against the background of growing media coverage of the issue of intermarriage between non-Jewish female immigrants from the FSU with Christian- Palestinian citizens. These intermarriages were referred to as a rather problematic way of immigrant adaptation (Raijman/ Pinsky, 2011). Avi positions his argument against the background of "law", but at the same time he acknowledges that his problem with the phenomenon is on another level ("I am not used to this"); Igal mentions the phenomenon as well, yet he explains it more straightforwardly: "[there is] a problem with Russian whores and Christian Arabs" (Igal, p. 28).

Notions of Palestinian Israelis, as derived from the narratives, carry elements of cultural racism. Avi euphemistically calls those who in his opinion cause social problems "[people] from the villages" in Upper Galilee, in contrast to himself who lives in the Jewish city of Natserat Illit. "village people" carry the connotation of people with a low intellect, ${ }^{2}$ however, the connotation is neither new nor specific for FSU immigrants. In this regard, the interviewees are certain they are in line with the Israeli nationalist discourse about the Palestinian minority. These stereotypes can be traced in Israel's political culture (Rabinowitz 2002), however, here they become reinforced by personal experiences. Rabinowitz shows in an investigation of early anthropological studies in Israel that even back then Palestinians were referred to as uncivilized. Yet, the stereotyping of Muslim minorities or rather non-white minorities also fits the (post-) Soviet notion, as Shumsky (2004) shows in his analysis about the construction of the superiority of Russian culture. Avi even links the others to dirt, a common feature of cultural racism which aims at constructing cultural superiority based on the dichotomy between civilized and uncivilized. Empirically, this phenomenon has been described, e.g. with regard to Pakistani and Indian immigrants in the UK (Nowicka/ Krzyzowski, 2016). Those same "[people] from the villages", the others Avi refers to, would come to the city and destroy the

2 On the stereotyping of villagers as people of lower intellect or "incompetent" (Fiske et al. 2002). 
public park - not local (Jewish) inhabitants who care for their community, one may add:

"Once there was a water fountain, today there are only drug addicts and garbage everywhere, everyday come all kind of people from the villages, drug addicts, alcoholics, it's a mess over there, it's dirty everywhere.” (Avi, p. 7).

As shown above, similar stereotypes are applied in the narratives when the interviewees speak of personal encounters with Mizrahim. The difference between the stereotyping of Mizrahim and the stereotyping of Palestinians is that with regard to the former one can observe a process, and, as a consequence, a change: the longer the interviewees live in the country, i.e. the more frequent and direct personal encounters are, the less do the interviewees apply collective negative stereotypes, but reflect upon the respective encounters. With regard to Palestinians, there is no such process. Wagner and his colleagues (e.g. Pettigrew et al. 2011; Zick et al. 2008; Wagner et al. 2003) claim that intergroup contact would diminish negative stereotypes toward the out-group and have overall positive outcomes. They do not go into detail, however, about the specific nature of intergroup contact (cf. Pettigrew et al. 2011). In Natserat Illit, everyday-still indirect, though - encounters between Palestinians and Jews are deeply impacted by mistrust, as the examples show, and those encounters, together with events on the national and international level, reproduce mistrust; as Avi states: "people from the village, they will stab me like a sheep" (Avi, p. 13). Consequently, Palestinian citizens are othered as a group which threatens the Jewish inhabitants', and, as a consequence, also the Jewish collective's economic and cultural existence. They are presented as a symbolic threat against which (Jewish) Israelis must defend their "group boundaries" (Barth 1969).

\subsection{ANALYSIS OF DISCURSIVE PRACTICE VII: "PALESTINIANS = HAMAS"}

Katya carefully avoids speaking about internal or foreign affairs; she prefers to talk about her work as a parliamentary assistant. When she feels she comes too close to political opinions, she interrupts her speech and states: "I don't 
want to talk about it" (Katya, p. 31, p. 32). Yet at times she feels the need to make a statement. Katya comes to talk about "the people who are on the other side", and means Palestinian non-citizens, while speaking about how much she agrees with the Yisra'el Beitenu party's ideology with regard to foreign politics:

"[We need] to demonstrate to outside that we are not wimps, and not, not, not, not only peace talks - in the end - which means, yes, yes, one does need to show muscles sometimes, peace talks are very important, right, but, ehm, (4), but not only. There is, there is something that I don't really, ehm, love, but, ehm, (..), friends, ehm, friends simply, ehm, many tell me: 'what is possible to achieve with a good word and a pistol is much more than [what is possible to achieve] only with a good word.' It's - there is-it's simply a translation from English, yes, something like that, so yes, a good word, and also (...), and also — not only a good word - and also, and also you can't ignore that, because the moment you see your friends go, ehm, go, ehm, to fight, if, there in the North [the Lebanon war in 2006] or the South [the Gaza war in 2009], and you don't know whether they'll return, and you don't know what's going on there, and you receive SMS messages, ehm, 'I am going to be not available [on the phone], ehm, I don't know, I don't know for how long, so don't miss me, and don't think that I-like, I am simply not available', what am I supposed to feel, what — am I supposed to feel love for the people who are on the other side of, of, of the border? Really not, really not, so, because of this it's very easy for me to connect to that [part of the party's ideology], with regard to internal affairs I don't know, I don't know, internal affairs, that's already, ehm, there are already many aspects.” (Katya, p. 7)

Katya tells her story against the background of several wars and military operations in the years prior to her interview; she directly refers to the Lebanon War against Hisbollah in 2006, and the Gaza War (Operation Cast Lead) in 2009. She tells a story of emotional involvement-it is about a close friend in reserve duty who was sent to the Lebanese border at the very beginning of the war in 2006-and will refer to it as an argumentative basis throughout her interview. Lukas tells a similar story; he tells me how he was interested in that his friends who already serve share those experiences with him. Yet, as his statement shows, he does not only receive information and satisfy his curiosity but also becomes emotionally involved, stumbling, fearing for the lives of those friends when they get wounded in a military operation: 
"I have several friends [who are already doing their military service], like, one of them serves as, like (..), ehm, nu, (..), he watches over the airplanes, repairs them and, like, checks if everything works, and there is one, let's say, in a fighting unit, he goes to the [occupied] territories and to the border control, [...], they talk about what they are going through, like, what they experienced, [...] and also my aunt was in the army, and she told me about the border controls that — when she was there - about the things that happened, like, once they had - there was an attack when she was standing there and she was wounded at the shoulder, she, like, talked about this when we came to visit her." (Lukas, p. 16)

In both Katya's and Lukas's narratives, Palestinians exist only indirectly: citizens as an abstract group with whom they have not got any real contact ("them", "there are Arabs in Israel", p. 31) and non-citizens as the "people who are on the other side of the border". The fact that Palestinian noncitizens are the others who cause Katya to part with her friends-an emotional act — because they represent a threat to national security obviously make it easier for her to "demonstrate to outside that we are not wimps".

Halperin et al. show in their study that this "fear" is a negative emotion, moderated through the perception of threat, plays a major role in the maintenance of negative attitudes toward individuals and social groups, constructed as others, They find that "exclusionist political attitudes [...], [i.e.] the opposition to the granting of civil and political rights to residents and immigrant minority groups [in the Israeli context, above all, Palestinian citizens]" (Halperin et al. 2009: 998) increases after traumatic events like terror attacks. Those attitudes function as a "psychological resource gain" and they help the respondents to "cope with [...] [their] life" (Halperin et al. 2009: 1008). The two examples outlined above confirm the findings of Halperin et al.. Besides, they show that negative emotions can also be triggered not only by the actual event but also by the memory of that event: both Katya and Lukas talk about incidents that occurred in the past; those they worried about have already returned and are out of danger. However, both of them have embodied the past experience of a threat in the form of an emotional, bodily, reaction into their dispositional repertoires and now, while talking about the experience, they look at the events through the lens of their embodied dispositions.

Several authors emphasize the emotional or affective aspect that ideology can create, in particular emotions of love (toward one's own group) 
and hate (toward a perceived other) (e.g. Ahmed 2004; Bar-Tal 2001; Zuckermann 1999; Dowse/ Hughes 1986). Besides, emotions as collective memory or "cultural codes", are conceptualised as an integral aspect of a society's political culture (Gavriely-Nuri 2012): For the Israeli political culture this is particularly true with regard to perceived conflict or existential threat (Bar-Tal/ Antebi 1992a: 634). In their suggestion of how to conceptualise national identity, David and Bar-Tal emphasize the importance of the emotional dimension of belonging to a collective (David/ Bar-Tal, 2009: 360), of feeling attached (Ahmed 2004: 28). Ahmed stresses the link between "constant [collective] history" (and collective memorisation) and "personal [in this aspect also bodily] perception" of social interaction with perceived "others" (Ahmed 2004: 32). She starts her analysis of emotions, love of the in-group and hatred toward outsiders from the definition that "emotions are what move us" (Ahmed 2004: 27). Gold conceptualises emotions as culturally constructed and thus socially shared, yet internal states mediating an individual's "sense of belonging" (Gold 2015: 114-5). In her case study on the emotional dimension of the IsraeliPalestinian conflict, she shows that both sides employ means of triggering negative emotions like humiliation (Gold 2015: 117-8).

The interviewees speak about many emotions. Above all, they make the relationship between Jews and Palestinians emotional and they themselves are emotionally involved in that relationship. With regard to Palestinians, the interviewees speak in terms of negative emotions of betrayal and fear; this is in line with the previous findings outlined above. The interviewees also speak of love, however, interestingly, not (only) with regard to a particular "in-group" - to speak in socio-psychological terms - but "love of the land of Israel". This is a phrase which mainly appears in the context of talking about Zionist values, yet the interviewees stress "love of the land of Israel" differently. Most interviewees use it to stress that IB is a "Zionist party" (e.g. Ilan, p. 24) and in direct reference to Zionism, namely as one of its principles, as Max outlines: "repatriation, love of the land of Israel, security" (Max, p. 10). Avi prefers to translate it into "patriotism", because he is hesitant about Zionist values: when talking about his civic engagement for the local immigrant youth in Natserat Illit, he mentions that he recently co-founded a

"Facebook group 'Young Zionist of Natserat Illit', but 'Zionist' I would like to be erased, I am not (...) - I don't think it's something good, ok, but anyway I learn[ed?] 
about it in school, it's not that is an idea, that is a great idea, I don't support it that much.” (Avi, p. 7)

Katya, in turn, connects "love of the land of Israel" to nationalism:

"I am a nationalist somehow, I also don't want—sure, this is right necessarily because I basically love - what is a nationalist basically? I love my country very much, I love my people very much.” (Katya, p. 31)

Based on what has been outlined regarding emotions, Katya here talks about Palestinians on two levels: on the (material) level of personal experiencewhich contains emotional experience of fear, love and yearning - she states "[we need] to demonstrate to outside that we are not wimps", and agrees with IB's ideology of demonstrating strength (cf. Bar-Tal 2001). The tone of Katya's argument is persuasive: she builds it around a you-story ("you don't know whether they'll return, and you don't know what's going on there, and you receive SMS messages"), appealing to her listeners' imagination and expecting them to put themselves into her position and thus appealing to their sympathy and compassion. The personal story about her friend leaving for war makes it even more emotional and appealing.

On the (discursive) level of argument, however, Katya is more hesitant and seeks confirmation with her friends who tell her about the word and the pistol. ${ }^{3}$ She shows the same hesitation with regard to internal affairs, i.e. how to deal with Palestinian citizens ("with regard to internal affairs I don't know, I don't know, internal affairs, that's already, ehm, there are already many aspects"); I assume here Katya talks as a lawyer, not a lay citizen.

However, I argue that Katya's goal of telling the story about her friend leaving for war is not only to appeal to her listeners' compassion but to present a justification of "showing strength". While at first glance arguing for a peaceful co-existence, Katya indirectly equals Palestinian non-citizens with the Islamist terror organisation Hamas in Gaza. Reflecting about where she stands politically, Katya says:

3 "[W] hat is possible to achieve with a good word and a pistol is much more than [what is possible to achieve] only with a good word“" (see above). 
"I am a nationalist somehow, I also don't want—sure, this is right necessarily because I basically love - what is a nationalist basically? I love my country very much, I love my people very much, about my (.) religion I can't tell, because I am not (..) particularly religious (..). That doesn't mean that I don't accept someone who (.), who is different, who is from another country, absolutely not! But I am, ehm, I am proud of what I am. So, yes, it is possible to consider me a nationalist, that's, that's how I see it."

Interviewer: "But can you accept someone who is different in your country or are you such a nationalist that you say: 'our country is ours and not for somebody else!'?"

Katya: "Good question (laughs)! Basically, the fact that we live (.), two people live here, there are Arabs in Israel (..), and basically, they also want peace, just as we do. I live - that is very, that is, that is, that is strange because (.) - let's say I live on this side of the street and (.) there is a house where Arab live and (.) - us and them and (..) - there is a particular family that runs a shop and we always do our shopping there, so (.) - why, why should I say this country belongs to me alone or it does not (.) if in the end we all want peace? I (.) don't want to bring up here my political standpoint, I don't want, I (.) don't want-whether-I don't want to say whether I am in favour, ehm, a state (.) for Jews alone, or whether I am in favour, ehm, of accepting others, I don't even want to start this [discussion] because basically what is important is that there will be, will be calmness, peace in this region already, it is enough already, it is enough, we fought here (..) about what? We need to find a way to live, find a way to live somehow - if we, we can't - they can't throw us into the sea, we can't throw them into the sea, this will just not happen, this just must not happen, so one needs, we do need to live side by side. If - we don't have a choice so we have to do this, we have to get along (4), I don't have anything else, I don't want to say (..) - yes, I do love my country, I am a nationalist somehow, I (...) — how far, how far I really, ehm, (..) identify (4) - that is simply, that is simply not right to say that I, I am ready (...) I don't, don't know-I am starting now an inner (.) dispute between me and myself, and I don't want to because, because it is simply not right (..) - we need to, need to live in peace between the people of one state, between the people of half the state and, and the people and half the state and the second people, or simply as one people (..)let the politicians find a solution, and I (..), and we must learn (.) to live-there is simply no choice - the politicians will fasten [something, i.e. find a solution] (laughs)." (Katya, p. 31-2)

Katya directly refers to slogans Hamas used as anti-Israeli propaganda ("they can't throw us into the sea"). But instead of making the source of this 
propaganda clear, a terror organisation, Katya presents it as a fact that "they", "people who are on the other side of the border", even Palestinians in general, would agree upon.

\subsection{ANALYSIS OF DISCURSIVE PRACTICE VIII: TWO SIDES OF THE SAME COIN}

In the context of presenting Palestinians as terrorists, Ilan finally connects Palestinians to a broader perception of threat: "Islamisation" of Western democracies, which he sees Israel a part of. The presentation of an existential threat combined with the lack of recognition of what Israel does to defend moral values serve as the basis to disqualify any external, particularly "European" critique of Israeli (foreign) policy as unqualified; Here, Ilan directly addresses his warning to me as a visitor from Germany, or, Europe in general:

"[W]e are not Switzerland, we are not Denmark, people in Germany, maybe for them it is a little hard to catch, like, why Germany of all, from abroad, like, the situation we are in, and the policemen who are outside and check your bag every time, and, like, these things, like-in the United States this, like, now has begun a little to do this in this direction because of the terror that is there, it will also come to Europe, I promise to you that it will also come to Europe, I am also sure that in a little while it will come to France, to England, because there they have much Islamisation and, like- not, not Muslims, that's not an evil thing, but extremists, which is an evil thing, like, like there is extremism in every place, I believe that the extremists also - there is Nature Karta, I don't know if you know them or not, extremist ultra-orthodox, which is an evil thing, too, all extremism is an evil thing, so, we in this state, like, there is nothing you can do about it, we have to defend ourselves somehow, contribute, like, more than other people." (Ilan, p. 16)

Ilan repeats his justification for self-defence against the threat of Islamisation when talking about Israel's role in the region, yet downplaying the country's active part in the regional conflicts of the past:

"We [Israel] are a little different, we are such a small pitskalle [Yidd., tiny leftover], we want to survive, we don't want to do anybody wrong, not right, leave us alone, we 
need to defend ourselves more than other-, there are sixty Muslim states around us, and they are not exactly our best friends." (Ilan, p. 24)

In this quote, Ilan does not even mention that there are also Palestinian, Christian and "Muslim", citizens living in Israel. In his adaptation of the ethno-nationalist discourse of the Jewish State, but assumingly also in his personal experience, those citizens simply do not exist. However, he adds a qualification, condemning all kinds of extremism, including Jewish (religious) forms. Thus, in Ilan's eyes, it is not only, but mainly Muslim extremism against which Israel has to defend itself. Ilan's presents a connection of how he perceives existential threat at present with former threatening experiences; in this context he mentions in the informal part of the interview that he and his parents had suffered from those incidents back in Ukraine. Thus, Ilan constructs a double- or even triple-perception of being othered in his story: first as a Jew, second as a Russian-speaking Israeli, and third as an Israeli or "Westerner" in general. Against the background of his personal experience, he presents Palestinians, "Muslims" as the others who threaten him and his State. Against the background of the collective (Jewish) experience of threat, Ilan is finally able to belong. 


\section{The Claim of Citizen's Rights: "I Came Here to Live Among Jews"}

This chapter deals with the presentation of IB. Above all, I will look at how the interviewees establish a notion of the Yisra'el Beitenu party as the political power that speaks plainly with respect to the "real problems" of Israeli society and is able to offer an alternative political path. In this context, the Yisra'el Beitenu party is presented as being in line with the Zionist discourse. Besides, I will analyse how the interviewees present the party's political leader, Lieberman, and other people important to them. They do so constantly referring to the public discourse, and thus actively reproducing and modifying that discourse. Negative images are consequently replaced with positive counter-images and justified with special knowledge which is based on an alleged insider perspective. However, the interviewees hardly discuss the party's ideological programme. When they do so, they refer to slogans which have circulated in Israeli public discourse, above all the party's recent election campaign slogans that have already been described in the respective chapters about contribution and loyalty.

\subsection{ANALYSIS OF DISCURSIVE PRACTICE IX: "ZIONIST VALUES"}

Zionism is a common frame in the narratives, but not all the interviewees place their understanding of citizenship explicitly in this context. Vicky's example is one of how motivation to serve is linked in the narratives with a 
particular interpretation of Israeli citizenship and the role Zionism as a particular form of nationalism plays in it:

"I became more interested in what is really going on with regard to politics during adolescence because I was in a youth movement called the ,Zionist youth movement', ehm, there I more considered Zionism and actions that need to be undertaken, and afterwards also in the army, ehm, I became more interested in why actually we fight so many (...) wars and what leads to what." (Vicky, p. 16)

In narratives where civic engagement is linked to citizenship in a causal nexus, Zionism is presented as one of the main pillars of Israeli citizenship. In this context, it is striking that its content is hardly elaborated but is presented as shared knowledge and thus does not require any further explanation. Another way of reading this argument is that the interviewees simply do not know how to fill the term; it is used to cover and to explain everything and nothing. The most "detailed" definition of what Zionism comes from Max, one of the members of the Knesset the Yisra'el Beitenu party had at the time of the interview with him. Max makes the statement in the context of describing the Yisra'el Beitenu party as a "Zionist party" and states that "[Zionism] consists of three basic principles: 'repatriation, love of the land of Israel, security"' (Max, p. 10). This view is very much in line with the state ideology.

However, in most cases the interviewees struggle to explain how they understand it. Ilan, for example, tries to explain what Zionism is when talking about why young people vote IB and only refers to official party slogans:

"In Israel [...] young people are generally more conservative, more Zionist, and the older ones vote rather for Avoda [the Labour party], Meretz, like, more liberal- [...]. Again, like, the young generation, which is the generation that serves in the military or has to go to the military or is just after the military or is in reserve duty, ok, they know exactly what is going on in the country, like, they live this every day, they are at the university, they see what's going on in the media, they, they are more active, like, older people who work, no idea, at the work place or pensioners, or people from the older generation that usually vote Avoda and so on-no idea, maybe they see the things a little different, like, it's their right, I get it, simply, the young generation, like, those who are in reserve duty—ehm, again, those who - no idea, are more involved 
in social life, (pause), ehm, they see the situation in Israel as - (pause) in a way similar or the same as the party [Yisra'el Beitenu] simply says, like, and it speaks to them more likely, in my opinion at least, and it's not only the party, you also have to talk about the [party] leader, Avigdor Lieberman, right—we talked about this, the Zionism of the party, the nationalism of the party, the patriotism, all these things." (Ilan, p. 245)

Ilan's statement can be taken as a template for what the interviewees understand by Zionism, i.e. the version that the Yisra'el Beitenu party presents in its programme: "patriotism" or "love the country" (Max), and "nationalism" or the presentation of the State of Israel as a Jewish State in line with the ethno-nationalist discourse.

\subsection{ANALYSIS OF POWER RESOURCES III: AN IDEOLOGICAL MATCH}

An important aspect of the interviewees' notion of the political party is what can be called a socialisation into the party, i.e. the process of adopting a political ideology with time spent. Katya describes an ideological match of her own world view and the party's official ideology, in particular with regard to foreign affairs, and experiences a similar process of socialisation into the party the longer she works with them so closely.

However, one can also find attempts to emphasise that one is still a selfreflexive and critical individual being, despite being employed by the party's Knesset faction. Katya claims to maintain a distance with regard to ideology, stating that she keeps her "real convictions" to herself because they are private, and they must not interfere with her work. At the same time, it should be of no interest to her employers what her personal convictions are as long as "my opinions should not interfere with my work" (Katya, p. 16f, p. 40), "I am not obliged to accept the ideologies, [...] I am not a representative" (Katya, p. 40). To stress her independent thinking, she emphasises the strategic reasons for her involvement with the party and implies her perception of a need for justification. This is reinforced by her main argument that she first and foremost wants to help people in need-against which ideological background this is done is of secondary interest: 
"[Y]ou can actually change something - the moment I say that I am calling from an MK's office [...], [a]nd that is why I chose, right for now, to accept that [being engaged with the Yisra'el Beitenu party], because I also want to learn the rules of the game." (Katya, p. 8)

Accordingly, she stresses that she also works according to her profession as a lawyer, but against the background of actually having the power to change things: "I simply want to go into a law and check where, where it is possible to change it the way I want it to work" (Katya, p. 3). From a backward perspective, the argument of "learning the rules" can be read as a post-hoc justification to herself and others for staying in her current position: once she gets the opportunity to "actually change something" through her political engagement, her engagement with the Yisra'el Beitenu party is justified. To underline this interpretation, Katya claims she had no prior interest in current politics: "I didn't know the MK [members of the Knesset] at all, not according to their name, neither to their faces, only, ehm, only the basic(s) [differences] between them" (Katya, p. 2). In this context, Katya is also downplaying the importance of an ideological match between her own political convictions and the party's ideological programme: "Yachimovich from Avoda [the Israeli Labour Party] is too socialist [..], although she is a very smart woman" (Katya, p. 6-7).

The importance of a commonly shared cultural capital, however, is a minor issue and Katya is one of the few who, alongside with Ilan, makes it an issue. But she also mentions regarding a single, in her eyes funny incident when all members of a Knesset committee realised they could switch to the Russian language because they were all "Russians". Above all, she makes it an issue in order to explain that she does not get along with her colleague, an Israeli-born: "maybe, again, maybe simply because we were not, (..), we did not come from that cultural background" (Katya, p. 21).

In contrast, Ilan speaks about the fear of losing the asset of cultural capital. Interestingly, he is the only one of the participants who talks entirely from a personal angle. He clearly chooses his ambitions to start a political career as the main topic of his narrative. 


\section{Key story: "The fortune teller"}

Ilan starts by telling me about his dream of "becoming someone big":

"Ehm, when I was four, really little, a fortune teller came, do you know what a fortune teller is, like, however, enters the hairdresser's, ok, where my mother was working, there were some other twenty people, and she entered, passed all of them, everyone, everyone, everyone, approached of all people some - she was a gipsy, a gipsy, like that, gipsy, like, some authentic, she came to my mother and said, like, 'I want to, I want, like, to read, like, your hand, tell you the future about everything.' Ehm, like, for free, for nothing, simply wanted to read her hand. (Pause) all right, (pause), ehm, my mother said 'alright, gladly, what, like, great', and she [the fortune teller] started to tell her, like, 'you are three souls in the family' (..) which is right, 'you have a child', she said, right, 'the child is sick at the moment', like, I was four, I had something, bronchitis, no idea what, I was sick, she was right, she said 'you won't live in this flat any longer', [...] 'you won't live in this flat, and afterwards you won't live in this country', which was, like, long before the borders opened and everything, this was something very, like, unrealistic, weird, it's, like, she said some other things, too, of which everything was right or came true, like, that's it, and, like, there was one sentence, I don't know, that she said, like, about when I will be grown up, then, I don't know, my mother, my father behaved toward me apparently then accordingly, I don't know, my grandfather, my grandmother, doesn't matter, like, I am the only child, [...] she [the fortune teller] said that 'your son will become a great man', she said, (pause) that's it, from that moment on I grew up in the way that my mother always believed that I (pause) will become a great man.” (Ilan, p. 17-8)

Ilan's mother was foretold two decisive moments in their family's life: emigration and the chosenness of their son. While the first event is rather concrete ("you won't live in this flat, and afterwards you won't live in this country"), the second, the one which concerns their son's far future ("I was four"), is rather blurry. The story has without doubt been retold in the family many times and in Ilan's interview the "prophecy" carries a mystic element. As the only child of the family, Ilan may have been treated "accordingly", in terms of expectations of his parents toward him, which were above his own toward himself. Ilan presents himself as ambitious; yet him creating this impression can as well be read as a way to cover the stress connected to those high expectations to "become a great man", to succeed and not to fail. Ilan's aspiration for a successful political career can be read in the light of 
Bourdieu's concept of habitus the embodied belief in his fate is inscribed into how he presents his expectations for the future:

"I am a very ambitious person, (pause) a maximalist, I am not sure whether this is the right word, but ambitious, that's for sure! Everything I do, I want to do it in the(pause) everything, what I do, I want to reach (pause) and to tend to reach the first place, like, [...] so to speak, with regard to the highest achievement, so, you can imagine, what is the first place from the political point of view, where I incline to, and what from the point of view of economics, like-I am simply afraid to speak out things that will sound-, like, it is a little childish from my point of view to say it now, because the Lord knows what will be." (Ilan, p. 12)

Ilan presents himself as someone who knows exactly what it takes to achieve a certain goal, in his case: to make a political career; in particular, he presents gaining (high) education as a chance to be better off than his parents and to make the prophecy come true. Again, Ilan demonstrates his ambitions: he tells me that in the eighth grade, he changed his local public high school for a prestigious boarding school "for gifted children" (Ilan, p. 2); he takes a special bus to get there every day. ${ }^{1}$ In contrast to the expectations Ilan has about his future, he admits that he has entered the political field by chance and that he has not got a clear strategy how to do that; he gives a post-hoc rationalisation for his interest in politics instead:

"[...] [T] he ability to have influence on your life, on the life of the people who are close to you, on, ehm, on life and on, (pause) the state in general, to design it (..) the way you think (..) that it is more right, your 'I believe', like, that's how I at least personally - maybe it's too pretentious, I believe that I know how to do it in a much better way, like, I don't know if the best way, but much better than it is today for sure, there are many things to improve, like, basically the power you have, like - I want power, power to change things to the better, ok, to the better for my friends, for my friends, for everyone, ok, like, this is very simple that there are two central powers in the world, and in Israel in particular, this is politics and economics, ok, which in my

1 The school's website says (in its Russian version) that immigrants of the "Great Aliyah" revitalised the system of special schools' villages in Israel, and with this also the school at hand. Either way, they stress that one of the school's goals is to support pupils who really want to learn. 
opinion-like, now to start a business I didn't have any priority or any preference what do first or how to do what, nor did I have a built plan that I do a), afterwards b), afterwards c), I do, like, no-I know more or less the direction, ehm, it's like a car, like you drive a car, ok, and you have headlamps, and you know you that you want to go from A to B, (pause) they light you 100 meters, and so you drive 100 meters, and then you see, like, something new, another turn, another crossing, and when I get there I see, like, what is more right, I look, like, really, like how it l-logical, I can arrange something." (Ilan, p. 11-2)

Ilan is insecure about how to behave correctly in a new and unfamiliar field, and moreover a field of activity he did not explicitly choose, but which opened a door to him "by chance". However, he presents his attempt to be successful in the field as if it was his destiny, and yet he lacks the necessary resources. Ilan's story must be read against the background of his parents' process of adaptation in Israel. Ilan's family arrived in Israel in 1992, at the beginning of the "Great Aliyah" from Ukraine. He only tells me two things about his parents: first, that his parents "were without high education" (Ilan, p. 1), and second, because they lacked high education "it was difficult for them to integrate in terms of work" (Ilan, p. 1):

"My parents live in [a development town in the south], (..) ehm, (..), my parents are, ehm, (...), that's just it, without high education, OK, they are not, not - usually people who arrived from Russia were physicians, engineers, (.), people with a high status that came to Israel, and for them it was, that's how it is, the absorption was difficult with regard to work, and everything, so my parents, like, for them (..) the absorption was relatively difficult, but, like, my parents, they-like, my father was a plumber over there, and my mother was a hairdresser, and they started to do manual work." (Ilan, p. 1)

In contrast to Ilan, none of the other interviewees even mention their parents' education. Ilan might be embarrassed by his parents' lack of secondary education who in his eyes differ from the "people who came from Russia [who] were physicians, engineers, people with very high status", (cf. also Glöckner 2011). This goes along with him repeating that his parents cannot advise him because they lack appropriate education. Let alone the circumstances of choosing that school, which cannot be reconstructed in the interview, to achieve (higher) education has an important function for Ilan: 
it allows him to distinguish himself from his parents, to prove that he is part of the "Great Aliyah" and thus belongs.

On the other hand, Ilan presents himself as experiencing disadvantages because of his migration background for strategic reasons. First of all, he applies the definition of the International Organisation of Migration (IOM) of who an immigrant is, a very technical definition which he emphasises does not fit: "I am not an immigrant, who is? The IOM says "people who have lived for five years in the country"" (Ilan, p. 20). Ilan speaks of difficulties to enter certain circles of power because the "ruling elite is not your elite" (Ilan, p. 23); he considers himself as part of an elite, yet the interesting and tricky question is: part of which elite. Consequently, Ilan presents the Yisra'el Beitenu party as a "niche for Russian-speaking political newcomers like me [to learn the business of politics]" (Ilan, p. 14). However, he admits that it is not the common way to start a political career right at the top but at the local level, e.g. in "student cells of parties who form the future elite" (Ilan, p. 22). Yet Ilan concedes: “only you don't have connections” (Ilan, p. 22).

However, he presents his engagement with the Yisra'el Beitenu party as a decision based on an ideological match and he emphasises that the decisive ideological component for him is the party's pursuit of "Zionism". To emphasise the importance of the issue to him even more, he tells me about his previous engagement:

"Ehm, I am a research associate at the Institute for Zionist Strategies, (..) ehm, who provide position papers on all kinds of issues, things, meet at some forums with judges of the Supreme Court, with politicians and these things." (Ilan 9)

Summarising the story about his engagement with the party, Ilan thinks aloud about whether he could also have become engaged with another political party and states that his engagement with the Yisra'el Beitenu party is very much related to his recruitment by a party representative he had met by chance on another occasion:

"It depends, like, maybe Likud yes, Meretz, I don't—, I believe that not, yes, a party (..) — again, Zionism, like, in my understanding, ehm, (..) - I couldn't fit, simply, for example, I exaggerate, into a party, no idea, an Arab party or again Meretz, no idea, but Likud, Kadima, no idea, like, there is a little difference, but I believe it also 
depends, and it's, like, let's say, since I have been with the party, so, I undergo such a kind of socialisation, and the longer I am with the party, that's how it is, my opinions get more in line with the line of the party, like, either that I know better the basis of [the] party, and so I-basically the more I identify with it, by and by, I think, for now this is fine, if I would co-like, but generally, like, to the very party, relatively, I'd say, that I have come to it by chance (.), like, I don't know.” (Ilan, p. 9-10)

In contrast to Ilan, who presents himself as marginalised, most interviewees perceive their own position as quite close to the political centre, both in terms of ideology and power. This is mirrored by them referring to public discourse as a confirmation, as Igal does: "many think that way" (Igal, p. 3). Accordingly, they aim at proving the political party they are engaged with is - against claims in public discourse - in line with Israeli political culture. IB is presented not only as in line with the Zionist discourse by the interviewees, but also as the natural political choice of young Israelis, as Ilan explains:

"In Israel [...] young people are generally more conservative, more Zionist, and the older ones vote rather for Avoda [the Labour party], Meretz, like, more liberal [...] Again, like, the young generation, which is the generation that serves in the military or has to go to the military or is just after the military or is in reserve duty, ok, they know exactly what is going on in the country, like, they live this every day, they are at the university, they see what's going on in the media, they, they are more active, like, older people who work, no idea, at the work place or pensioners, or people from the older generation that usually vote Avoda and so on - no idea, maybe they see the things a little different, like, it's their right, I get it." (Ilan, p. 24)

Accordingly, Ilan is confused when I tell him I understood-maybe wanted to understand in the context of the study - "extremist" (קצוני) instead of "conservative" (שמרוני) and categorically denies this. Instead, he regards this "conservati[sm]" as absolutely in line with what is publicly wanted and allowed. 


\subsection{ANALYSIS OF DISCURSIVE PRACTICE X: CATCHY SLOGANS}

As it is with Zionism, so it is with IB's ideological programme: though the interviewees talk at length about their engagement with the party, they hardly talk about the party's political programme or concrete political acts. By and large, the interviewees know the technical procedures of political activity much better than the party's ideology, in general the interviewees only know the electoral slogans about service and loyalty. However, there is a difference in the notion of and reference to the ideology of the Yisra'el Beitenu party, depending on the position of the interviewee regarding the party's "ideological centre". Interviewees at the periphery (e.g. Avi, Katya) are more reflective than those who are closer to core party figures (e.g. Igal) or are one themselves (Max). Particularly the narratives of those at the "periphery" mirror an inner dispute about these official ideological slogans, namely on two occasions: on the one hand when the interviewees talk about concrete experiences that they feel made or currently make them reflect their political viewpoint, on the other hand when they are directly asked in the interview situation to justify a certain ideological position.

Katya's narrative shall serve as an example for a certain indecision between claiming an ideological match and hesitating. While talking about foreign affairs, Katya first states "I agree with the party's ideology very much". At the same time, she feels the need to explain to me-here as a person not residing in Israel permanently and thus assumingly not knowing the conditions of everyday life in Israel-why she agrees with those "extremist" and "nationalist" (Katya, p. 27) views and refers to the "current reality" as the context of her argument in order to justify it. She tells me the story of a close friend she used to date and who sent her a text message from his mobile phone while he was on the way to the Northern border:

"[We need] to demonstrate to outside that we are not wimps, and not, not, not, not only peace talks, in the end, which means, yes, yes, one does need to show muscles sometimes, peace talks are very important, right, but, ehm, (4), but not only, there is, there is sth. that I don't really, ehm, love, but, ehm, (..), friends, ehm, friends simply, ehm, many tell me: "what is possible to achieve with a good word and a pistol is much more than only with a good word', it's, there is, it's simply a translation from English, yes, something like that, so yes, a good word, and also (...), and also, not only a good 
word, and also, and also you can't ignore that, because the moment you see your friends go, ehm, go, ehm, to fight, im—, there in the North or the South, and you don't know whether they'll return, and you don't know what's going on there, and you receive SMS messages, ehm, 'I am going to be not available [on the phone], ehm, I don't know, I don't know for how long, so don't miss me, and don't think that I, like, I am simply not available', what am I supposed to feel, what, am I supposed to feel love for the people who are on the other side of, of, of the border, really not, really not, so, because of this it's very easy for me to connect to that [part of the party's ideology], with regard to internal affairs I don't know, I don't know, internal affairs, that's already, ehm, there are already many aspects." (Katya, p. 7)

Katya is more sceptical about the methods employed by the party to gain votes, especially of younger voters and returns to speaking of a "brainwash" (Katya, p. 27) when turning to young people, and misusing fact that "young people [still] learn to evaluate". Against the background of family memory, she hesitates to employ those methods:

"I simply remember myself in school, I, I, I know that going into details (..), we were not up to it at all, (..) young people get the slogans, yes, now, to what extent this is right, to what extent this is right with regard to - from the point of view of the party it surely is right, because it brings her a new electorate, to what extent this is right with regard to, ehm (..), how is it called, ehm, to what extent this is wanted that the party does it, I don't know, (4) it depends, again, we talk about the state level, if, ehm, if the country, country - the country needs to raise a new generation, the country needs to raise a new generation, it needs to prepare them already from a young age, so if this is, if this is to speak about youth organisations, ehm, they talk in slogans, so yes [...], again, I can't tell you to what extent this is wanted because we live in that reality (...) and every country does this at the end of the day (laughing), it's not that only we do that $[\ldots]$, obviously, obviously it is wanted by the state, because it has to continue its - it has to continue its erection [...], because if it doesn't raise a new generation, it obviously will not go on to exist, so obviously it is right, [...] to what extent it is right to raise them [the new generation]? (5) I don't know, also? don't know, don't know, it's very hard for me to come to a certain opinion (2), maybe, maybe it's right, maybe it's not right, ehm, I simply, I simply remember how, ehm, how, ehm, my grandmother was at her time brainwashed, that? (4) my grandfather especially, he (2), he believed in Stalin so much, it's simply unbelievable, (2) my 
grandmother also believed in him, that is simply, that is simply, that is the way that I think it is not wanted." (Katya, p. 27-9).

One can even feel her hesitation when one reads the quote through the marks for pauses in her speech. Katya becomes hesitant when thinking about IB's methods to catch (young) voters through slogans:

"Because of that [i.e. young people's inclination to extremism] our party can also allow itself to play with young people than with? because it's very easy to carry [them] away with extremist opinions, extremist opinions are generally more-, "sexier", more attractive." (Katya, p. 27).

Yet I argue, against the background of her employment with "our party", Katya feels she needs to add two important qualifications: first, she refers to "other countries" to emphasise that Israel is not special in this regard, but quite "normal". Second, she adds that there are moral boundaries concerning the extent to which the slogans to educate or "brainwash" adolescents are used and refers to family memories to express her doubts in the method:

"The question is to what extent we use it, if we use it in order to raise them [the new generation], in order to develop them-yes, but, ehm, if they go afterwards and-(..), disgrace a mosque or a synagoge, or draw, ehm, (..) all kinds of things that are not wanted on the walls, or (..) - it's not, and there is no need to do that either, [...] to what extent it is right to raise them [the new generation] - (5) I don't know, alsodon't know, don't know-, it's very hard for me to come to a certain opinion (2), maybe, maybe it's right, maybe it's not right, ehm, I simply, I simply remember how, ehm, how, ehm, my grandmother was at her time brainwashed, that-(4) my grandfather especially, he (2), he believed in Stalin so much, it's simply unbelievable, (2) my grandmother also believed in him, that is simply, that is simply, that is the way that I think it is not wanted." (Katya, p. 28-9).

As argued above, at the same time she stresses her loyalty to her employer, refusing to talk about her doubts about the party's means to reach political goals, stating "my political opinions should not interfere with my work". Yet at the same time she does not want to openly condemn the party; she wraps this uneasiness into the trust in the adolescents' moral development instead. This is the easiest way out: to ignore one's personal doubts. In order to stress 
her loyalty, she also emphasises there are particular situations which allow to ignore those "moral boundaries", and directly refers to the "current reality" as the context of the need to use simple slogans in order to catch votes and gain political power.

\subsection{ANALYSIS OF DISCURSIVE PRACTICE XI: "PAPA LIEBERMAN"}

The interviewees speak at large about the party's founder and current leader, Lieber- man-partly because they are asked how they see him by the interviewer, but mainly because some of the interviewees claim to have a personal relationship with him. As will be shown, this claim can be interpreted as serving the goal of constructing a counter-image of Lieberman's to the one which is perceived by the interviewees as dominant in the public discourse. However, there are other people in the party, too, presented as important persons to the interviewees, depending on their individual experiences with IB.

Three main images of Lieberman can be analytically derived from the narratives: Lieberman as a non-fascist, Lieberman as a political leader, and Lieberman as "papa". The interviewees present these images in contrast to the public discourse about the Yisra'el Beitenu party in their narrativesGutwein $^{2}$ (2009) for example describes the Yisra'el Beitenu party as rightwing populist and compares it to - at that time still a new phenomenon"hate parties" of European style like Haider's FPÖ, Le Pen's Front National or Wilder's Partij voor de Vrijheid-and actively contribute to the construction of a counter-image. Personal encounters matter, and usually those encounters are much more important than ideological agreement (cf. Smith/ Zipp 1983); people vote IB because they know the candidates personally, ideology is of minor importance.

The discursive image of the Yisra'el Beitenu party and its political leader, Lieberman, the interviewees construct in their narratives, is very much impacted by their personal encounters. In this context, Lieberman as a

2 Daniel Gutwein. How the left elevated Lieberman. Haaretz (English Edition), 2009. Retrieved from: http://www.haaretz.com/print-edition/features/howthe-left-elevated-lieberman-1.269990 
person is often described as friendly, attentive or charismatic, showing leader qualities.

Katya's argument shall serve as an example.Katya speaks about Lieberman when speaking about her agreement with the party's ideology on issues of foreign affairs. In this context, she gives the following answer to the interviewer's question about whether Lieberman is a "fascist":

"He wants to show that he is an extremist, maybe because of that [people say he is a fascist], but (2), I don't know, (2) fascist? He is extremist, but fascist? He is not, I know him personally! Ok, this is because I am now a part of his party, although (..) also, as an equivalent, I don't, don't see a fascist in him, I also-, now I also know, I got to know him personally from personal talking, he is far from that [being a fascist]." (Katya, p. 29)

She realises that her first, and very emotional response to this image is "because I am now a part of his party"; in this context, she is personally involved and feels attacked. Upon, second thoughts, however, Katya thinks about the meaning of fascism and finally justifies Lieberman's political views and actions: "rather people misunderstand him, he loves his country very much" (Katya, p. 30).

In many of the narratives a blurred or distorted notion of Lieberman appears, very much impacted by personal flattery:

"I also, now I also know, I got to know him personally from personal talking, he is far from that [being a fascist], there are things that I don't connect with, but his way of talking, his way of behaving is, it is very clear to me, it is very, ehm, (..) it's very natural for me." (Katya, p. 29)

As Katya finally states: "he talks to us" (Katya, p. 30), acknowledging that Lieberman, disregarding party-internal hierarchies, treats everyone equally. Igal also claims to know him personally from kitchen talks at home and even refers to Lieberman as "papa" (Igal, p. 11). In a similar vein, he states Lieberman's trustworthiness:

"He [Lieberman] talks the naked truth, he plans big things, I convinced many of my friends to vote for him, now they come and complain, saying 'Igal, he hasn't achieved 
anything of what he promised', so I tell them 'it's not his fault, he is bound to a coalition, it's the state of the political system in Israel'." (Igal, p. 11)

\subsection{ANALYSIS OF DISCURSIVE PRACTICE XII: "IT WAS CHEMISTRY"}

\section{Key story: Hamad the Druze}

As mentioned above, Ilan presents his narrative based on his need for recognition of his attempts at being successful. This need for recognition is also reflected in Ilan's story about his current involvement with the Yisra'el Beitenu party. Ilan tells me about the "very good work relations" with the MK he is working for, Hamad Am'ar, a Druze. He makes an effort to illustrate their relationship as special and very close, he shows his loyalty and gratitude. This quote might be understood better as part of the stories about Ilan's disappointment with his status within and his treatment by "the party". Working for Am'ar, he is still a bit of an outsider, but the Druze Am'ar is, too, and he, Am'ar, "knows to appraise your work" (Ilan, p. 15). Ilan's relationship with the party is rather hierarchic, while that with his boss is characterised by co-operation and (mutual) recognition. In this regard, Ilan presents their relationship as a process of fraternisation and solidarity among ethnic minorities, here Druze and Russian-speaking Israelis, against the "ruling elite" (see above: key story "the fortune teller"). ${ }^{3}$ Ilan expresses solidarity with people in a similar marginal position but he does so rather for strategic reasons since it allows him to stress the of the fact that he himself feels being marginalised (see above: fortune teller). Ilan defends a Druze MK among the IB people as if there had been an internal argument about Am'ar's right to represent Druze Israelis in the name of IB: "it's like-, (...) he is more Yisra'el Beitenu than other people [who are with] the Yisra'el Beitenu party, ok?!” (Ilan, p. 7). To strengthen his argument, Ilan lists Am'ar's contributions to his own (Druze) community and thus to the Israeli society in general:

3 In the context of this statement, the "ruling elite" includes IB's inner circle people, too. 
"He is a disabled veteran, served in the army, was injured, contributes to the state (pause), founded a youth movement, he leads the Druze youth movement, 8-, approximately, 12,000 people, kids, he helps them very much, in every regard [...] he contributes 'mountains' to the state, and I think very few people, like, at all, in the Knesset and so (pause) did so much for the sake of, I don't know, for the sake of the people, for the sake of the rest of the State, this is what I think." (Ilan 14)

Still, Ilan may have his difficulties with this solidarity: to describe how marginal Druze people in the Israeli society are in his view, he tells me the story about how he drove to his job interview in Am'ar's home town and that it was so far north that he was afraid his GPS would not find the place (Ilan, p. 8), while he literally puts himself and his own hometown, Ashdod, into the country's centre.

\subsection{ANALYSIS OF DISCURSIVE PRACTICE XIII: "SECOND-CLASS CITIZENS"}

In contrast to the two dimensions conditioning Israeli citizenship in the eyes of the interviewees - contribution and loyalty - the interviewees leave the issue of citizen's rights out almost entirely. Yet, as was shown in the previous chapters, the interviewees construct their reading of Israeli citizenship completely against the background of an ethno-nationalist discourse of belonging to the Jewish collective and apply the presentation of Palestinians as the other as a discursive strategy: the Palestinians again serve as the others against which the interviewees discursively construct their notion of good citizens. On grounds of an ethno-nationalist discourse, the interviewees present the argument of conditional citizen's rights as if it had a rational and "very logical" (Ilan, p. 13) basis - even more so since neither the Yisra'el Beitenu party nor the interviewees directly attack a particular social group but claim all Israeli citizens to be equal: those who do not fulfil their obligations as citizens, do not earn citizen's rights. In order to stress this argument, the interviewees frequently disturb the non-Jewish minorities in Israel and their different statutes with regard to citizen's duties. Having in mind that Druze and Bedouin citizens do serve in the IDF and besides are relatively silent and the legal option of doing national service for those who 
do not serve for whatever reasons, the interviewees can claim equal duties for all citizens.

However, a closer look shows that the interviewees argue against the background of adopting a particular reading of Israeli citizenship: the ethnonationalist reading of the State of Israel as a Jewish state. Non-Jewish minorities who contribute and show loyalty to the Jewish state, i.e. remain silent, are tolerated. I further argue that Jewish segments who do not contribute or are not loyal in the eyes of the interviewees, in turn, are tolerated because of their belonging to the Jewish people. This way they are able to present Palestinian citizens as the only part of Israeli society which does not contribute and is not loyal and in addition imposes an existential threat upon that society. The rational consequence in the interviewees' opinion is to deprive those segments of Israeli society who do not contribute of their basic citizen's rights. The interviewees do not openly express this conclusion, but there are hints between the lines of what they say. The interviewees connect the perception of threat with the discourse of loyalty as an argumentative basis to legitimise their questioning of the right of citizenship for Palestinian Israelis. Loyalty, in the interviewees' interpretation, here becomes a means to define who is worthy of citizen's rights, but also who must earn them and how. Jewish citizens are supposed to meet at least one condition of citizenship by being Jewish and are thus considered worthy of citizen's rights. Non-Jewish citizens still have to earn their rights through service and loyalty. In this context, Ilan gives examples that individuals representing other national minorities, apart from Palestinians, do earn their citizen's rights through their actions. Ilan, for instance, repeats how much the Druze MK he works for is in line with IB ideology and states:

"The core of IB['s ideology] is very simple, (..) ehm, it's like, love of the state of Israel. I understand it, like, (.) at the core, ehm (.) - you have the right to get as much as you give, that is to say as much as you give to the state, as much you get, like, (.) to me that sounds very logical, right? If you are a citizen who fulfils his obligations, you are entitled to full rights, and if you don't [fulfil your obligations], like, you are not [entitled to full rights] but part of them. If you don't give anything to the statewhy should I who pays taxes, who serves in the army, who does everything (.) - and someone else [who does not give anything] gets discrimination fees (.), rights, pension, convalescence [fees] and all those things on my account? It doesn't sound 
logical to me, like, (...) [Hamad, the Druze MK] is army veteran, served in the army, got wounded, served the country, (.) founded a youth movement, is the head of that youth movement of 12,000 members, children (..), he helps them a lot, a lot, like, from every point of view, like, helps them, like, [...], [Hamad] serves the country a lot." (Ilan, p. 13)

This reading of Israeli citizenship means two things: while Druze or Bedouin citizens are able to earn their citizen's rights, it has become almost impossible for Palestinian citizens to do so. 


\section{A Grounded Theory of Belonging: “All [Jewish] Israelis, Unite!"}

My initial research interest was the question of how (and why) young Israelis with an FSU family background become engaged with the Yisra'el Beitenu party. In order to find answers to this initial question, I organised the collection and analysis of data with the help of the grounded theory approach, as initially developed by Strauss and Glaser (Glaser/ Strauss 2011). Against the background of a theoretical sampling, I conducted in-depth interviews about civic engagement with interviewees engaged with the political party on different levels (national vs. local), in different forms (formal vs. informal), in different positions within the party's structure (central vs. peripheral), and in different modes (active vs. passive). In the course of the analysis of the material, I developed more detailed questions concerning the material, such as: How do the interviewees contextualise their engagement against the background of their perceived position in Israeli society? How do they actively position themselves in that society and which are the resources and strategies they apply here? How do the interviewees develop a sense of their belonging and which role does their civic engagement play in that process? Finally, what role does their presentation of Israeli citizenship play in that process?

Once belonging had emerged as the key category, I suggested applying Bourdieu's concepts of social space, field, capital, and social practice as an integrated framework in order to be able to take the perspective of the interviewees in particular or that of citizens with an immigrant family background in general to understand how they adapt to a new social space and actively construct and make sense of their place. I put particular 
emphasis on the analysis of how the interviewees a) relate toward the different forms of capital in their possession as resources or the perceived lack of them in order to pursue a particular argumentative strategy, and b) how they apply these power resources strategically when speaking about their engagement with the Yisra'el Beitenu party in particular and about the broader context of their engagement, that is their perception of Israeli society and Israeli citizenship. This means, I paid particular attention to the realisation of power resources in the discursive practice of the interview situation, i.e. how they present the power resources they have at their disposal in their narratives.

With reference to Bourdieu's statement that the existing social order can be challenged, one of the basic claims I made in the present study was that the interviewees are social actors. Within that social order or social space under examination, namely the Israeli society, they pursue a strategy of reinsuring or improving their objective and subjective positions in a particular field - here: the field of politics - as a social group - here: Israelis with an FSU family background, and thus also in Israeli society. In this context, Keller (2011a) points to the "emphasis on the active and interpretative efforts of social actors in the (re-)production and transformation of symbolic orders in [those] discourses" (Keller 2011a: 36).

I was able to make statements about the interviewees' sense of belonging at the moment the interview took place and in retrospective. Yet on the basis of interview material I was not able to make statements about the process of the development of their sense of belonging or, in other words, from where they had started. As it is often the case in qualitative empirical studies, I had to deal with limited resources of time and money to stay in the field and to get access to it and thus was not able to return to the field in order to reinterview the participants after some time. Besides, the interviews are framed by the particular situation in which the interviews took place and by the fact that I as their interview partner was a foreigner. This has certainly played a role in the way the interviewees make statements explicit or explain them in more detail than what might have been the case with an Israeli, or even more so, an FSU-born interviewer. Conversely, they certainly left things out for the same reasons. In this context, in the process of analysis I sometimes had to use the help of people with knowledge of the language and the Israeli political culture but who were not participating in the process of carrying out the interviews. 
In this final chapter, firstly, I will develop a material theory about the interviewees' presentation of Israeli citizenship as a strategy of belonging, as it has emerged from the interview material. Secondly, I will critically discuss the findings of the present study with regard to the theoretical part as well as to the findings of previous empirical studies on the issue of immigrant adaptation.

\subsection{CITIZENSHIP}

The interviewees take their talking about engagement with the Yisra'el Beitenu party as a starting point to speak about their reading of Israeli citizenship. Citizenship is conceptualised in the context of the study as the "membership of a political community" (Lister/ Pia 2003:. 8), featured by four core dimensions in a particular relationship: (political, cultural, economic) rights, duties, participation and identity (Delanty 1997: 9). The narratives display all four dimensions, yet in a hierarchical order. Citizenship, as the interviewees present it, is conditional and two dimensions are of particular importance to them: citizen's duties of serving the country and being loyal to the Jewish state and, in return, the granting of full citizen's rights in the form of Israeli citizenship itself. In this context, civic engagement is not presented as active participation in Delanty's sense, but as a duty alongside service and loyalty. Finally, identity or identification with the Jewish state are at the bottom line of the hierarchy.

The interviewees base their understanding of Israeli citizenship on three pillars: the adaptation of the ethno-nationalist discourse, which emphasises the Jewish character of the Israeli state and, connected to that, the adaptation of the hegemonic discourse, which presents military service as a moral obligation in various contexts of socialisation, personal or second-hand experiences as Israelis with an immigrant background and ways of coping with those experiences as well as the adaptation of the Yisra'el Beitenu party's ideology. 


\subsection{SERVING THE COUNTRY}

In the interviews, serving the country means first and foremost military service. Military service is presented as mandatory for all Israeli citizens, regardless of nationality. This is the interviewees' reality and their personal experience; against the background of their own experience of having served in the IDF they claim that every citizen has to serve and serves. The obligation to serve is taken for granted and by referring to their own service they prove they have fulfilled their moral obligation. The interviewees adapt the hegemonic discourse of serving the country also with regard to its ideological basis: on the one hand they speak about the obligation with constant reference to a perceived security threat in the context of the ongoing territorial conflict between Israel and the Palestinians. On the other hand, they present service as an integral part of the Zionist foundations of the State. Yet at the same time, they know-through public discourse, less through personal experience - that not every Israeli citizen serves in the military; in particular, the interviewees speak about three social groups who do not fulfil their citizen's duty: the Jewish ultra-orthodox, the so-called "mishtamtim" (Hebr., "dodgers"), and Palestinian citizens. Their claim must be understood against the background of recent developments in Israeli society: on the individual as well as the collective level, the link between military service as a civic duty has been challenged through the emergence of various civil rights movements (cf. Zemlinskaya 2008), political events (cf. Helman 1999) or increasing numbers of individuals dodging their draft (cf. Livio 2012). In the context of those developments, a major argument in the interviews is that serving the country is not only compulsory because "this is the law" but because "it's a matter of fairness, [...] there are whole communities that do not take part, [...] but not only minorities do not take part, also an egoistic majority".

However, the interviewees put emphasis on the non-service of Israel's Palestinian minority over Jewish segments which do not serve. Interestingly, the interviewees do not speak so much about religious or rather ultraorthodox Jewish Israelis who do not serve in the IDF for religious reasons ${ }^{1}$

1 Only after the interviews had been conducted, the High Court ruled that the Tal law which gave ultra-orthodox Jewish citizens the option of deferring their service in the IDF is unconstitutional (Ettinger/ Cohen 2012). 
but first and foremost about secular Jewish as well as non-Jewish citizens who do not do military service. ${ }^{2}$ This emphasis has to be read against IB's demand of equally mandatory service of all Israeli citizens, if not in the military, then in the form of national service in a citizen's community. In this context, the interviewees stress the option of doing national service as an alternative to military service, in particular for those Jewish or non-Jewish citizens who do not want to serve in the IDF for one or another reason. Yet they do not accept any of those reasons, but rather present the option of an alternative national service as equally mandatory - as does the Yisra'el Beitenu party-instead of an opportunity granted to national minorities. Consequently, Palestinian citizens, who in their majority do not make a demand on that legal opportunity, are presented as a collective which does not serve their country and thus does not fulfil their citizen's duties.

\subsection{LOYALTY TO THE JEWISH STATE}

The interviewees' notion of loyalty to the Jewish state is constructed against their presentation of cleavages within the Israeli society; in particular they emphasise political (left-wing vs. right-wing) and national (Jewish vs. Palestinian) cleavages. The interviewees position themselves as Jewish, political right-wing, secular and middle-class. Against the background of discursive events in the recent past (the Lebanon war in 2006, the Gaza war in 2009, the Gaza flotilla raid in 2010), they claim to be loyal citizens on the basis that they criticise or question neither political authorities nor the IDF. Against the background of the same discursive events against which the interviewees display their loyalty, Palestinian citizens are presented as disloyal. Again, as it was the case with service of the country, the interviewees make a qualitative difference between those citizens whom they consider loyal and not loyal to the Jewish State. The interviewees describe a feeling of betrayal, again followed by the perception of an existential threat to Israel's existence. The political left is accused of being disloyal because

2 That the interviewees rarely mention religious Jewish Israelis here can be explained with personal experiences they have made. In the interviews one can find several stories of solidarity the interviewees have encountered with Jewish Israelis of Mizrahi origin who were often featured as religious. 
of their different approach to the peace process and critique of government and the IDF during these more recent military operations.

As it is the case with service of the country, the interviewees talk about loyalty to the Jewish State with reference to one of IB's ideological demands; here it is the demand to introduce a loyalty oath for all Israeli citizens, a pledge to Israel's character as a Jewish State. In the last decade or so, one could observe the growing tendency to emphasise the Jewish aspect of Israel over its democratic aspect. The (Jewish) interviewees do not see any problem in that development, yet at the same time, they do not understand that nonJewish minorities and also political left-wing Jewish citizens perceive that development as problematic and as a way toward further legal and political exclusion.

\subsection{PALESTINIAN CITIZENS AND NON-CITIZENS AS A PERCEIVED THREAT}

The interviewees speak about various rifts and cleavages which they perceive as threatening. In other words, Palestinians, citizens and noncitizens, are not the only social group raising the concern of the interviewees. However, the interviewees construct a qualitative difference between the threat perceived from different ethnic, political or religious, but Jewish groups vs. the threat that national others impose on them and the Israeli state. I argue that the interviewees consciously target Palestinians, and they do so against the background of the Yisra'el Beitenu party's electoral slogans about service and loyalty.

This threat is presented as threefold: Palestinian citizens are presented as a symbolic threat to the Israeli culture and the Zionist project; Palestinian non-citizens on the regional level or as part of the "Muslim world" are presented as a symbolic and existential threat.

On the local level, the interviewees from Natserat Illit come to speak about a symbolic threat imposed by Palestinian "villagers" who come to the Jewish city, which, in return, is in danger of losing its Jewish character. Their argument is set against the Zionist discourse of preserving Jewish hegemony in parts of the country with a large non-Jewish, Palestinian population.

On the national level, Palestinian non-citizens are presented as an existential threat with whom Israelis are constantly at war. Additionally, the 
interviewees claim Palestinian citizens betrayed their Jewish co-citizens in showing solidarity with those "people beyond the border".

Finally, on the global level, Israel is presented as being jeopardised by the broader process of "Islamisation of the Western world".

Against the presentation of Palestinians as a threat, the interviewees construct who they are themselves and where they belong. In this context, the interviewees also contrast their perception of Palestinians as a threat with their own emotions of love for their Jewish collective, and, more abstract, the Jewish State, as well as of hate and betrayal for the others. The interviewees can draw here on deeply rooted negative stereotypes of Palestinians as the cultural other in Israeli political culture. As a result, the interviewees actively engage in and reproduce the exclusionary ethnonationalist discourse about the non-Jewish other, against whom the Jewish collective is constructed.

\subsection{CITIZEN'S RIGHTS}

Previous empirical findings about how young (secular Jewish, religious Jewish and Palestinian) Israelis read citizenship display individualistic approaches to citizen's rights as well as collective approaches with regard to citizen's duties, e.g. mandatory military service (Pinson 2004).

In contrast to those findings, the participants in the present study emphasise first and foremost the aspect of duties. In addition, they discursively terminate the link between those duties and (Jewish) nationality, which so far has determined the nature of those duties demanded of Israeli Jewish citizens and demand equal citizen's duties regardless of the individual citizen's nationality. However, this termination has implications, of course, for the arrangement of Israeli citizenship in particular for national minorities which so far have enjoyed particular rights.

The dimension of citizen's rights is hardly explicitly mentioned in the narratives. However, one can draw conclusions regarding the rights dimension from what the interviewees have explicitly said: against the background of arguing that Palestinian Israelis would be disloyal and would not serve the country they live in, the interviewees claim they have delivered the proof that they themselves are good citizens because they have fulfilled their obligations. This way, they present themselves as even better than other 
Jewish citizens who either do not serve or are disloyal. Consequently, the interviewees can not only claim their rights as citizens to belong, but to belong to the dominant group within that Jewish State. In that position, again, they have the legitimate power to design Israeli citizenship; and in their ethno-nationalist reading of it, there is no room for non-Jewish citizens.

The interviewees claim these rights at the expense of Palestinian Israelis. At a first glance, the interviewees present their reading of Israeli citizenship as entirely based on rationality: those who fulfil their duties are granted rights. Yet they terminate the agreement that national, non-Jewish, minorities-minorities apart from Palestinians are not even mentioned in the narratives-need exemptions or are entitled to particular minority rights. Instead, they regard an ethno-nationalist reading of citizenship as a legitimate means.

\subsection{ENGAGEMENT WITH THE YISRA'EL BEITENU PARTY}

The Yisra'el Beitenu party can be understood as a political means the interviewees refer to enforce the power they consider legitimate for their own social group. The interviewees hardly refer directly to the Yisra'el Beitenu party's ideology, yet their presentation of Israeli citizenship has to be read as a constant reference to IB's 2009 electoral campaigns about service and loyalty. In this context, there are frequent references to the "Zionist character of the Yisra'el Beitenu party" in the narratives by which the interviewees aim at showing that the party's ideological programme is in line with the Israeli political mainstream. In particular, service and loyalty serve as a link to Zionism as the foundation of the state.

At the same time, the interviewees are aware of the public discourse about the party and the party's leader. Against the background of public discourse, they carefully construct a counter-image of public party figures, above all the party leader Lieberman, in order to show that those people are appropriate to represent mainstream Israeli voters, again, instead of the extreme right-wingers in the party. The interviewees especially use the inside and direct knowledge they claim to have gained from several party members they have worked with as a discursive strategy to deconstruct public images of those people. 


\subsection{CITIZENSHIP AS A DISCURSIVE STRATEGY: THE INTERVIEWEES' SENSE OF BELONGING}

By applying the suggested framework to the interview material, I was able to show that the interviewees have particular power resources - particular forms of capital - at their disposal. On the one hand, they have gained these power resources especially during socialisation in early childhood, mainly in their families. On the other hand, the interviewees have more or less consciously reproduced or modified their resources over time in Israel where they have spent most of their lives. Further, I showed that the participants in the present study use their power resources strategically to actively construct a sense of belonging to Israeli society. The interviewees' objective position has to be analysed in the context of their migration background. ${ }^{3}$

I conceptualised their objective position as twofold: the interviewees' legal and their social status. In the Israeli context, all of those individuals who entered the country under the Law of Return receive immediate citizenship. With regard to their social status, the interviewees above all talk about personal experiences when their Jewishness and thus their sense of belonging was questioned. Depending on their length of stay in Israel, they speak about these experiences as direct and present or past experiences. If these are presented as past experiences, the interviewees have developed strategies of coping. Usually, these strategies include a reference to personal suffering from anti-Semitic incidents before migration and to adopting a "Jewish atmosphere" at home after they had come to Israel. By doing so, the interviewees reproduce the "Israeli national ethos" of home-coming (Rapoport/ Lomsky-Feder 2002). Only individual voices present themselves as "Sabras", or Israeli-born, and categorically reject any impact of their family's migration background on their own sense of belonging to Israeli society. In the present study, those voices are represented by Igal. Yet, most interviewees promote a Russian-Jewish identity as a result of negotiating their social status of being "immigrants" and their sense of belonging, of being Jewish. The — quite sensitive - issue of being Jewish and, above all,

3 I define migration background in the present study as follows: individuals who themselves have immigrated to Israel from another country or have at least one parent who immigrated from another country. 
being a Halakhic Jew is very relevant in the interviews. It is so essential for the interviewees that most of them feel the need to make this explicitly clear to their audience-which is not only me as their immediate partner in the interview situation, but also potential Israeli readers-at the very beginning of their stories. The emphasis on their belonging to the Jewish collective must be read against the background of personal experiences in the context of migration to Israel.

However, the interviewees do not make a "qualitative difference" (Bourdieu 1985: 730) in Bourdieu's sense between Halakhic and nonHalakhic or non-Jewish members of the social group of Israelis with an FSU family background. On the contrary, the interviewees do not make this difference concerning the Halakhic status an issue, ${ }^{4}$ which can be read as a strategy to further strengthen their position as a social group in the Israeli society through pure numbers.

Previous empirical studies have shown that immigrants (of the first generation) construct their sense of belonging to the host society in different modes. For the case of Israelis with an FSU family background, studies on belonging have revealed that they have found several ways to actively construct a sense of belonging. One of these ways is to adapt to the dominant religious discourse: Neiterman and Rapoport interviewed immigrant girls in religious boarding schools and they showed that, on the one hand, teachers at those schools "inculcate religiosity among [those] girls" (Neiterman/ Rapoport 2009: 173). On the other hand, the interviewees actively participate in this process of inculcation by presenting it as something they have actively chosen in the interviews. Schmidt (2006) reports a similar finding for nonJewish immigrant women in Israel: one empirical type of interviewees converted to Judaism in order to deal with the pressure of being Jewish according to the Halakhah they describe, in order to belong to the Jewish community in Israel. Yet in the interviews, these women present their conversion as an act of free will and a process they have actively chosen. Another way of developing a sense of belonging reveals Remennick's study on transnationalism among FSU immigrants (Remennick 2002). She finds hints of a transnational or rather virtual sense of belonging across immigrant

4 The exception to this rule is Igal. By doing so, he adapts those voices in the ethnonationalist discourse that doubt the right of parts of several immigrant groups, here: those from the former Soviet Union, to belong to the Jewish collective. 
networks situated in the various host countries of FSU immigration and back in the former Soviet Union. In her study on the political behaviour of Russian-speaking Jews in three different countries-Ukraine, Israel, and Germany-Olena Bagno shows that immigrant adaptation takes place against the background of a particular cultural context (Bagno 2011b; 2009). The participants in her study revealed some similarities with regard to habitual dispositions and displayed a particular understanding of political behaviour. However, depending on their country of residence, the participants highly differed with regard to that understanding.

Against the background of previous studies, the empirical findings of the present study on how young people with an immigrant background construct a sense of belonging over time reveal the seeds of a new phenomenon. The interviewees as the younger generation of Israelis with an FSU family background (" $1.5^{\text {th" }}$ and second generations) who spent most of their lives in the country, have been able to adapt and have adopted the Israeli ethnonationalist discourse.

But - in contrast to what existing theories of immigrant incorporation may indicate - the ethno-nationalist discourse is not "inculcate[d] [...] among" them (Neiterman and Rapoport 2009: 173). On the contrary, as I have shown, the interviewees actively construct their sense of belonging to Israeli society. Using the presentation of a particular reading of Israeli citizenship, they adapt the Israeli ethno-nationalist discourse in order to make sense of their personal experiences in the Israeli society as a discursive strategy. On the basis of that sense-making, they position themselves in a dominant place in the field of politics. In particular, they adopt the Israeli ethno-nationalist discourse in two dimensions: a) the Zionist foundations of the state in the form of contribution (military service) and loyalty ("love of the Jewish state"), and b) Palestinian citizens and non-citizens impose an existential security threat to that Jewish collective. Besides, against the background of the former two dimensions, the interviewees can claim that the Yisra'el Beitenu party preserves the Zionist foundations of the state, or rather the Jewish collective.

The presentation of Israeli citizenship as conditional serves the interviewees to achieve two goals: First, they present themselves as good citizens who fulfil all their citizen's duties and consequently claim their rights as (Jewish) Israeli citizens to belong to the Jewish collective. 
Second, they "make qualitative distinctions" (Bourdieu 1985: 730) between good citizens, i.e. themselves, not-as-good citizens, i.e. other (Jewish) citizens who in the eyes of the interviewees only partly fulfil their duties, and second-class citizens, i.e. Palestinian citizens, who, again, in the eyes of the interviewees, do not fulfil any of their citizen's duties.

As shown above, the interviewees state there are several segments of Israeli (Jewish) society that do not fulfil their duties in one of the two dimensions, which condition the allocation of rights in their reading of Israeli citizenship. Jewish ultra-orthodox and secular dodgers of military service do not fulfil their duties in the dimension of serving the country; political leftwing citizens are presented as disloyal to the Jewish state because they criticise the government or the policies of other official institutions. In the interviewees' line of argument, Palestinian Israelis fulfil neither one of the dimensions presented as conditional, regardless of the reasons for (not) doing so. They are presented as disloyal and as not showing solidarity with their Jewish Israeli co-citizens. Additionally, Palestinian Israelis are presented as a symbolic and existential threat on different levels.

By doing so, the interviewees challenge their own objective position in Israeli society — which they perceive as weak in relation to the dominant social group, Ashkenazi Israelis - and position themselves actively not only within that dominant social group, but at the top of it. In other words, the interviewees actively apply discursive strategies to reproduce the symbolic hierarchy between Jewish and non-Jewish segments of Israeli society; yet at the same time they challenge the symbolic hierarchy within the Jewish segment. They do so by reinforcing distinctions between themselves, Israelis with an FSU family background as a social group, and social groups in other objective positions within Israeli society.

Above all, "mak[ing these] qualitative distinctions" (Bourdieu 1985: 730) shall justify social and legal inequalities between the Jewish and Palestinian segments in Israeli society. In this context, the interviewees discursively terminate the threefold notion of Israeli citizenship Peled (2011) defines and do not further distinguish between different (legal) approaches to determine the rights and duties of Jewish and non-Jewish, in particular Palestinian, Israeli citizens.

For the sake of emphasis on a shared Jewish nationality and the Jewish character of the Israeli state, the interviewees concentrate their argument on the non-Jewish segments, in particular the Palestinian minority. Concluding 
from their line of argument about conditional Israeli citizenship, they suggest Palestinian Israelis should be not allowed to claim any citizen's rights in any of their areas (economic cultural, political) because they do not fulfil their duties as Israeli citizens as presented by the interviewees. As a consequence of their line of argument, Palestinian Israelis cannot be regarded actual citizens. The interviewees openly discuss this with regard to the cultural and economic dimensions of citizen's rights, i.e. Palestinians' recognition as a national minority and access to social welfare. They also indicate that the Palestinian minority has not got any basis on which to claim political rights, i.e. their right to hold an Israeli passport and to settle within the borders of the Israeli state.

Previous research on aspects of the Israeli political culture have already stated a shift in public opinion, in particular regarding anti-democratic tendencies, in the context of growing societal cleavages and rifts. By arguing this way, the interviewees are in line with the political agenda of the party they are engaged with. For example, they directly refer to IB's suggestion to introduce a "loyalty oath" as a necessary condition to for the provision of basic civil, social and political rights. This oath is claimed to concern all Israelis but is aimed particularly at Palestinian Israelis and must be interpreted as an attempt to win back legitimisation on ethno-nationalist grounds in order to reintegrate the Jewish segments. While back in the 1980s right-wing extremist parties were still banned when they publicly demanded such an oath, more recently it has become publicly acceptable. Another example is the growing acceptance of an exchange of territories - for instance in the form of the so called "Lieberman Plan"_ of parts consisting of significant Jewish settlements in the West Bank and Israeli core land with major Palestinian settlements along the Green Line of 1967 (cf. Waxman 2012: 22).

According to Bourdieu (2013), the political field is very close to the field of power and directly subordinate to the latter. One can conclude from this that the social group in power is legitimised to define who gains legitimate access to a particular social space in the form of citizenship at a given time. Through their claim of belonging to the dominant social group in Israeli society on grounds of their contribution as good citizens, the interviewees claim for themselves and for their social group to have the power to execute symbolic violence, i.e. to deprive those segments of Israel citizenship, and, implicitly, use physical violence against non-Jewish, or, rather Palestinian 
citizens, i.e. to deport them. The participants in the present study do so by adapting central slogans of Lieberman's Yisra'el Beitenu party, as expressed in the party's 2009 electoral campaign.

However, these slogans are no longer an extreme right political position in Israeli society. On the contrary, the interviewees do find several linking points in the Israeli ethno-nationalist discourse to which they link their arguments: first, in a historical perspective, they can draw on Jewish nationalism, Zionism, disregarding the rights of national minorities in the area.

Second, in a contemporary perspective, the Israeli political culture has been coined by a growing mistrust in the country's Palestinian citizens and its Palestinian neighbours, accompanied by negative stereotyping of that national minority as the others against whom a Jewish-Israeli identity has been constructed. Negative stereotyping of Muslim minorities, or "orientalism" (Lerner 2010), has also been an integral part of the (post-) Soviet political culture and may serve the interviewees as an additional linkage between their individual habitual dispositions and the ethnonationalist discourse.

Third, based on the negative image of Muslims in general and Palestinians in particular, the interviewees can put special emphasis on the presentation of non-Jewish citizens, Palestinians in particular, as imposing an existential threat to the Jewish State and the Jewish collective in general.

Fourth, this perceived threat, again, does not concern Israel exclusively. Rather, it is possible to draw parallels to recent societal developments across European countries, which make anti-Muslim sentiments, or, rather subtle or blatant racism, increasingly acceptable in the "midst of society".

Israel is, of course, still a particular case with regard to the Israeli (and Jewish) history of threat or threat perception, which Zuckermann (1999) refers to as the "central axes of fear". These threats have at least partly been real and of an existential nature aiming at physical annihilation. The interviewees are aware of this basic fear and refer to a perceived threat to their and the country's very existence when they emphasise the necessity of military service on the one hand and of recent military operations to stop that threat on the other hand. However, they also present Palestinian citizens as a social group which collectively imposes a symbolic threat on the Israeli (Jewish) society in terms of differences in "cultural values", and this is where the Israeli case is no longer exceptional. When one compares Pedahzur's 
definition of a new Israeli extreme right and his description of the Yisra'el Beitenu party as being one of this new right's representatives with recent developments in other Western democracies, Europe and the U.S. (Pehahzur 2001), one finds similarities in both potential voters' profile, especially with regard to their perception of the (symbolic) threat (to European countries, (e.g. Zick et al. 2011), and the respective parties' emphasis on security issues. In a similar vein, Gutwein ${ }^{5}$ describes the Yisra'el Beitenu party as right-wing populist and compares it to "hate parties" of European style like the FPÖ in Austria, Le Pen's Front National in France or Wilder's Partij voor de Vrijheid in the Netherlands.

While the political parties Gutwein lists in his article seem a bit outdated nowadays, the phenonomen is not. On the contrary, the so-called "refugee crisis", as the major influx of Syrian civil war refugees is referred to in public discourse europe-wide, has added fuel to the fire, and in this context new, anti-immigrant, or rather "anti-Islam"-related political parties have emerged in various member states of the European Union. Traditional political parties have not found another strategy to handle the challenge those newly founded political parties pose to their own electorate but to adapt the anti-immigrant rhetoric of the latter.

In both the Israeli and the European cases, demand and supply side meet in their emphasis on a perceived threat of "Islamisation". For the Israeli case, however, the interviewees add a second layer by linking the notion to the ethno-nationalist discourse and thus present the Palestinian others as causing both a symbolic and an existential threat to the Jewish collective.

Against the background of a threat of "Islamisation", the interviewees can link the emergence of the Yisra'el Beitenu party to right-wing populist developments in those societies and present Israel as being part of a broader process. In times when emotions have become more important than facts, even mainstream democratic politicians feel obliged to respond to the exaggerated and uninformed fears of "worried citizens" and demand loyalty from national or ethnic, in particular Muslim minorities. ${ }^{6}$

5 Daniel Gutwein. How the left elevated Lieberman. Haaretz (English Edition), 2009. Retrieved from: http://www.haaretz.com/print-edition/features/howthe-left-elevated-lieberman-1.269990

6 I have in mind here the German Chancellor, Angela Merkel, who recently demanded just the same of permanent residents or German citizens whose 
Argumentum e contrario, Israeli society cannot allow itself to regard the Yisra'el Beitenu party's campaigning as well as their concrete parliamentary initiatives as a peripheral problem. It can also not allow itself to regard the party as "sectoral", representing a very specific and relatively small constituency. The empirical findings of the present study analysis confirm major rifts and cleavages within the Israeli society with regard to national and political issues. Not only the rise of Naftali Bennett's right-wing religious Jewish Home party is a concrete sign of a development in which the anti-Palestinian discourse has become dominant — a discourse, which has been fueled by the campaigns and parliamentary initatives of the Yisrael Beitenu party. At the time the manuscript for this book has been prepared for publication, the Netanyahu administration passes the Jewish State Bill (July 2018), which among others removes Arabic as an official language alongside Hebrew.

Against this background, it is even more worrying that to date there is no loud and powerful public voice reminding this society of their Jewish AND democratic basis, securing first and foremost the citizen's rights of ethnic and national minorities in Israel over excluding those minorities first discursively, and legally afterwards, on grounds of their minority status.

families have arrived from Turkey ("Türkeistämmige"), i.e. Muslims in their majority (e.g. FAZ 2016; ZEIT 2016). 


\section{Bibliography}

Sara Ahmed. Collective Feelings Or, the Impressions Left by Others.

Theory, Culture \& Society, 21(2): 25-42, April 2004.

Richard Alba and Victor Nee. Rethinking Assimilation Theory For a New

Era of Immigration. International Migration Review, 31(4): 826-874, 1997.

Oz Almog. The Sabra: the Creation of the New Jew. The S. Mark Taper

Foundation Imprint in Jewish Studies. Berkeley, CA: University of

California Press, 2000.

Gabriel Abraham Almond and Sidney Verba. The Civic Culture. Political

Attitudes and Democracy in Five Nations. Berlin, Boston: Princeton

University Press, reprint edition, 2016 (1963).

Anna Amelina. Beyond Methodological Nationalism: Research

Methodologies for Cross-border Studies. Routledge, London, 2012.

Anna Amelina, Kenneth Horvath, and Bruno Meeus, editors. An Anthology

of Migration and Social Transformation. IMISCOE Research Series.

Springer International Publishing, Cham, 2016.

Karin Amit. Social Integration and Identity of Immigrants from Western

Countries, the FSU and Ethiopia in Israel. Ethnic and Racial Studies, 35(7): 1287-1310, August 2011.

Benedict Anderson. Imagined Communities: Reflections on the Origin and Spread of Nationalism. London [u.a.]: Verso, 2006 (1983).

Floya Anthias. Ethnic Ties: Social Capital and the Question of

Mobilisability. The Sociological Review, 55(4): 788-805, 2007.

Asher Arian, Michail Philippov, and Anna Knafelman. Auditing Israeli

Democracy: Twenty Years of Immigration from the Soviet Union. The 
Israel Democracy Institute, Jerusalem: Israeli Democracy Index, August 2010.

Asher Arian, André Krouwel, Mark Pol, and Raphael Ventura. The Election Compass: Party Profiling and Voter Attitudes. In: Asher Arian and Michal Shamir, editors, The Elections in Israel - 2009, pp. 275-298. New Brunswick, NJ [u.a.]: Transaction Publishers, 2011.

Will Atkinson. Phenomenological Additions to the Bourdieusian Toolbox: Two Problems for Bourdieu, Two Solutions from Schuetz. Sociological Theory, 28(1): 1-19, 2010.

Henry Bäck and Maritta Soininen. Immigrants in the Political Process. Scandinavian Political Studies, 21(1): 29-50, 1998.

Olena Bagno. The Price of Fear: Israel Beitenu in 2009. In: Asher Arian, Alan Arian, and Michal Shamir, editors, The Elections in Israel - 2009. New Brunswick, NJ [u.a.]: Transaction Publishers, 2011a.

Olena Bagno. Political Newborns: AS Journey from Ukraine to Israel and Germany. Harvard University, Cambridge, MA: Paper Presented at the Conference on the Contemporary Russian-Speaking Jewish Diaspora, Davis Center for Russian and Eurasian Studies, November $2011 \mathrm{~b}$.

Olena Bagno. The Invasion of Neo-Khazars or the Arrival of Democratic Man? Democratic and Political Participation of Immigrants from the Former Soviet Union in comparative perspective. Tel Aviv University, Tel Aviv: PhD thesis, 2009.

Daniel Bar-Tal. Shared Beliefs in a Society: Social Psychological Analysis. Thousand Oaks, Calif. [u.a.]: SAGE Publications, July 2000.

Daniel Bar-Tal. Why Does Fear Override Hope in Societies Engulfed by Intractable Conflict, as It Does in the Israeli Society? Political Psychology, 22(3): 601-627, 2001.

Daniel Bar-Tal and Dikla Antebi. Beliefs about Negative Intentions of the World: A Study of the Israeli Siege Mentality. Political Psychology, 13(4): 633-645, 1992a.

Daniel Bar-Tal and Dikla Antebi. Siege Mentality in Israel. International Journal of Intercultural Relations, 16(3):251-275, 1992b.

Karolina Barglowski. Social Expectations in Transnational Social Spaces: Linking Migration and Social Inequalities, Faculty of Sociology at the University of Bielefeld: Ph.D. thesis, 2015; Retrieved from: https://pub.uni-bielefeld.de/publication/2901709 
Eva Barlösius. Pierre Bourdieu. Frankfurt am Main/ New York: Campus Verlags GmbH, $2^{\text {nd }}$ edition, 2011.

Fredrik Barth. Ethnic Groups and Boundaries: The Social Organization of Culture Difference. Bergen: Universitetet i Bergen, 1969.

Michael Beizer. Kampf um die Aliyah. Die Otkazniki-Bewegung der 1980er Jahre am Beispiel Leningrads. In: Julius H. Schoeps, Karl E. Grözinger, Willi Jasper, and Gert Mattenklott, editors, Russische Juden und transnationale Diaspora, Berlin/ Wien: Philo Verlagsgesellschaft $\mathrm{mbH}$, MENORA Jahrbuch für deutsch-jüdische Geschichte 2004, pp 73-94., 2005.

Uri Ben-Eliezer. Multicultural Society and Everyday Cultural Racism: Second Generation of Ethiopian Jews in Israel's 'Crisis of Modernization'. International Journal of Middle East Studies, 31(5): 935-961, 2008.

Yehuda Ben Meir and Olena Bagno-Moldavsky. Vox populi: Trends in Israeli Public Opinion on National Security 2004-2009. Memorandum 106, Tel Aviv: The Institute for National Security Studies (INSS), Tel Aviv University, November 2010.

Guy Ben-Porat and Shlomo Mizrahi. Political Culture, Alternative Politics and Foreign Policy: The case of Israel. Policy Sciences, 38(2): 177-194, 2005.

Guy Ben-Porat and Bryan S. Turner. Introduction: Contemporary Dilemmas of Israeli Citizenship. In Bryan S. Turner and Guy Ben-Porat, editors, The Contradictions of Israeli Citizenship: Land, Religion and State, pp. 1-22. London: Routledge, 2011.

Tony Bennett and Elizabeth Silva. Introduction: Cultural Capital-Histories, Limits, Prospects. Poetics, 39(6): 427-443, 2011.

Moshe K. Berent. The Ethnic Democracy Debate: How Unique is Israel? Nations and Nationalism, 16(4): 657-674, 2010.

Ben Berger. Political Theory, Political Science and the End of Civic Engagement. Perspectives on Politics, 7(02): 335-350, 2009.

Michael Billig. Arguing and Thinking. European Monographs in Social Psychology. Cambridge [u.a.]: Cambridge University Press, 1989.

Michael Billig. Banal Nationalism. London [u.a.]: SAGE Publications, 1997. Reprint.

Karen Bird. The Political Representation of Women and Ethnic Minorities in Established Democracies: A Framework for Comparative Research. 
Aalborg University: Working Paper, Presented for the Academy of Migration Studies in Denmark (AMID), November 2003; Retrieved from: http://ipsa-rc19.anu.edu.au/papers/bird.htm November 2003.

Christian Bjørnskov. The Multiple Facets of Social Capital. European Journal of Political Economy, 22(1): 22-40, 2006.

Irene Bloemraad. Becoming a Citizen in the US and Canada: Structured Mobilization and Immigrant Political Incorporation. Social Forces, 85(2): 667-695, 2006.

Pierre Bourdieu. Ökonomisches Kapital, kulturelles Kapital, soziales Kapital. Soziale Welt, Sonderband 2: Soziale Ungleichheiten: 183-198, 1983.

Pierre Bourdieu. The Social Space and the Genesis of Groups. Theory and Society, 14(6): 723-744, 1985.

Pierre Bourdieu. The Forms of Capital. In John E. Richardson, editor, Handbook of Theory and Research for the Sociology of Education, pp. 280-291. London: Greenwood Press, 1986.

Pierre Bourdieu. Die feinen Unterschiede. Kritik der gesellschaftlichen Urteilskraft (La distinction). Frankfurt am Main: Suhrkamp, 1987.

Pierre Bourdieu. Das politische Feld. In: Franz Schultheis and Stephan Egger, editors, Politik, Schriften zur politischen Ökonomie / Pierre Bourdieu 2, pp. 97-112. Frankfurt am Main: Suhrkamp Verlag, 2013.

Pierre Bourdieu and Loic J. D. Wacquant. Die Logik der Felder. In: Reflexive Anthropologie (Réponses pour une anthropologie réflexive), chapter II.2., pp. 95-249. Frankfurt am Main: Suhrkamp Verlag, 1996 (1992)a.

Pierre Bourdieu and Loic J. D. Wacquant. Soziologie als Sozioanalyse. In: Reflexive Anthropologie (Réponses pour une anthropologie réflexive), chapter II.1, pp. 95-123. Frankfurt am Main: Suhrkamp Verlag, 1996 (1992)b.

Pierre Bourdieu and Loic J.D. Wacquant. Reflexive Anthropologie (Réponses pour une anthropologie réflexive). Frankfurt am Main: Suhrkamp Verlag, 1996.

Pierre Bourdieu and Loic J.D. Wacquant. Habitus, illusio und Rationalität. In: Reflexive Anthropologie (Réponses pour une anthropologie réflexive), chapter II.3., pp. 147-174. Frankfurt am Main: Suhrkamp Verlag, 1996 (1992)c. 
Sebastian Braun. Putnam und Bourdieu und das soziale Kapital in Deutschland. Leviathan, 29(3): 337-354, 2001.

Herbert E. Brekle. War With Words. In: Ruth Wodak, editor, Language, Power and Ideology. Studies in Political Discourse, pp. 81-91. Amsterdam and Philadelphia: John Benjamins Publishing Company, 1989.

Franz Breuer. Reflexive Grounded Theory: Eine Einführung für die Forschungspraxis. Wiesbaden: VS Verlag für Sozialwissenschaften, 2. Auflage, 2010.

Franz Breuer, Petra Muckel, and Barbara Dieris. Reflexive Grounded Theory: Eine Einführung für die Forschungspraxis. Wiesbaden: Springer, 3., vollständig überarbeitete Auflage, 2018.

Michael Bruter and Sarah Harrison. The Future of Our Democracies? Young Party Members in 6 European Democracies. Houndmills: Palgrave Macmillan, 2009.

Antony Bryant and Kathy Charmaz, editors. The Sage Handbook of Grounded Theory. Los Angeles u.a.: SAGE Publications, reprint edition, 2008.

Ebru S,. Canan-Sokullu. Domestic Support for Wars. Armed Forces \& Society, 38(1): 117-141, 2012.

Carol A. Cassel and Celia C. Lo. Theories of Political Literacy. Political Behavior, 19(4): 317-335, 1997.

Central Bureau of Statistics. Society in Israel 2010. Annual Report 3, Jerusalem, October 2010. (Hebrew).

Central Bureau of Statistics. Immigrants from the (former) Soviet Union: 25 Years of Immigration. Report, Israel Central Bureau of Statistics, Jerusalem, 2016. (Hebrew).

Michel de Certeau. The Practice of Everyday Life. Berkeley, Calif.: University of California Press, 2008.

Kanchan Chandra and Steven Wilkinson. Measuring the Effect of "Ethnicity". Comparative Political Studies, 41(4-5):515-563, April 2008.

Adele E. Clarke. Von der Grounded-Theory-Methodologie zur Situationsanalyse. In Günter Mey and Katja Mruck, editors, Grounded Theory Reader, chapter 10, pp. 207-229. Wiesbaden: VS Verlag für Sozialwissenschaften, 2011. 
Adele E. Clarke and Reiner Keller. Engaging Complexities: Working against Simplification as an Agenda for Qualitative Research Today. Adele Clarke in Conversation with Reiner Keller. Forum Qualitative Sozialforschung/Forum: Qualitative Social Research, 15(2), 2014.

Nick Crossley. The Phenomenological Habitus and Its Construction. Theory and Society, 30(1):81-120, 2001.

Russell J. Dalton. Citizenship Norms and the Expansion of Political Participation. Political Studies, 56(1):76-98, March 2008.

Adam Danel. A Methodological Critique of the Concept of Ethnic Democracy. Journal of Israeli History, 28(1):37-54, 2009.

Ohad David and Daniel Bar-Tal. A Sociopsychological Conception of Collective Identity: The Case of National Identity as an Example. Personality and Social Behaviour Review, 13(4):354-379, 2009.

Nivi Dayan. The Empowerment of Russian Immigrants in Israel: Towards Successful Integration and the Role of Integration in Minimizing Discrimination and Hostility. Lecture at the ICSW Expert Meeting, Bratislava, June 13-15 2004.

Eline A. de Rooij. Patterns of Immigrant Political Participation: Explaining Differences in Types of Political Participation between Immigrants and the Majority Population in Western Europe. European Sociological Review, 28(4):455-481, August 2012.

Gerard Delanty. Models of Citizenship: Defining European Identity and Citizenship. Citizenship Studies, 1(3):285-303, November 1997.

Robert E. Dowse and John A. Hughes. Political Culture and Ideology, chapter 8, pp. 226-250. Chichester a.o.: John Wiley \& Sons, $2^{\text {nd }}$ edition, 1986.

Alan Dowty. Is Israel Democratic? Substance and Semantics in the "Ethnic Democracy" Debate. Israel Studies, 4(2):1-15, 1999.

Alan Dowty. Introduction: the Tribalisation of Israel? In: Alan Dowty, editor, Critical issues in Israeli Society, pp. 1-6. Westport, Conn.: Praeger, 2004.

Susan A. Dumais. Cultural Capital, Gender, and School Success: the Role of Habitus. Sociology of Education, 75(1):44, 2002.

Kim Ebert and Dina Okamoto. Legitimating Contexts, Immigrant Power, and Exclusionary Actions. Social Problems, 62(1):40-67, 2015. 
Jason D. Edgerton and Lance W. Roberts. Cultural Capital or Habitus? Bourdieu and Beyond in the Explanation of Enduring Educational Inequality. Theory and Research in Education, pp. 1-28, 2014.

S.N. Eisenstadt. Collective Identities, Public Spheres, Civil Society and Citizenship in the Contemporary Era -with Some Observations on the Israeli Scene. Citizenship Studies, 12(3):203-213, 2008.

Rivka A Eisikovits. Intercultural Learning Among Russian Immigrant Recruits in the Israeli Army. Armed Forces \& Society, 32(2):292-306, 2006.

Joakim Ekman and Erik Amnå. Political Participation and Civic Engagement: Towards a New Typology. Working Paper 2, Youth \& Society (YeS), Örebro University, 2009. Retrieved from: https://inforum.oru.se/PageFiles/14371/Ekman\%20and\%20Amn\%C3\% A5\%202009-1.pdf

N. Elias and A. Kemp. The New Second Generation: Non-Jewish Olim, Black Jews and Children of Migrant Workers in Israel. Israel Studies, 15(1):73-94, 2010.

Guy Enosh and Shiri Katz. The Persistence of Vision: Interest of Israeli Youth in Social and Political Issues. In: Hilke Rebenstorf, editor, Democratic development? East German, Israeli and Palestinian Adolescents., pp. 104-114. Wiesbaden: VS Verlag für Sozialwissenschaften, 2004.

Zsolt Enyedi. The Social and Attitudinal Basis of Political Parties: Cleavage Politics Revisited. European Review, 16(03):287-304, 2008.

Umut Erel. Migrating Cultural Capital: Bourdieu in Migration Studies. Sociology, 44(4): 642-660, 2010.

Thomas Faist. Migrants as Transnational Development Agents: An Inquiry into the Newest Round of the Migration-Development Nexus. Population, Space and Place, 14(1):21-42, 2008.

Thomas Faist. The mobility Turn: A New Paradigm for the Social Sciences? Ethnic and Racial Studies, 36(11):1637-1646, 2013.

Bryan Fanning and Neil O'Boyle. Immigrants in Irish Politics: African and East European Candidates in the 2009 Local Government Elections. Irish Political Studies, 25(3): 417-435, 2010.

Bryan Fanning, Kevin Howard, and Neil O’Boyle. Immigrant Candidates and Politics in the Republic of Ireland: Racialization, Ethnic Nepotism, or Localism? Nationalism and Ethnic Politics, 16(3-4):420-442, 2010. 
Meindert Fennema and Jean Tillie. Political Participation and Political Trust in Amsterdam: Civic Communities and Ethnic Networks. Journal of Ethnic and Migration Studies, 25(4):703-726, October 1999.

Meindert Fennema and Jean Tillie. Civic Community, Political Participation and Political Trust of Ethnic Groups. Connections, 24(1):26-41, 2001.

Reinhard Fiehler, Hg. Verständigungsprobleme und gestörte Kommunikation. Radolfzell: Verlag für Gesprächsforschung, 2002.

Orlando Figes. Die Tragödie eines Volkes: die Epoche der russischen Revolution 1891 bis 1924 (A people's Tragedy. The Russian Revolution 1891-1924). Wilhelm Goldmann Verlag, München, $2^{\text {nd }}$ edition , 2001 (1998).

Gideon Fishman. Characteristics of Israeli Society: the Context in Which Youth is Brought up. In: Hilke Rebenstorf, editor, Democratic development? East German, Israeli and Palestinian Adolescents, pp. 5370. Wiesbaden: VS Verlag für Sozialwissenschaften, 2004.

S. T. Fiske, A. J. C. Cuddy, P. Glick, and J. Xu. A Model of (often Mixed) Stereotype Content: Competence and Warmth Respectively Follow from Perceived Status and Competition. Journal of Personality and Social Psychology, 82(6):878-902, 2002.

Erich Fromm. Das jüdische Gesetz. Zur Soziologie des Diaspora-Judentums. München: Wilhelm Heyne Verlag, 1989 (1922).

Ariely Gal. Spheres of Citizenship: The Role of Distinct Perceived Threats in Legitimizing Allocation of Political, Welfare and Cultural Rights in Israel. International Journal of Intercultural Relations, 35(2):213-225, March 2011.

Dalia Gavriely-Nuri. Cultural approach to CDA. Critical Discourse Studies, 9(1):77-85, 2012

As'ad Ghanem. The Expanding Ethnocracy: Judaization of the Public Sphere. Israel Studies Review, 26(1):21-27, 2011.

As'ad Ghanem, Nadim N. Rouhana, and Oren Yiftachel. Questioning "Ethnic Democracy": A response to Sammy Smooha. Israel Studies, 3(2):253-267, 1998.

Zvi Gitelman. The "Russian Revolution" in Israel. In Alan Dowty, editor, Critical Issues in Israeli Society, chapter 5, pp. 95-108. Westport, Conn.: Praeger, 2004.

Barney G. Glaser. Theoretical Sensitivity. Advances in the Methodology of Grounded Theory. Mill Valley, California: Sociology Press, 1978. 
Barney G. Glaser and Anselm L. Strauss. The Discovery of Grounded Theory: Strategies for Qualitative Research. London: Weidenfeld and Nicolson, 1968.

Barney G. Glaser and Anselm L. Strauss. Grounded Theory. Strategien qualitativer Forschung. Bern: Huber, $3^{\text {rd }}$ edition, 2010 (1998).

Barney G. Glaser (in cooperation with Judith A. Holton). Der Umbau der Grounded- Theory-Methodologie. In Günter Mey and Katja Mruck, editors, Grounded Theory Reader, pp. 137-161. Wiesbaden: VS Verlag für Sozialwissenschaften, 2011.

Olaf Glöckner. Zwischen High Tech und Marginalität. Wissenschaftler aus der früheren Sowjetunion und ihre Integration in Israel. In Julius $\mathrm{H}$. Schoeps, Karl E. Grözinger, Willi Jasper, and Gert Mattenklott, Hg., Russische Juden und transnationale Diaspora, volume 15 of MENORA. Jahrbuch für deutsch-jüdische Geschichte 2004, pp. 307-327. Berlin, Wien: Philo Verlagsgesellschaft mbH, 2005.

Olaf Glöckner. Immigrated Russian Jewish Elites in Israel and Germany After 1990: Their Integration, Self Image and Role in Community Building. Doctoral thesis, Potsdam: University of Potsdam, April 2011.

Dana Gold. The Politics of Emotion: A Case Study of the Israeli-Palestinian Conflict. Israel Studies Review, 30(2):113-129, December 2015.

Giora Goldberg. The Growing Militarization of the Israeli Political System. Israel Affairs, 12(3):377-394, 2006.

Deborah Golden. Belonging Through Time: Israelis, Immigrants and the Task of Nation- Building. PhD thesis, University of Haifa: Faculty of Education, 1996.

Deborah Golden. "Now, like Real Israelis, Let's Stand Up and Sing": Teaching the National Language to Russian Newcomers in Israel. Anthropology \& Education Quarterly, 32(1): 52-79, 2001.

Deborah Golden. Belonging through Time: Nurturing National Identity among Newcomers to Israel from the Former Soviet Union. Time \& Society, 11(1):5-24, 2002.

Ken Goldstein and Zvi Gitelman. From "Russians" to Israelis? In: Asher Arian and Michal Shamir, editors, The Elections in Israel - 2003, chapter 11, pp. 245-260. New Brunswick and London: Transaction Publishers, 2004.

Bianca Gonzalez-Sobrino. The Threat of the "Other": Ethnic Competition and Racial Interest. Sociology Compass, 10(7):592-602, 2016. 
Milton Myron Gordon. Assimilation in American Life: the Role of Race, Religion, and National Origins. New York: Oxford University Press, 1964.

Gulie Ne'eman Arad. Israel and the Shoah: A Tale of Multifarious Taboos. New German Critique, 90:5-26, 2003.

Eran Halperin and Daniel Bar-Tal. Socio-Psychological Barriers to Peace Making: An Empirical Examination within the Israeli Jewish Society. Journal of Peace Research, 48 (5):637-651, 2011.

Eran Halperin, Daphna Canetti, Stevan E. Hobfoll, and Robert J. Johnson. Terror, Resource Gains and Exclusionist Political Attitudes among New Immigrants and Veteran Israelis. Journal of Ethnic and Migration Studies, 35(6):997-1014, 2009.

James Harris. The Great Fear: Stalin's Terror of the 1930s. Oxford: Oxford University Press, 2016.

Helen Haste. Lay Social Theory: The Relation between Political, Social, and Moral Understanding. New Directions for Child and Adolescent Development, 1992(56):27-38, 1992.

Helen Haste. Constructing the Citizen. Political Psychology, 25(3):413-439, 2004.

Helen Haste and Amy Hogan. Beyond Conventional Civic Participation, Beyond the Moral-Political Divide: Young People and Contemporary Debates about Citizenship. Journal of Moral Education, 35(4):473-493, 2006.

Helen Haste and Judith Torney-Purta. Introduction. New Directions for Child and Adolescent Development, 1992(56):1-26, 1992.

Sarah Helman. War and Resistance: Israeli Civil Militarism and Its Emergent Crisis. Constellations, 6(3):391-410, 1999.

Tamar Ruth Horowitz, editor. The Soviet Man in an Open Society. Lanham, MD: University Press of America, 1989.

Orit. Ichilov. Political Learning and Citizenship Education under Conflict: the Political Socialization of Israeli and Palestinian Youngsters. Routledge Advances in International Relations and Global Politics 29. Routledge, London; New York, 2004.

Dirk Jacobs and Jean Tillie. Introduction: Social Capital and Political Integration of Migrants. Journal of Ethnic and Migration Studies, 30(3):419-427, May 2004. 
Siegfried Jäger. Kritische Diskursanalyse. Eine Einführung (Critical Discourse Analysis: An Introduction). Edition DISS 3. Unrast-Verlag, Münster, $4^{\text {th }}$ edition, 2004.

Siegfried Jäger, Manuela Bodjadzijev, and Serhat Karakayali. Soll der Begriff "Integration" kritisiert oder verteidigt werden? DISS Journal, 20(12), 2010. Retrieved from: http://www.diss-duisburg.de/ 2010/12/soll-der-begriff-\%e2\%80\%9eintegration-kritisiert-oder-vertei digt-werden/

Richard Jenkins. Pierre Bourdieu. Key sociologists. Routledge, London [u.a.], revised edition, 2006 (2002).

Christian Joppke. Beyond National Models: Civic Integration Policies for Immigrants in Western Europe. West European Politics, 30(1):1-22, January 2007.

R. Kahane and Tamar Rapoport. Informal Youth Movements and the Generation of Democratic Experience. In Orit Ichilov, editor, Political Socialization, Citizenship Education, and Democracy, pp. 221-240. New York, NY: Teachers College Press, 1990.

Eran Kaplan. Review: Post-Post-Zionism: A Paradigm Shift in Israel Studies? Israel Studies Review, 28(1):142-155, June 2013.

Udo Kelle. Die Bedeutung theoretischen Vorwissens in der Methodologie der Grounded Theory. In Rainer Strobl, editor, Wahre Geschichten? Zu Theorie und Praxis qualitativer Interviews: Beiträge zum Workshop "Paraphrasien, Kodieren, Interpretieren" ... im Kriminologischen Forschungsinstitut Niedersachsen am 29. und 30. Juni 1995 in Hannover, pp. 23-47. Baden-Baden: Nomos Verlagsgesellschaft, 1996.

Udo Kelle. "Emergence" vs. "Forcing" of Empirical Data? A Crucial Problem of "Grounded Theory" Reconsidered. Forum Qualitative Sozialforschung/ Forum: Qualitative Social Research, 6(2), May 2005.

Udo Kelle and Susann Kluge. Vom Einzelfall zum Typus. Fallvergleich und Fallkontrastierung in der qualitativen Sozialforschung. Wiesbaden: Springer, $2^{\text {nd }}$, revised edition 2010 (1999).

Reiner Keller. Diskurse und Dispositive analysieren. Die wissenssoziologische Diskursanalyse als Beitrag zu einer wissensanalytischen Profilierung der Diskursforschung (Analysing Discourses and Dispositifs. Profiling Discourse Research in the Tradition of Sociology of Knowledge). Forum Qualitative Sozialforschung/ Forum: Qualitative Social Research, 8(2):Art. 19, May 2007 (German). 
Reiner Keller. Diskursforschung. Eine Einführung für SozialwissenschaftlerInnen (Discourse Research: An Introduction For Social Scientists). Wiesbaden: VS Verlag für Sozialwissenschaften, $4^{\text {th }}$ edition, 2011 a.

Reiner Keller. Wissenssoziologische Diskursanalyse: Grundlegung eines Forschungsprogramms. Wiesbaden: VS Verlag für Sozialwissenschaften, $3^{\text {rd }}$ edition, $2011 \mathrm{~b}$.

Vladimir (Ze'ev) Khanin. The New Russian Jewish Diaspora and 'Russian' Party Politics in Israel. Nationalism and Ethnic Politics, 8(4):37-60, 2002.

Vladimir (Ze'ev) Khanin. Ha'Elita haHadasha shel Dovre Rusit beYisra'el. In Eliezer Ben-Refael and Yitzak Sternberg, editors, Elitot Hadashot beYisra'el, pp. 97-115. Yerushalayim: Mosad Byalik, 2007.

Vladimir (Ze'ev) Khanin. The Israel Beiteinu (Israel Our Home) Party between the Mainstream and "Russian" Community Politics. Israel Affairs, 16(1):105-123, 2010.

Vladimir (Ze'ev) Khanin. Russian-Jewish Political Experience in Israel: Patterns, Elites and Movements. Israel Affairs, 17(1):55-71, January 2011.

Baruch Kimmerling. Patterns of Militarism in Israel. European Journal of Sociology / Archives Européennes de Sociologie, 34(2):196-223, 1993.

Baruch Kimmerling. The Invention and Decline of Israeliness: State, Society, and the Military. Berkeley, Calif.: University of California Press, 2005.

Paul W. Kingston. The Unfulfilled Promise of Cultural Capital Theory. Sociology of Education, 74:88-99, 2001.

Bert Klandermans. The Demand and Supply of Participation: Social Psychological Correlates of Participation in Social Movements. In D. Snow, S. A. Soule, and Kreisi H., editors, The Blackwell Companion to Social Movements., Oxford: Blackwell Publishers, 2004.

David Koren. Arab Israeli Citizens in the 2009 Elections: between Israeli Citizenship and Palestinian Arab Identity. Israel Affairs, 16(1):124-141, 2010.

Beate Krais and Gunter Gebauer. Habitus. Bielefeld: transcript Verlag, 3. Auflage, 2010.

Jan Kruse, Stephanie Bethmann, Debora Niermann, and Christian Schmieder. Qualitative Interviewforschung in und mit fremden 
Sprachen: Eine Einführung in Theorie und Praxis. Weinheim [u.a.]: Beltz Juventa, 2012.

Ronald La Due Lake and Robert Huckfeldt. Social Capital, Social Networks, and Political Participation. Political Psychology, 19(3):567-584, 1998.

Bernard Lahire. From the Habitus to an Individual Heritage of Dispositions. Poetics, 31: 329-355, 2003.

Michèle Lamont and Annette Lareau. Cultural Capital: Allusions, Gaps and Glissandos in Recent Theoretical Developments. Sociological Theory, 6(2):153-168, 1988.

Annette Lareau and Elliot B. Weininger. Cultural Capital in Educational

Research: a Critical Assessment. Theory and Society, 32(5):567-606, 2003.

Udi Lebel. Civil Society versus Military Sovereignty: Cultural, Political, and Operational Aspects. Armed Forces \& Society, 34(1):67-89, May 2007. Zeev Lerer and Sarit Amram-Katz. The Sociology of Military Knowledge in the IDF: From "Forging" to "Deciphering". Israel Studies Review, 26(2):54-72, 2011.

Julia Lerner. "Russians" in Israel as a Post-Soviet Subject: Implementing the Civilizational Repertoire. Israel Affairs, 17(1):21-37, 2010.

Y. Levy. Military Hierarchies and Collective Actions. In Guy Ben-Porat and Bryan S. Turner, editors, The Contradictions of Israeli Citizenship: Land, Religion and State, pp. 40-62. London: Routledge, 2011.

Ruth Lister and Emily Pia. Theories of Citizenship, chapter 1. Basingstoke; New York: Palgrave Macmillan, 2003.

Ruth Lister, Noel Smith, Sue Middleton, and Lynne Cox. Young People Talk About Citizenship: Empirical Perspectives on Theoretical and Political Debates. Citizenship Studies, 7(2):235-253, July 2003.

Oren Livio. Avoidance of Military Service in Israel: Exploring the Role of Discourse. Israel Studies Review, 27(1):78-97, June 2012.

Edna Lomsky-Feder and Tamar Rapoport. Homecoming, Immigration, and the National Ethos: Russian-Jewish Homecomers Reading Zionism. Anthropological Quarterly, 74(1): 1-14, 2001.

Edna Lomsky-Feder and Tamar Rapoport. Seeking a Place to Rest: Representation of Bounded Movement among Russian-Jewish Homecomers. Ethos, 30(3):227-248, 2002.

Edna Lomsky-Feder and Tamar Rapoport. Speaking their Language? Identity, Home and Power Relations in Interviews with Immigrants. In 
M. H. Menna Barreto Abraho, editor, The Autobiographic Adventure: Theory and Practice, pp- 329-354. Porto Alegro: Edipaers, 2003.

Edna Lomsky-Feder, Tamar Rapoport, and Julia Lerner. Orientalism through the Lens of Migration: Russian Students Discover Mizrahut (Orientalism beMivhan heHagira: Studentim Rusim Qor'im Mizrahut) (Hebrew). Teoriya uViqoret, 26 (Spring):119-147, 2005.

David Marsh, Therese O'Toole, and Su Jones. Young People and Politics in the UK: Apathy or Alienation? Basingstoke; New York: Palgrave Macmillan, 2007.

Peter Martin. Racism, Differentialism, and Antiracism in Everyday Ideology: a Mixed-Methods Study in Britain. International Journal of Conflict and Violence (IJCV), 7 (1):57-73, 2013.

Lois McNay. Gender, Habitus and the Field: Pierre Bourdieu and the Limits of Reflexivity. Theory, Culture \& Society, 16(1):95-117, 1999.

Hill'a Meller. Nash Dom/ Yisrael Beiteinu - Home, Family and Nation in the Construction of a "Russian" Israeli Party. Paper presented at the 2010 Midwestern Conference on Literature, Language, and Media, Northern Illinois University, 2010. Retrieved from: http://www12.georgetown. edu/students/hm272/writing_files/Nash\%20Dom\%20(Website\%20Vers ion).pdf

Günter Mey and Katja Mruck. Grounded-Theory-Methodologie: Entwicklung, Stand, Perspektiven. In Günter Mey and Katja Mruck, editors, Grounded Theory Reader, pp. 11-48. Wiesbaden: VS Verlag für Sozialwissenschaften, 2011a.

Günter Mey and Katja Mruck, editors, Grounded Theory Reader. Wiesbaden: VS Verlag für Sozialwissenschaften, 2011b.

Fayneese Miller. The Personal and the Political in Reasoning and Action. New Directions for Child and Adolescent Development, 1992(56):5364, 1992.

Jody Miller and Barry Glassner. The "Inside" and the "Outside": Finding Realities in Interviews. In David Silverman, editor, Qualitative Research, chapter 8, pp. 131-148. SAGE, ${ }^{\text {rd }}$ edition, 2010.

Cas Mudde. Right-Wing Extremism Analyzed. A Comparative Analysis of the Ideologies of Three Alleged Right-Wing Extremist Parties (NPD, NDP, CP'86). European Journal of Political Research, 27(2):203-224, 1995. 
Cas Mudde. The Single Issue Party Thesis: Extreme Right Parties and the Immigration Issue. West European Politics, 22(3):182-197, July 1999.

Cas Mudde. The Ideology of the Extreme Right. Manchester University Press, 2002.

Mohanad Mustafa and As'ad Ghanem. The Empowering of the Israeli Extreme Right in the $18^{\text {th }}$ Knesset Elections. Mediterranean Politics, 15(1):25-44, 2010.

Roy Nash. Bourdieu, 'Habitus', and Educational Research: Is it all Worth the Candle? British Journal of Sociology of Education, 20(2):175-187, June 1999.

Roy Nash. The Educated Habitus, Progress at School, and Real Knowledge. Interchange, 33(1):27-48, 2002a.

Roy Nash. A Realist Framework for the Sociology of Education: Thinking with Bourdieu. Educational Philosophy and Theory, 34(3):273-288, 2002 b.

Mihaela Nedelcu. Migrants' New Transnational Habitus: Rethinking Migration through a Cosmopolitan Lens in the Digital Age. Journal of Ethnic and Migration Studies, 38(9): 1339-1356, July 2012.

Elena Neiterman and Tamar Rapoport. Converting to Belong: Immigration, Education and Nationalisation among Young "Russian" Immigrant Women. Gender and Education, 21(2):173-189, 2009.

Greg Noble and Megan Watkins. So, How Did Bourdieu Learn to Play Tennis? Habitus, Consciousness and Habituation. Cultural Studies, 17(34):520-539, November 2003.

Magdalena Nowicka and Lukasz Krzyzowski. The Social Distance of Poles to Other Minorities: a Study of Four Cities in Germany and Britain. Journal of Ethnic and Migration Studies, 0(0):1-20, 2016.

Ami Pedahzur. Supporting Conditions for the Survival of Extreme RightWing Parties in Israel. Mediterranean Politics, 5(3):1-30, September 2000.

Ami Pedahzur. The Transformation of Israel's Extreme Right. Studies in Conflict \& Terrorism, 24(1):25-42, January 2001.

Ami Pedahzur and Avraham Brichta. The Attractiveness of the Seemingly Unattractive: An Israeli Case. Local Government Studies, 26(3):55-70, September 2000.

Ami Pedahzur and Yael Yishai. Hatred by Hated People: Xenophobia in Israel. Studies in Conflict \& Terrorism, 22(2):101-117, May 1999. 
Reuven Pedatzur. Israel Failed and Fell into the Gaza Flotilla Trap. Israel Debates 4, Friedrich Ebert Stiftung Israel, Herzliya, August 252010.

Yoav Peled. Ethnic Democracy and the Legal Construction of Citizenship: Arab Citizens of the Jewish State. The American Political Science Review, 86(2):432-443, June 1992.

Yoav Peled. Citizenship Betrayed: Israel's Emerging Immigration and Citizenship Regime. Theoretical Inquiries in Law, 8(2):Article 10, July 2007.

Yoav Peled. The Rise and Fall of Liberal Nationalism. In Guy Ben-Porat and Bryan S. Turner, editors, The Contradictions of Israeli Citizenship: Land, Religion and State, pp. 278-292. London: Routledge, 2011.

Yoav Peled and Doron Navot. Ethnic Democracy Revisited: On the State of Democracy in the Jewish State. Israel Studies Forum, 20(1):3-27, May 2005.

Thomas F. Pettigrew, Linda R. Tropp, Ulrich Wagner, and Oliver Christ. Recent Advances in Intergroup Contact Theory. International Journal of Intercultural Relations, 35(3): 271-280, 2011.

M. Philippov and E. Bystrov. All by Myself? The Paradox of Citizenship among the FSU Immigrants in Israel. In Guy Ben-Porat and Bryan S. Turner, editors, The Contradictions of Israeli Citizenship: Land, Religion, State, chapter 12, pp. 258-277. London: Routledge, 2011.

M. Philippov and A. Knafelman. Old Values in the New Homeland: Political Attitudes of FSU Immigrants in Israel. Israel Affairs, 17(1):38-54, 2011.

Halleli Pinson. Rethinking Israeliness: Citizenship Education and the Construction of Political Identities by Jewish and Palestinian Israeli Youth. Ph.D. Thesis, Cambridge, UK: University of Cambridge, 2004.

Alejandro Portes and Min Zhou. The New Second Generation: Segmented Assimilation and its Variants. The ANNALS of the American Academy of Political and Social Science, 530(1):74 -96, November 1993.

Jonathan Potter and Margaret Wetherell. Discourse and Social Psychology: beyond Attitudes and Behaviour. SAGE Publications, London, 1987.

Annick Prieur and Mike Savage. Updating Cultural Capital Theory: a Discussion Based on Studies in Denmark and in Britain. Poetics, 39(6):566-580, 2011.

Robert D. Putnam. Bowling Alone: the Collapse and Revival of American Community. New York [u.a.]: Simon and Schuster, 2000. 
Robert D. Putnam, Robert Leonardi, and Raffaella Nanetti. Making Democracy Work: Civic Traditions in Modern Italy. Princeton, NJ [u.a.]: Princeton University Press, Princeton paperbacks: Political science., 1994.

Ellen Quintelier. Who is Politically Active: the Athlete, the Scout Member or the Environmental Activist? Young People, Voluntary Engagement and Political Participation. Acta Sociologica, 51(4):355-370, December 2008.

D. Rabinowitz. Oriental Othering and National Identity: A Review of Early Israeli Anthropological Studies of Palestinians. Identities: Global Studies in Culture and Power, 9(3):305-325, 2002.

Dan Rabinowitz. Natives with jJckets and Degrees. Othering, Objectification and the Role of Palestinians in the Co-Existence Field in Israel. Social Anthropology, 9(1):65-80, 2001.

Dan Rabinowitz. Overlooking Nazareth. The Ethnography of Exclusion in Galilee. Cambridge Studies in Social and Cultural Anthropology 105. Cambridge, UK: Cambridge University Press, $3^{\text {rd }}$ edition, 2003 (1997).

Rebeca Raijman and Janina Pinsky. "Non-Jewish and Christian": Perceived Discrimination and Social Distance among FSU Migrants in Israel. Israel Affairs, 17(1):125-141, 2011.

David Ralph. "Always on the Move, but Going Nowhere Fast": Motivations for 'Euro-commuting' between the Republic of Ireland and Other EU States. Journal of Ethnic and Migration Studies, 41(2):176-195, 2015.

David Ralph and Lynn A. Staeheli. Home and Migration: Mobilities, Belongings and Identities. Geography Compass, 5(7):517-530, 2011.

Uri Ram. The State of the Nation: Contemporary Challenges to Zionism in Israel. Constellations, 6(3):325-338, 1999.

Tamar Rapoport and Edna Lomsky-Feder. "Intelligentsia" as an Ethnic Habitus: The Inculcation and Restructuring of Intelligentsia among Russian Jews. British Journal of Sociology of Education, 23(2):233-248, November 2002.

Tamar Rapoport and Edna Lomsky-Feder. WWII and Shoah as Memory Fields in Immigration: Personal Stories of Young "Russian" Jews in Israel. In Gabriele Rosenthal and Artur Bogner, editors, Ethnicity, Belonging and Biography: Ethnographical and Biographical Perspectives, pp. 121-144. Münster: LIT Verlag, 2007. 
Tamar Rapoport, Edna Lomsky-Feder, and Angelika Heider. Recollection and Relocation in Immigration: Russian-Jewish Immigrants "Normalize" Their Anti-Semitic Experiences. Symbolic Interaction, 25(2):175-198, 2002.

Diane Reay. "They Employ Cleaners to Do That": Habitus in the Primary Classroom. British Journal of Sociology of Education, 16(3):353-371, September 1995.

Diane Reay. Feminist Theory, Habitus, and Social Class: Disrupting Notions of Classlessness. Women's Studies International Forum, 20(2):225-233, 1997.

Diane Reay. "It's all Becoming a Habitus": Beyond the Habitual Use of Habitus in Educational Research. British Journal of Sociology of Education, 25(4):431-444, November 2004.

Larissa Remennick. Transnational Community in the Making: RussianJewish Immigrants of the 1990s in Israel. Journal of Ethnic and Migration Studies, 28(3):515-530, 2002.

Larissa Remennick. What Does Integration Mean? Social Insertion of Russian Immigrants in Israel. Journal of International Migration and Integration, 4(1):23-49, 2003.

Larissa Remennick. Twenty Years Together: the "Great Aliya" and Russian Israelis in the Mirror of Social Research. Israel Affairs, 17(1):1-6, 2010.

Larrisa Remennick. Russian Jews on Three Continents: Identity, Integration and Conflict. New Brunswick: Aldine Transaction and Transaction Publishers, 2007.

Susanne Rippl, Dirk Baier, und Klaus Boehnke. Europa auf dem Weg nach rechts? Die EU-Osterweiterung und ihre Folgen für politische Einstellungen in Deutschland, Polen und der Tschechischen Republik. Wiesbaden: VS Verlag für Sozialwissenschaften, 2007.

Svetlana Roberman. Commemorative Activities of the Great War and the Empowerment of Elderly Immigrant Soviet Jewish Veterans in Israel. Anthropological Quarterly, 80(4): 1035-1064, 2007.

Steven D Roper. The Romanian Party System and the Catch-All Party Phenomenon. East European Quarterly, 28(4):519-532, 1994.

Nadim N. Rouhana. Palestinian Citizens in an Ethnic Jewish State: Identities in Conflict. Yale University Press, 1997.

M. Savage and E. B. Silva. Field Analysis in Cultural Sociology. Cultural Sociology, 7(2): 111-126, 2013. 
Thomas Schäfer und Bettina Völter. Subjekt-Positionen. Michel Foucault und die Biographieforschung. In Bettina Völter, Helma Dausien, und Gabriele Rosenthal, editors, Biographieforschung im Diskurs, pp. 161187. Wiesbaden: VS Verlag für Sozialwissenschaften, 2005.

Dan Schiftan. The Flotilla and its Implications. Working Paper: Israel Debates 4, Friedrich Ebert Stiftung Israel, Herzliya, August 252010.

Tony Schirato and Susan Yell. Communication and Culture: An Introduction. London [u. a.]: Sage Publications, 2000.

Anja Schmidt. "Ich gebe mich hier nicht als Jüdin aus, ich verheimliche nichts, weil an meinem Gesicht zu erkennen ist, dass ich keine Jüdin bin.“ Fremd- und Selbstbilder nichtjüdischer Frauen in Israel. Eine empirische Studie. unpublished M.A. thesis, Institute of Jewish Studies at the University of Potsdam, June 2006.

Karen Schönwälder, Cihan Sinanoglu, and Daniel Volkert. Vielfalt sucht Rat: Ratsmitglieder mit Migrationshintergrund in deutschen Großstädten. Eine Studie des Max-Planck-Instituts zur Erforschung multireligiöser und multiethnischer Gesellschaften. Number 27 in Schriften zur Demokratie. Heinrich-Böll-Stiftung, 2011.

Alfred Schütz. The Homecomer. The American Journal of Sociology, 50(5):369-376, 1945.

Alfred Schütz. Der sinnhafte Aufbau der sozialen Welt. Eine Einleitung in die verstehende Soziologie. Frankfurt am Main: Suhrkamp Verlag, 1974.

Fritz Schuetze. Biographieforschung und narratives Interview. Neue Praxis, 13(3):283-293, 1983.

Gershon Shafir and Yoav Peled. Being Israeli: the Dynamics of Multiple Citizenship. Cambridge, UK: Cambridge University Press, 2002.

Gershon Shafir and Yoav Peled. Citizenship and Stratification in an Ethnic Democracy. Ethnic and Racial Studies, 21(3):408-427, August 2011.

Sami Shalom Shetrit. Mizrahi Politics in Israel: Between Integration and Alternative. Journal of Palestine Studies, 29(4):51-65, August 2000.

Sami Shalom Shetrit. Intra-Jewish Conflict in Israel. Routledge Studies in Middle Eastern Politics 13. London [u.a.]: Routledge, 2010.

Ella Shohat. The Invention of the Mizrahim. Journal of Palestine Studies, 29(1):5-20, 1999.

Dimitry Shumsky. Ethnicity and Citizenship as Perceived by Russian Israelis. Teoriya uViqoret, 19(Fall):17-40, 2001. (Hebrew). 
Dmitry Shumsky. Post-Zionist Orientalism? Orientalist Discourse and Islamophobia among the Russian-Speaking Intelligentsia in Israel. Social Identities, 10(1):83-99, 2004.

Martti Siisiainen. Two Concepts of Social Capital: Bourdieu vs. Putnam. International Journal of Contemporary Sociology, 40(2):183-204, 2003. Elizabeth Silva and Alan Warde. Introduction: the Importance of Bourdieu. In Elizabeth Silva and Alan Warde, editors, Cultural Analysis and Bourdieu's Legacy: Settling Accounts and Developing Alternatives, pp. 1-13. London: Routledge, 2010.

Alan Smart. Gifts, Bribes, and Guanxi: A Reconsideration of Bourdieu's Social Capital. Cultural Anthropology, 8(3):388-408, 1993.

Joel Smith and John F. Zipp. The Party Official Next Door: Some Consequences of Friendship for Political Involvement. The Journal of Politics, 45(04):958-978, 1983.

Sammy Smooha. Arabs and Jews in Israel, volume 1. Westview Press, Boulder (CO), 1989.

Sammy Smooha. The Model of Ethnic Democracy. Working Paper 13, European Centre for Minority Issues (ECMI), Flensburg, 2001.

Sammy Smooha. The Model of Ethnic Democracy: Response to Danel. Journal of Israeli History, 28(1):55-62, 2009.

Timothy Snyder. Bloodlands. Europa zwischen Hitler und Stalin. München: dtv Verlagsgesellschaft GmbH, 2010

Maria Sobolewska. Party Strategies, Political Opportunity Structure and the Descriptive Representation of Ethnic Minorities in Britain. 2013; Retrieved from:

http://www.humanities.manchester.ac.uk/socialchange/seminars/represe ntation/documents/MariaSobolewska.pdf

Damir Softic. Migranten in der Politik. Wiesbaden: Springer Fachmedien, 2016.

Isabel Steinhardt. Lehre stärkt Forschung: Studiengangentwicklung durch ProfessorInnen im Handlungssystem Universität. Wiesbaden: Springer Fachmedien, 2015.

Anselm L. Strauss. Qualitative Analysis for Social Scientists. Cambridge, NY: Cambridge University Press, 1987.

Jörg Strübing. Grounded Theory: zur sozialtheoretischen und epistemologischen Fundierung des Verfahrens der empirisch 
begründeten Theoriebildung. Wiesbaden: VS Verlag für Sozialwissenschaften, $2^{\text {nd }}$, revised edition, 2008.

Jörg Strübing. Grounded Theory: zur sozialtheoretischen und epistemologischen Fundierung eines pragmatistischen Forschungsstils. Qualitative Sozialforschung. Wiesbaden: Springer VS, $3^{\text {rd }}$, revised and extended edition, 2014.

Paul Sweetman. Twenty-First Century Dis-Ease? Habitual Reflexivity or the Reflexive Habitus. The Sociological Review, 51(4):528-549, 2003.

Celine Teney and Laurie Hanquinet. High Political Participation, High Social Capital? A Relational Analysis of Youth Social Capital and Political Participation. Social Science Research, 41(5):1213-1226, September 2012.

Jean Tillie. Social Capital of Organisations and Their Members: Explaining the Political Integration of Immigrants in Amsterdam. Journal of Ethnic and Migration Studies, 30 (3):529-541, 2004.

Judith Torney-Purta and Wendy Klandl Richardson. Anticipated Political

Engagement Among Adolescents in Australia, England, Norway and the United States. In Jack Demaine, editor, Citizenship and Political Education Today, pp. 41-58. Basingstoke: Palgrave Macmillan, 2004.

Judith Torney-Purta, Rainer Lehmann, Hans Oswald, and Wolfram Schulz.

Citizenship and Education in Twenty-Eight Countries: Civic Knowledge and Engagement at Age Fourteen. Technical Report, International Association for the Evaluation of Educational Achievement, 2001.

Yariv Tsfat, Tamir Sheafer, and Gabriel Weimann. War on the Agenda: the Gaza Conflict and Communication in the 2009 elections. In Alan Arian and Michal Shamir, editors, The Elections in Israel - 2009, pp. 225-249. New Brunswick [u.a.]: Transaction Publishers, 2011.

Carsten Ulrich. Deutungsmusteranalyse und diskursives Interview.

Leitfadenkonstruktion, Interviewführung und Typenbildung, 1999. Working Paper, Mannheimer Zentrum für Europäische Sozialforschung (MZES), Universität Mannheim.

Sidney Verba, Kay Lehman Schlozman, and Henry E. Brady. Voice and Equality: Civic Voluntarism in American Politics. Cambridge, MA [u.a.]: Harvard University Press, 1995.

Roland Verwiebe. Why Do Europeans Migrate to Berlin? Social-Structural Differences for Italian, British, French and Polish Nationals in the Period between 1980 and 2002. International Migration, 52(4):209-230, 2014. 
Loic J. D. Wacquant. Auf dem Weg zu einer Sozialpraxeologie. In: Pierre Bourdieu and Loic J. D. Wacquant. Soziologie als Sozioanalyse. Reflexive Anthropologie (Réponses pour une anthropologie réflexive), pp. 17-93. Frankfurt am Main: Suhrkamp Verlag, 1996 (1992).

Ulrich Wagner, Rolf Van Dick, Thomas F. Pettigrew, and Oliver Christ. Ethnic Prejudice in East and West Germany: the Explanatory Power of Intergroup Contact. Group Processes \& Intergroup Relations, 6(1):2236, 2003.

Dov Waxman. A Dangerous Divide: The Deterioration of Jewish-Palestinian Relations in Israel. The Middle East Journal, 66(1):11-29, January 2012. Jen. Webb, Tony. Schirato, and Geoff Danaher. Understanding Bourdieu. London; Thousand Oaks, Calif. SAGE Publications, 2002.

Sharon Weinblum and Julien Danero Iglesias. The Discursive Exclusion of Minorities: Narratives of the Self in Israel and Moldova. Critical Approaches to Discourse Analysis Across Disciplines (CADAAD), 7(1):164-179, 2013. Retrieved from: http://www.researchgate.net/ /profile/Sharon_Weinblum/publication/264788391_The_Discursive_Ex clusion_of_Minorities_Narratives_of_the_self_in_Israel_and_Moldova/ self_in_Israel_and_Moldova/links/53f0c4e20cf23733e812f2c3.pdf

Oren Yiftachel. Debate: the Concept of "Ethnic Democracy" and its Applicability to the Case of Israel. Ethnic and Racial Studies, 15(1):125136, January 1992.

Oren Yiftachel. "Ethnocracy": the Politics of Judaizing Israel/Palestine. Constellations, 6(3):364-390, 1999.

Yulia Zemlinskaya. Between Militarism and Pacifism: Conscientious Objection and Draft Resistance in Israel. Central European Journal of International \& Security Studies, 2(1):9-35, 2008.

Idith Zertal. From the People's Hall to the Wailing Wall: a Study in Memory, Fear, and War. Representations, 69(Winter):96-126, 2000.

Andreas Zick, Thomas F. Pettigrew, and Ulrich Wagner. Ethnic Prejudice and Discrimination in Europe. Journal of Social Issues, 64(2):233-251, June 2008.

Andreas Zick, Andreas Hövermann, and Beate Küpper. Die Abwertung der Anderen. Eine europäische Zustandsbeschreibung zu Intoleranz, Vorurteilen und Diskriminierung. Friedrich-Ebert-Stiftung, Forum Berlin, 2011. 
Moshe Zimmermann. Angst vor dem Frieden. Der Ausnahmezustand als israelischer Normalzustand. 22. November 2016, Vortragsreihe "Naher Oster-Ferner Frieden? Rechtliche, historische und politische Aspekte", Georg-August-Universität Göttingen, author's own notes.

Moshe Zuckermann. Zweierlei Holocaust. Der Holocaust in den politischen Kulturen Israels und Deutschlands. Wallstein Verlag, Göttingen, 1999. 
